\title{
Systems Engineering Framework for Railway Control \& Safety Systems
}

\section{Karl Michael King}

A Thesis Submitted for the Degree of Master of Science by Research

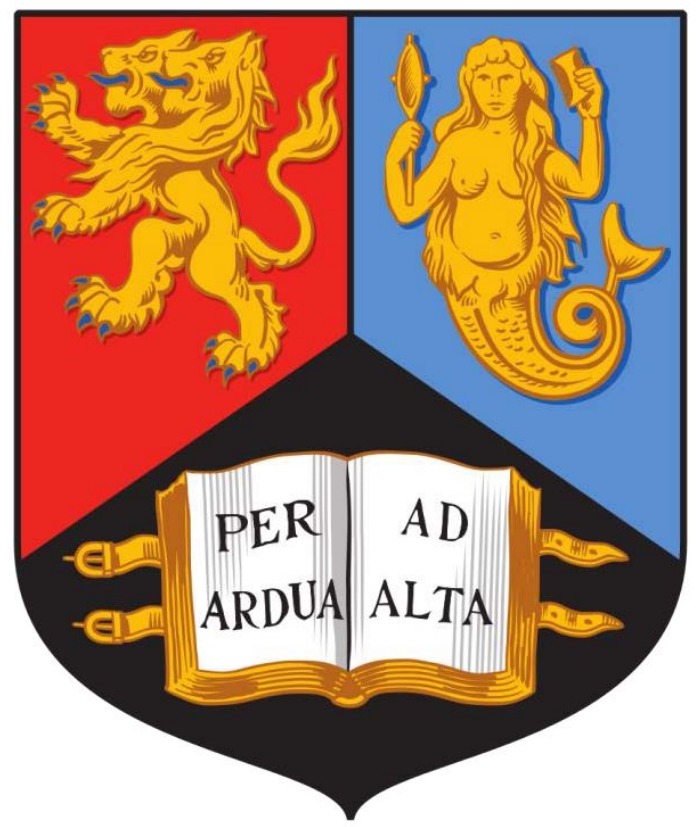

January 2018

Department of Electronic, Electrical and Systems Engineering

University of Birmingham 


\section{UNIVERSITYOF BIRMINGHAM}

\section{University of Birmingham Research Archive e-theses repository}

This unpublished thesis/dissertation is copyright of the author and/or third parties. The intellectual property rights of the author or third parties in respect of this work are as defined by The Copyright Designs and Patents Act 1988 or as modified by any successor legislation.

Any use made of information contained in this thesis/dissertation must be in accordance with that legislation and must be properly acknowledged. Further distribution or reproduction in any format is prohibited without the permission of the copyright holder. 


\section{EXECUTIVE SUMMARY AND ABSTRACT}

In this report I detail how I have investigated the feasibility of producing a systems engineering framework that can be applied to all forms of Railway Control \& Safety (RCS) systems in order to simplify their development, delivery and implementation. Based on this research, I propose two simple models that can be used to model conventional signalling, ERTMS, CBTC and PTC systems; a functional model and a physical model.

I have looked into how these models can be utilised to model specific systems and how this can then be used to identify the high-level functionality and interfaces of individual sub-systems across different physical locations and organisations. I go on to propose a simple method to keep track of individual subsystem locations and their high-level functionality. I also propose how the functional model can be represented as a negative-feedback control system.

I then examined the development and implementation of RCS systems and propose that these systems go through two unique V-cycles, a generic product development V-cycle (by suppliers) and a specific application V-cycle (by operators). I propose that this results in the whole system lifecycle being covered by a closed-loop $\mathrm{W}$-cycle that shows the complete development and procurement process for most metro railway RCS systems. I go on to propose that a more complex process is often required on mainline railways where there are often multiple sub-systems that are procured from separate suppliers and must be integrated into a single system.

I conclude with a study of different project delivery structures for RCS upgrade programmes and recommend a balanced system-centric structure.

My conclusions are that RCS systems are critical to both the safety and performance of the railway and are complex systems of systems. They have clearly defined functional sub-systems that contribute to these two key criteria. Based on my findings, I suggest that a systematic approach to the development, as well as the deployment, of RCS is therefore vital in order to ensure successful development, delivery and integration of modern RCS systems, such as ERTMS, TMS \& DAS. 


\section{ACKNOWLEDGEMENTS}

I would like to thank:

- My supervisors, Professor Clive Roberts and Professor Felix Schmid of University of Birmingham, for their guidance and support during the production of this thesis;

- Jeremy Gill for showing me the value and importance of systems engineering as well as stimulating my love of the subject;

- Mariana Somasundaram for encouraging me to undertake the programme of research that this thesis documents;

- Patrick Williamson for teaching me the importance of the interactions between People, Process and System, as well as acting as a sounding-board for many of my ideas for this research.

It is my opinion that this research could not have been carried out solely by desktop literature review. I am, therefore, extremely grateful to my many contacts within the rail industry who listened to my ideas and were willing to give me their valuable time to provide their views and discuss proposals.

Finally I would like to express my thanks to members of my family. I must thank my mother and father, Maureen and Geoffrey, the most supportive of parents, for always encouraging me in my pursuit of this research. Also, my thanks to my wife, Moira, who has encouraged and fully supported me throughout this research and the production of this report, even though this work coincided with the arrival of both of our beloved children, daughter Lucy and son Matthew. 


\section{NOTE TO THE READER}

The section 'Executive summary and Abstract' along with Chapters 1, 3, 4 and 8 of this thesis have been narrowly paraphrased from the following papers written by myself during this research:

- 'Systems Engineering Framework for Railway Control and Safety Systems' IRSE News Issue 218, 2016

- 'Systems Engineering Framework for Railway Control and Safety Systems' 2016 IEEE International Conference on Intelligent Rail Transportation (ICIRT), 2016

- 'Event Report on Systems Engineering for Train Control and Communications' IRSE News Issue 224, 2016

- 'A Systems Engineering Framework for Railway Control \& Safety System: The Mainline Challenge' Stephenson Conference, 2017

- 'Systematic Approach to Command Control Signalling CBTC Projects,' Systems Engineering Community Newsletter, Mott MacDonald, November 2012

- 'Delivering ERTMS Systems,' Systems Engineering Community Newsletter, Mott MacDonald, March 2013

Sections that are narrowly paraphrased from these papers have been highlighted by italics as well as being indented with reference to the relevant paper.

Parts of Chapters 1, 3, 4, 5 and 6 have also been narrowly paraphrased for a paper entitled 'Railway Control \& Safety Systems as a Closed Loop Negative Feedback Control System' that has been submitted for the IET International Conference on Railway Engineering (ICRE) 2018.

\section{Contents}

List of Figures

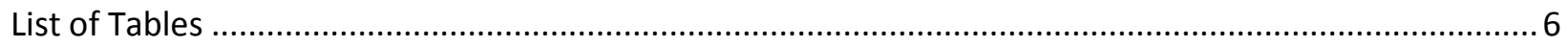

Glossary of Terms

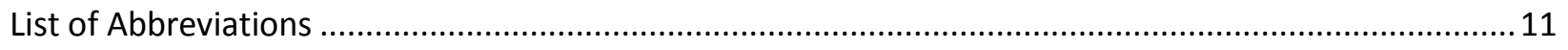

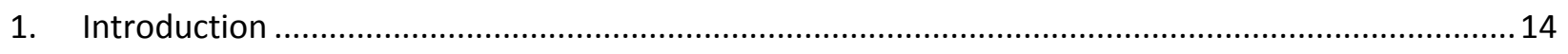

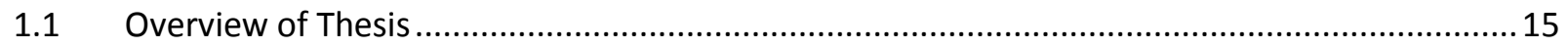

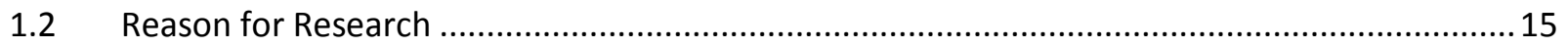

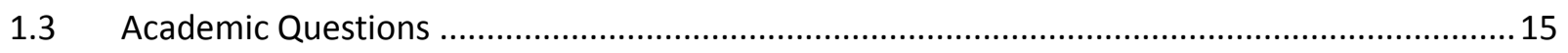

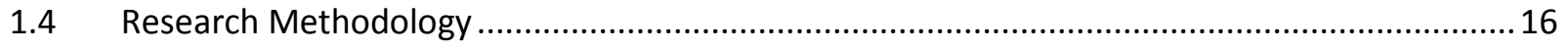

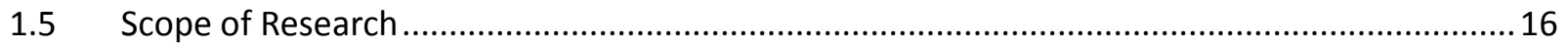

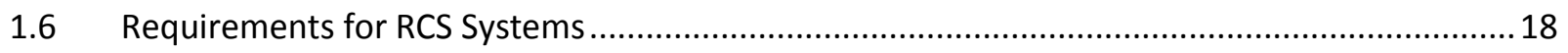

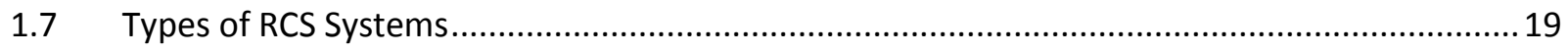

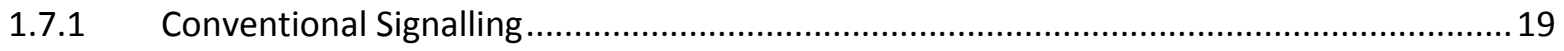




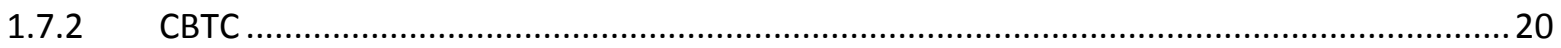

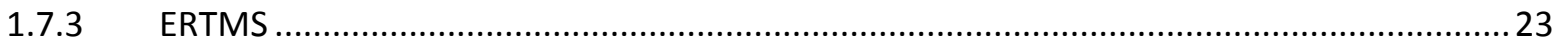

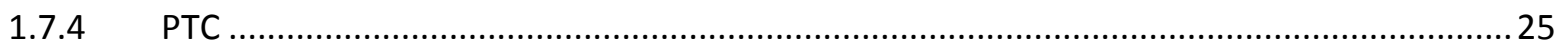

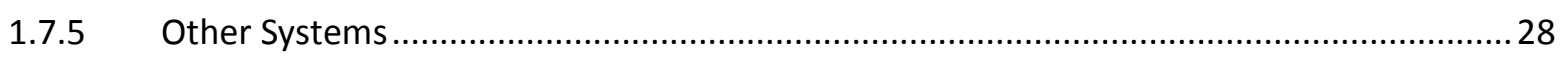

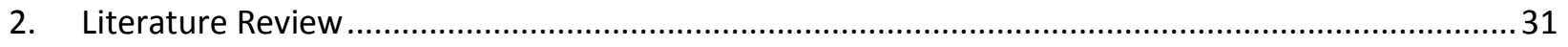

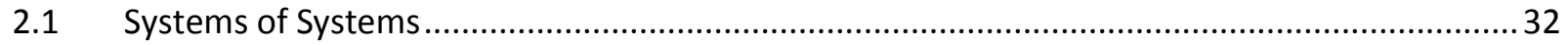

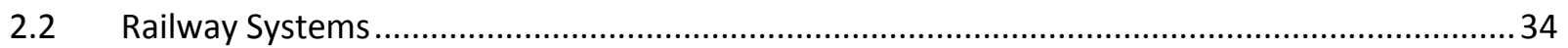

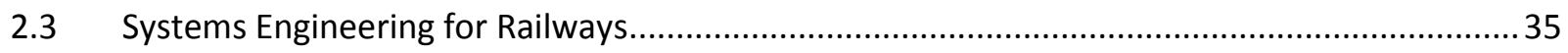

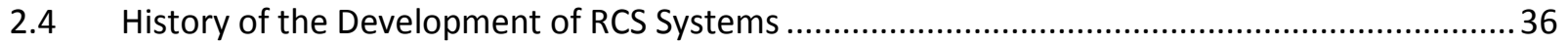

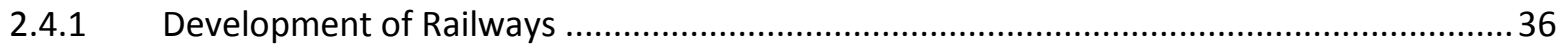

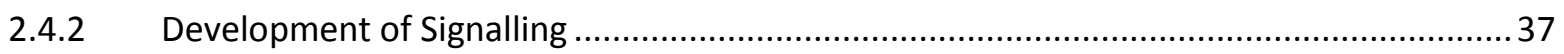

2.4.3 Development of Train Protection ............................................................................... 38

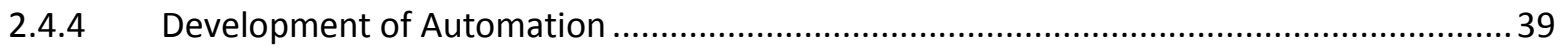

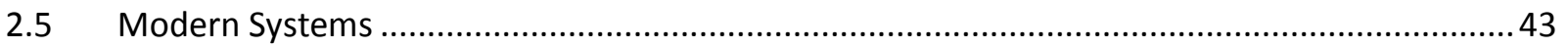

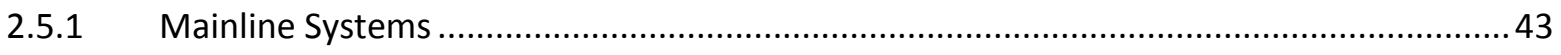

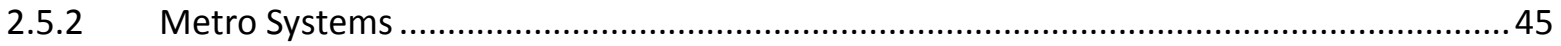

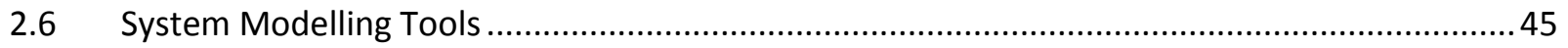

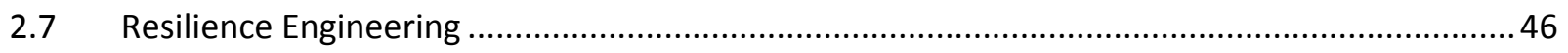

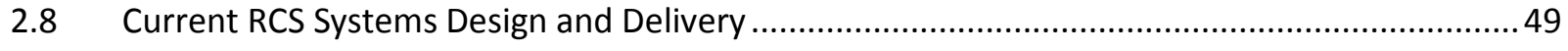

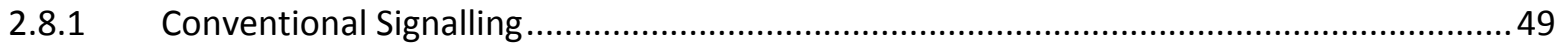

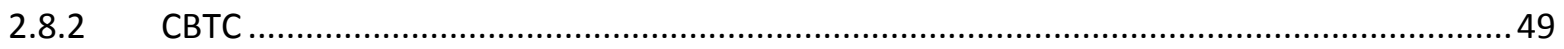

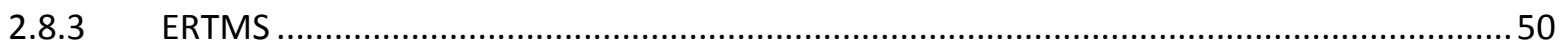

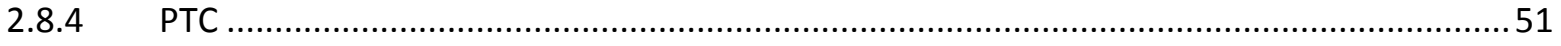

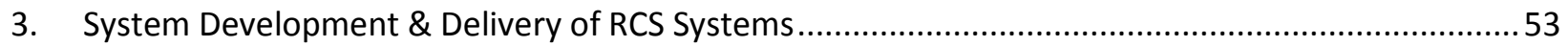

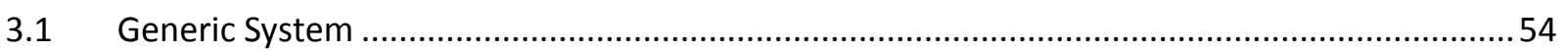

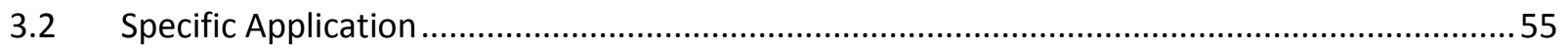

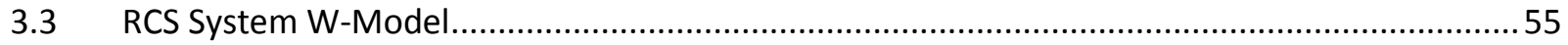

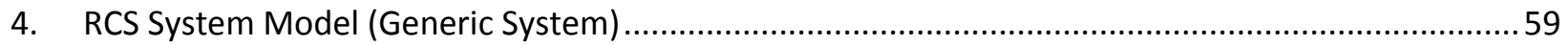

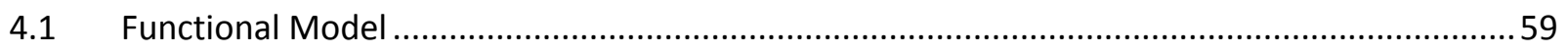

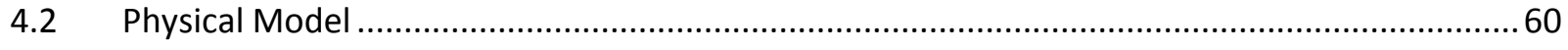

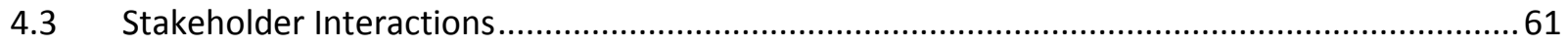

4.3.1 Physical Stakeholder Boundaries \& Interfaces .............................................................61 
4.3.2 Functional Stakeholder Boundaries \& Interfaces ......................................................... 61

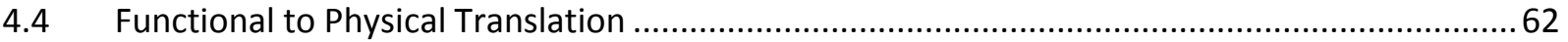

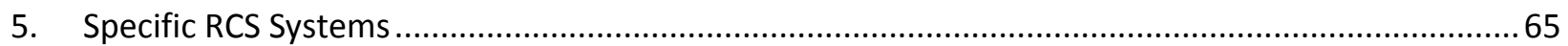

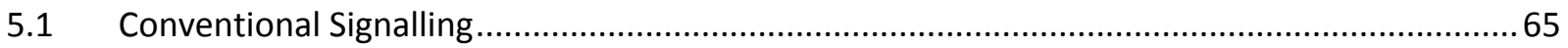

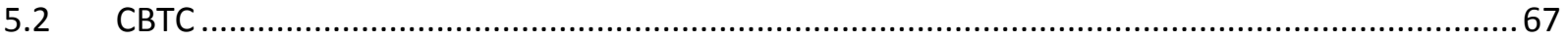

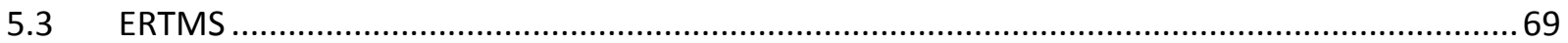

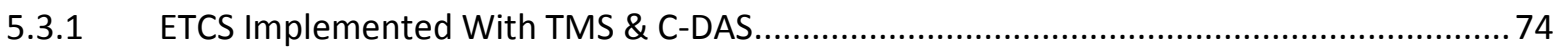

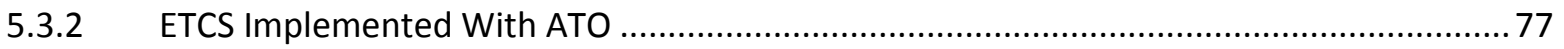

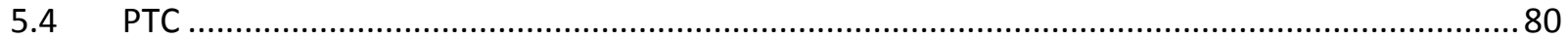

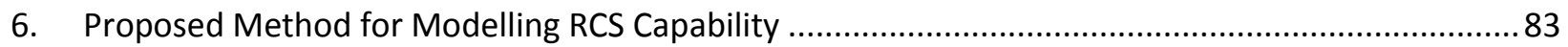

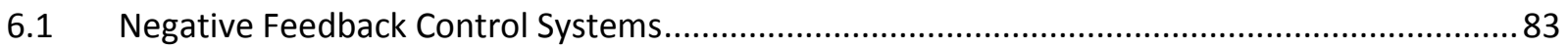

6.2 RCS as a Negative Feedback Control System ........................................................................... 84

6.3 Specific RCS Systems in a Negative-Feedback Model ................................................................ 85

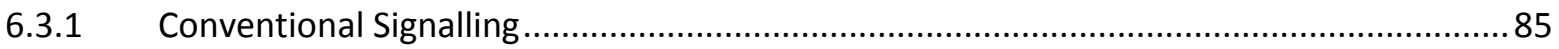

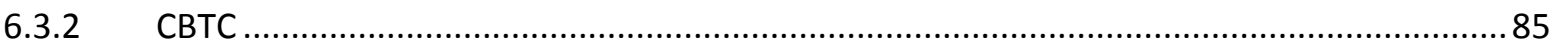

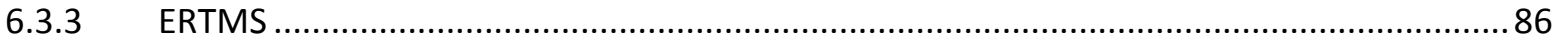

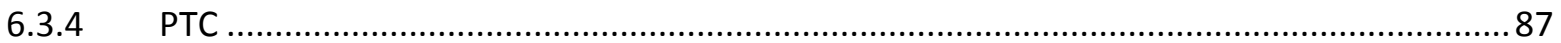

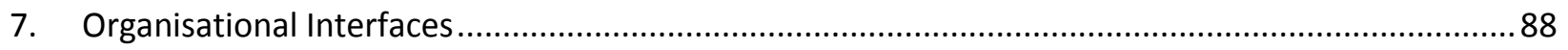

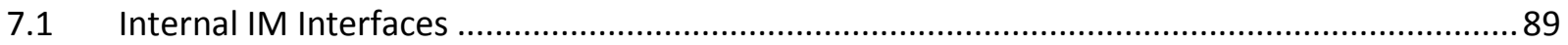

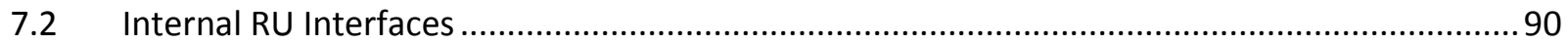

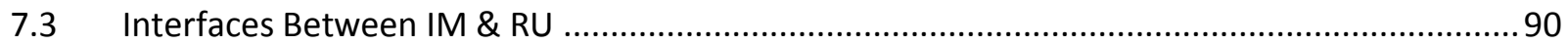

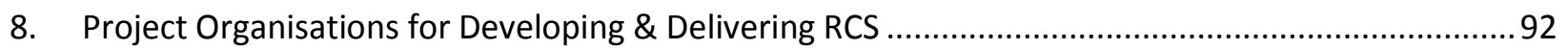

8.1 Current Project Delivery structures ….................................................................................. 94

8.1.1 Project Management Led Delivery.............................................................................. 94

8.1.2 Engineering Management Led Delivery .................................................................. 95

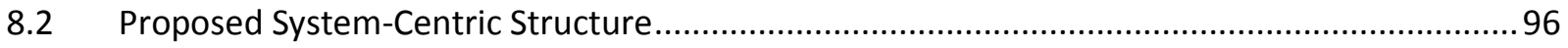

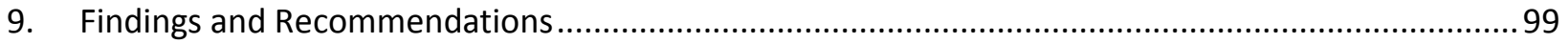

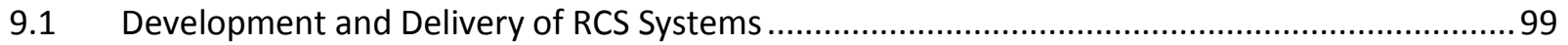

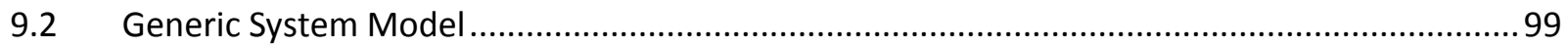

9.3 RCS As A Negative-Feedback Control System ...................................................................... 100

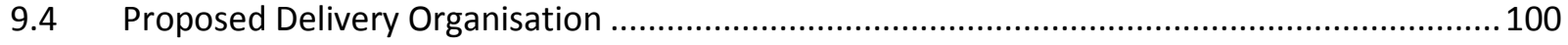

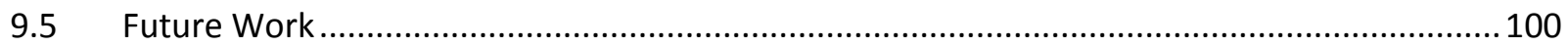




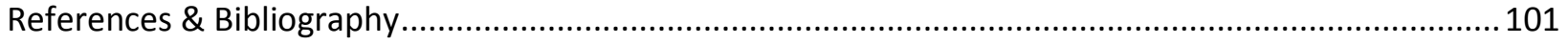

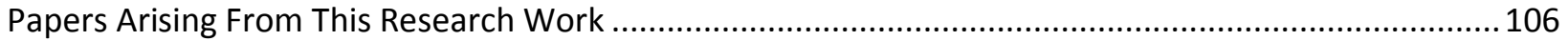

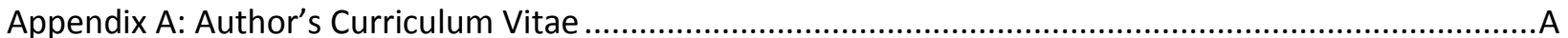




\section{List of Figures}

Fig. 1-1 Systems Engineering Lifecycle (Faulconbridge \& Ryan, 2014) ............................................... 17

Fig. 1-2 Activities in the Acquisition Phase (Faulconbridge \& Ryan, 2014) ............................................17

Fig. 1-3 Aspects of Project Delivery That Must be Integrated (Williamson, 2015) .................................. 18

Fig. 1-4 Common Sub-systems of Conventional Signalling (King, 2016) .............................................. 19

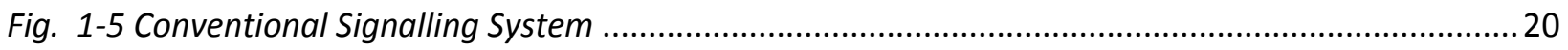

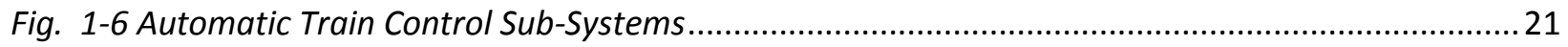

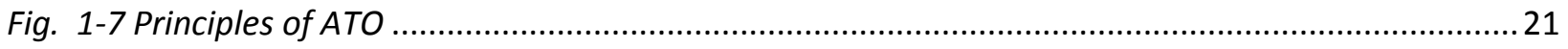

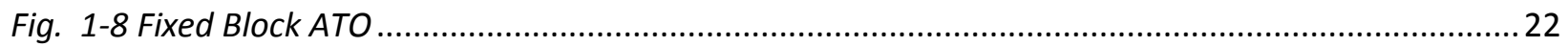

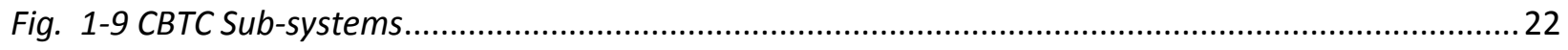

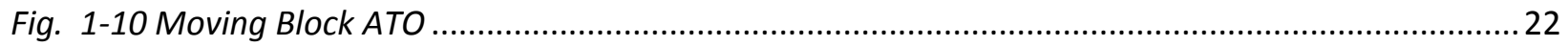

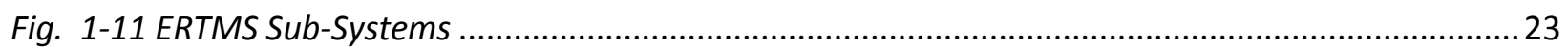

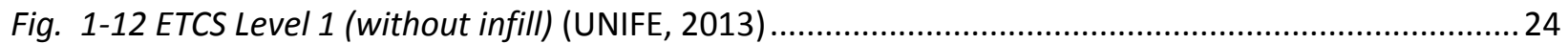

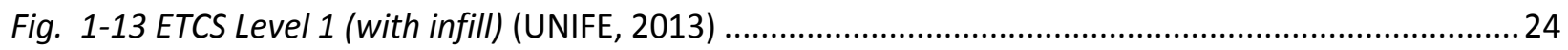

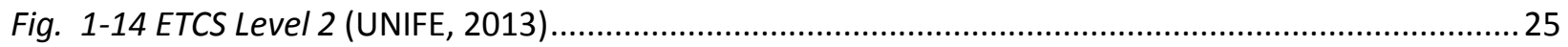

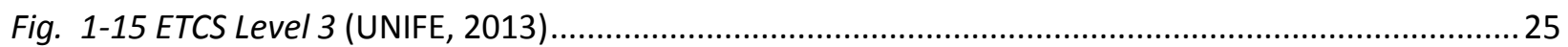

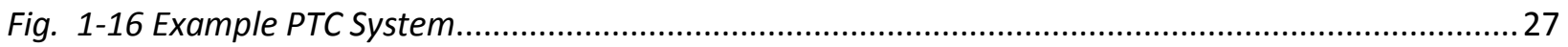

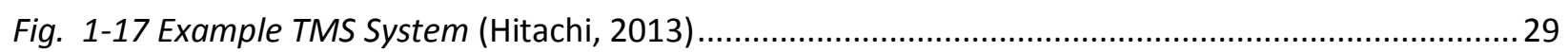

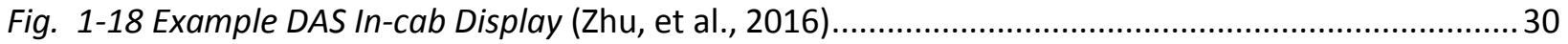

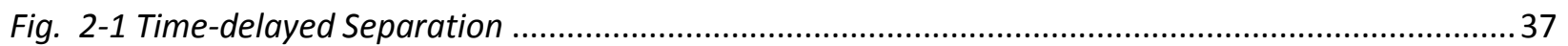

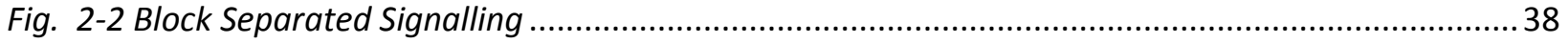

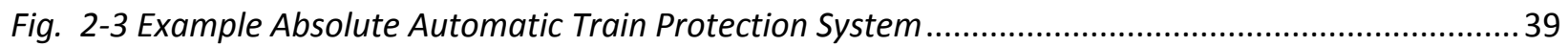

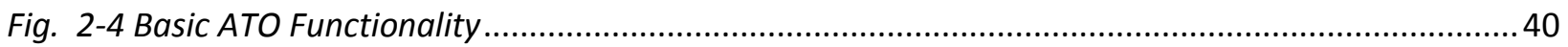

Fig. 2-5 Resilience Engineering set of possible outcomes (Leonhardt, et al., 2009) ................................47

Fig. 2-6 Safety Focus anno 2009 (Leonhardt, et al., 2009).................................................................. 47

Fig. 2-7 'Swiss Cheese' Model (Leonhardt, et al., 2009)........................................................................ 48

Fig. 3-1 Activities in the Acquisition and Utilisation Phases of the system lifecycle (Faulconbridge \& Ryan, 2014) .53

Fig. 3-2 Acquisition Phase activities and the major artefacts and reviews associated with each

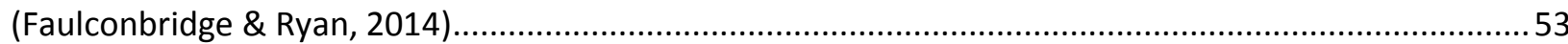

Fig. 3-3 Typical Supplier V-Cycle for Developing RCS Systems (King, 2016) ...........................................5

Fig. 3-4 Typical V-Cycle for Delivering RCS System on a Specific Railway (King, 2016)............................55

Fig. 3-5 Proposed W-Cycle for Complete RCS Development \& Implementation (Single Source Supplier)

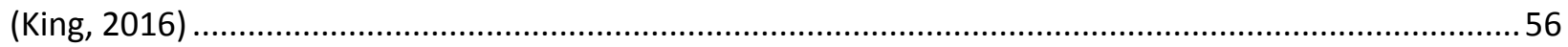

Fig. 3-6 W-Cycle for Complete RCS Development \& Implementation (Multiple Supplier Sub-systems) .... 58

Fig. 4-1 Generic RCS Functional Model (King, 2016) ..........................................................................5 59

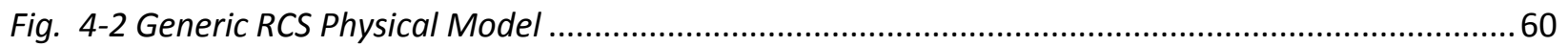

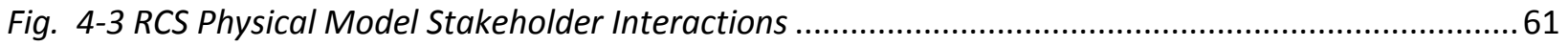

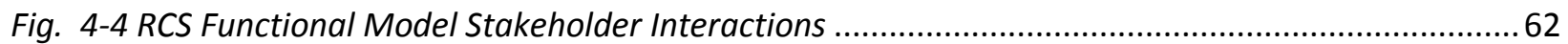

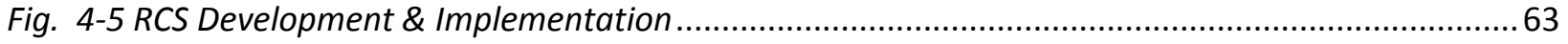

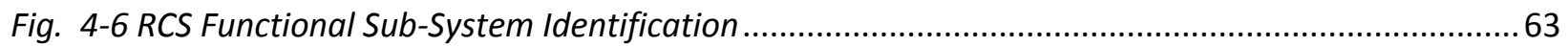




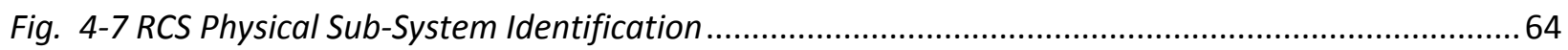

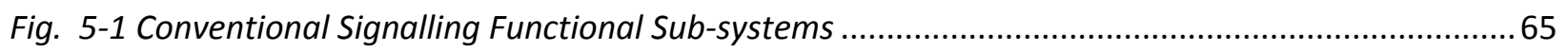

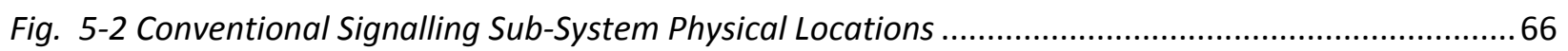

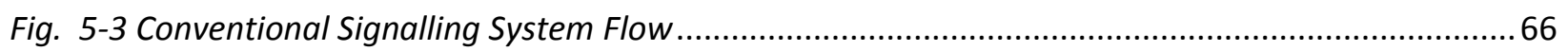

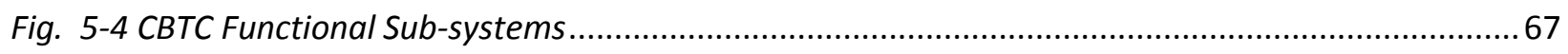

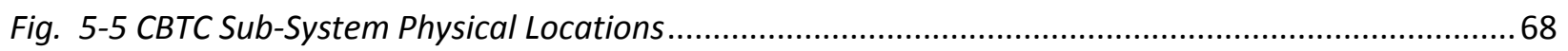

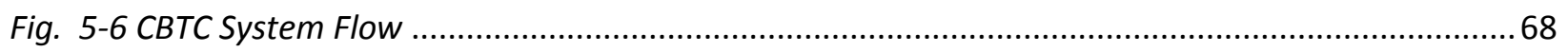

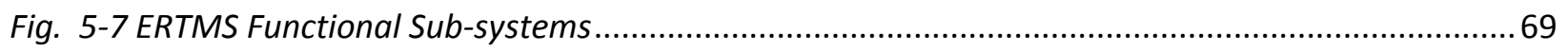

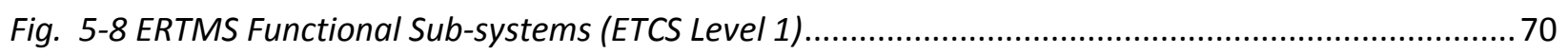

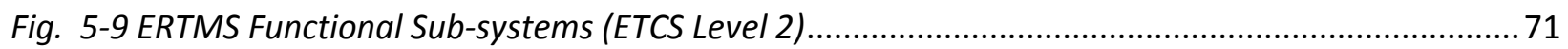

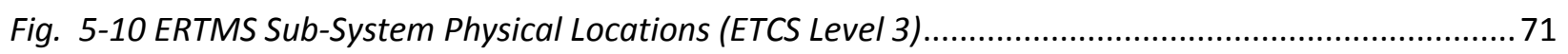

Fig. 5-11 ERTMS Sub-System Physical Locations (ETCS Level 1).............................................................. 71

Fig. 5-12 ERTMS Sub-System Physical Locations (ETCS Level 2) .......................................................... 72

Fig. 5-13 ERTMS Sub-System Physical Locations (ETCS Level 3)......................................................... 72

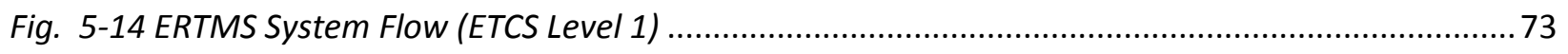

Fig. 5-15 ERTMS System Flow (ETCS Level 2) ……........................................................................... 73

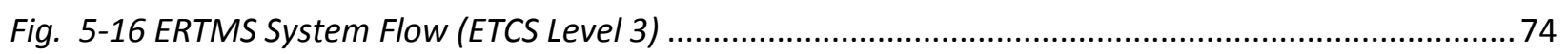

Fig. 5-17 ETCS With TMS \& C-DAS Functional Model.......................................................................... 75

Fig. 5-18 ETCS Level 2 With TMS \& C-DAS Functional Model...................................................................... 75

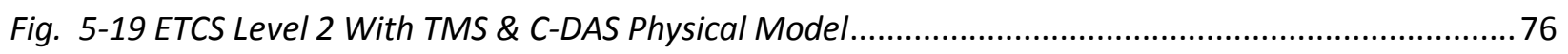

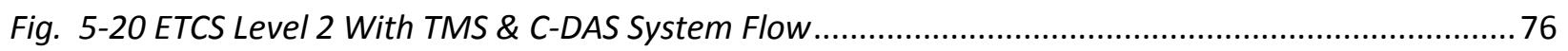

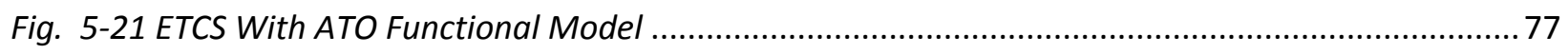

Fig. 5-22 ETCS Level 2 With ATO Functional Model ............................................................................ 78

Fig. 5-23 ETCS Level 2 With ATO Physical Model ................................................................................ 78

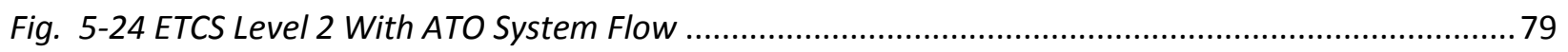

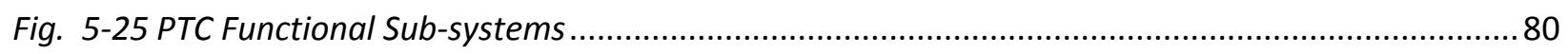

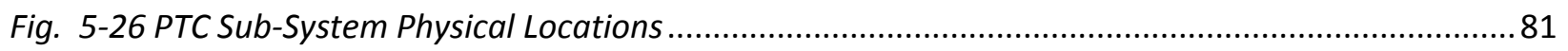

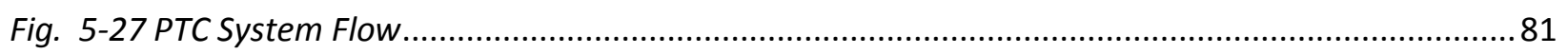

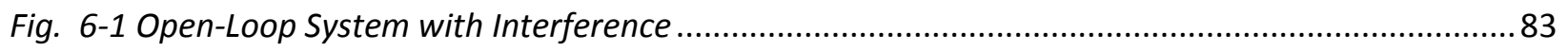

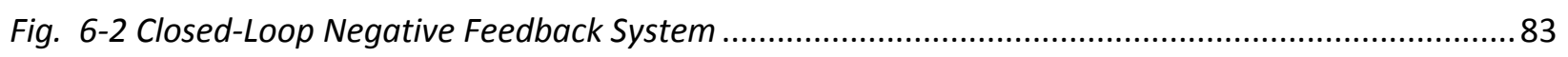

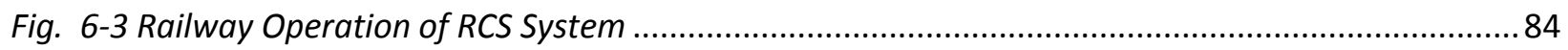

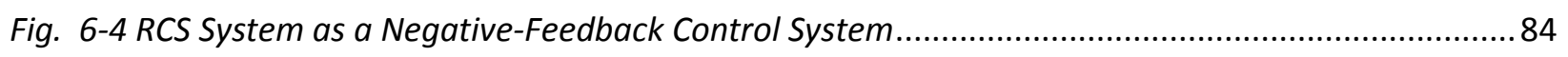

Fig. 6-5 Conventional Signalling System as a Negative-Feedback System (Broken Loop) ....................... 85

Fig. 6-6 CBTC System as a Closed-Loop Negative-Feed back System ...................................................... 85

Fig. 6-7 ERTMS Level 2 as a Negative-Feedback System (Broken Loop) ................................................ 86

Fig. 6-8 ETCS Level 2 With TMS \& C-DAS as a Closed-Loop Negative-Feedback System.......................... 86

Fig. 6-9 PTC as a Negative-Feedback System (Broken Loop)............................................................ 87

Fig. 7-1 ETCS Level 2 With TMS \& C-DAS System Flow Organisational Boundaries .................................. 88

Fig. 8-1 Challenges of RCS Delivery Structures .................................................................................. 92

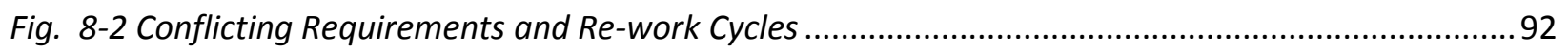

Fig. 8-3 Role of Systems Engineering Team ................................................................................... 93

Fig. 8-4 Systematic Approach to RCS Design \& Development ............................................................ 93 
Fig. 8-5 General Project Management Led Structure (King, 2016) ....................................................... 94

Fig. 8-6 General Engineering Management Led Structure (King, 2016) ............................................... 95

Fig. 8-7 Proposed System-Centric Structure (King, 2016) ................................................................. 98

\section{List of Tables}

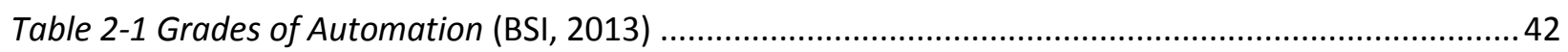

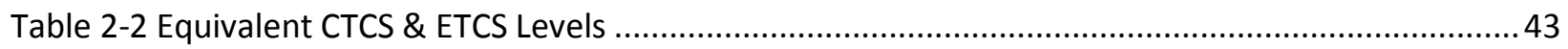

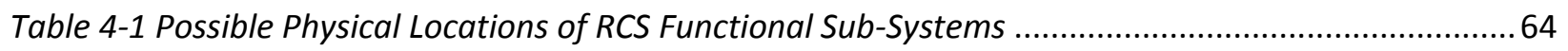

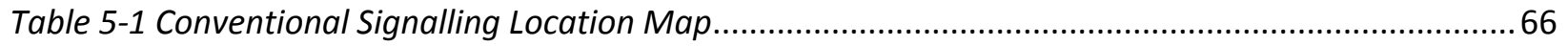

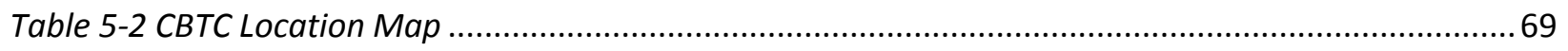

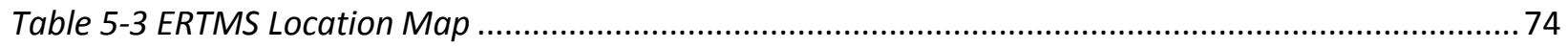

Table 5-4 ETCS Level 2 With TMS \& C-DAS Location Map ..................................................................... 77

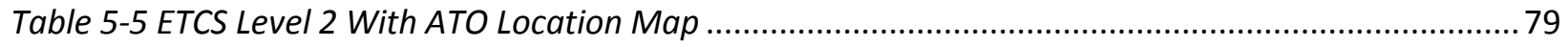

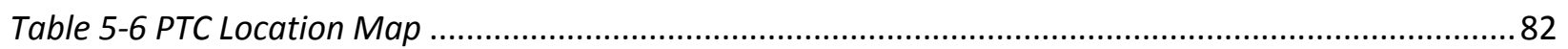

Table 7-1 ETCS Level 2 With TMS \& C-DAS Functional \& Organisational Interfaces ................................. 89

Table 7-2 ETCS Level 2 With TMS \& C-DAS Internal IM Interfaces........................................................... 89

Table 7-3 ETCS Level 2 With TMS \& C-DAS Internal RU Interfaces .......................................................... 90

Table 7-4 ETCS Level 2 With TMS \& C-DAS Organisational Interfaces ................................................... 90 


\section{Glossary of Terms}

The following section is used to define the meanings of the major terms and abbreviations that shall be adopted in this thesis. In many cases, there are different uses of the same terms and different terms to describe the same components and functionalities and these will be mentioned, where appropriate. Reference is made to the concept of the railway as a 'system of systems', which has emerging properties that are more advanced than those of the individual components (Hossein, et al., 2015).

\section{4-Foot}

The space between the running rails on an individual track of operational railway.

\section{ARS: Automatic Route Setting}

A component of a railway system of systems that automatically routes trains around the network according to a pre-loaded timetable.

\section{ATC: Automatic Train Control}

The combination of the ATO and ATP sub-systems. The ATP sub-system overrides the ATO system on the rare occasions where the latter malfunctions, e.g., in low adhesion situations. In some regions of the world, notably the USA, the term automatic train control or ATC refers to the automatic train protection functionality.

\section{ATO: Automatic Train Operation}

The component within a railway system of systems that replaces the driver and stops the trains at required points (usually stations). There are different levels of automation, e.g., attended and unattended operation.

\section{ATP: Automatic Train Protection}

The component within a railway system of systems that prevents trains from proceeding past their MA.

\section{ATR: Automatic Train Regulation}

The component within a railway system of systems that automatically routes trains throughout the network to optimize the performance of the network.

\section{ATS: Automatic Train Supervision}

The component within a railway system of systems that continuously monitors the positions and speeds of all trains on a line or network and controls their behaviour by means of ATR to achieve optimal operation. 


\section{CBI: Computer Based Interlocking}

A failsafe computer system that provides interlocking functionality for a railway system, such as Solid State Interlocking (SSI), WESTLOCK \& SMARTLOCK.

\section{CBTC: Communications Based Train Control}

A type of railway control that includes ATC and ATS sub-systems and uses radio or inductive transmission between the infrastructure and the trains, often enabling some form of moving block functionality. In some circles CBTC stands for Computer Based Train Control due to the heavy microelectronic-based computer systems in its design.

\section{CSS: Cab Signal System}

Any system that utilises an in-cab display to relay safety-critical movement authority data to the driver via a wireless communications channel.

\section{Conventional Signalling}

Any signalling and protection system that is based around the driver observing the indications of lineside signals to determine their right to proceed.

\section{CTC: Centralised Traffic Control}

A centralised OCS that provides automatic routeing functions for optimised traffic management.

\section{CTCS: Chinese Train Control System}

The Chinese standard system for ATP and in-cab signalling. Split into levels of operation very similar to ETCS.

\section{Danger Point}

The point beyond the LMA that the front of a train must not pass at a given point in time in order to avoid a hazardous situation.

\section{DAS: Driver Advisory System}

System that provides in-cab information to the train operator on how to optimise their driving style for consistency and efficiency. This can be combined with information received from the TMS via radio link to provide additional information to better regulate service in a similar way to ATO; this is known as Connected-DAS or C-DAS.

ERTMS: European Rail Traffic Management System

The European railway control system that consists of ETCS, ETML and GSM-R. 


\section{ETCS: European Train Control System}

The European standard ATP system that allows interoperability across borders and between equipment from different manufacturers. ETCS Level 1 is overlaid to conventional line-side signals and provides standard ATP functionality with continuous supervision of a train's speed and MA. ETCS Level 2 can operate both with and without lineside signals and includes an advanced in-cab display of the changing MA and speed limits (UNIFE, 2013).

\section{ETML: European Traffic Management Layer}

The proposed standardized European operating rules and ATS functions.

\section{GOA: Grade Of Automation}

Level of train control automation of a system, see Table 2-1.

\section{GSM-R: Global System for Mobile communications - Railways}

The European standard communications system for mainline railways that is based on the GSM standard and offers additional functionality, e.g., group calls and prioritization of calls. Within Europe, GSM-R is allocated to the radio spectrum in the $876-880 \mathrm{MHz}$ band for Uplink and the 921-925 MHz band for Downlink. However it has also been implemented in other countries outside the EU utilizing different bandwidths (UNIFE, 2013).

\section{IM: Infrastructure Manager}

"Any body or firm responsible for establishing, managing and maintaining railway infrastructure (including traffic management and control-command and signalling)", quoted from (RNE, 2013).

\section{Inx: Interlocking}

System which prevents conflicting routes to be set on a railway network.

\section{LMA: Limit of Movement Authority}

The point on the running line that a train is not authorised to pass at a given point in time during its journey.

\section{MA: Movement Authority}

The point on a running line that an individual train can safely travel to at a given point in time during its journey based on the speed of the train and the limits of the infrastructure.

\section{Mainline}

For the purposes of this report, Mainline refers to any heavy railway network that transports people between cities or across countries. 


\section{Metro}

For the purposes of this report, Metro refers to any city or suburban railway that provides mass transit of people.

\section{OCS: Operational Control System}

A Visual Display Unit (VDU) based system that allows central control of a railway.

\section{Protected Area}

Another term for the Limit of Movement Authority.

\section{PSD: Platform Screen Door}

The component of the railway system of systems that protects the passenger at the Platform-Train Interface (PTI).

\section{PTC: Positive Train Control}

The USA's standard for in-cab signalling and ATP.

\section{RU: Railway Undertaking}

"Any public or private undertaking whose principal business is to provide services for the transport of goods and/or passengers by rail", quoted from (RNE, 2013).

\section{TETRA: Terrestrial Trunked Radio}

Radio communication system often utilised for CBTC systems and favoured by emergency services for its resilience (TETRA and Oxford Information Labs., 2016).

\section{TMS: Traffic Management System}

A system that regulates and optimises the flow and routing of trains around a railway network.

\section{UNIFE: Union des Industries Ferroviaires Européennes}

An association of Europe's rail supply companies active in the design, manufacture, maintenance and refurbishment of rail transport systems, subsystems and related equipment. (UNIFE, 2013) 


\section{List of Abbreviations}

AADL Architecture Analysis \& Design Language

AAR Association of American Railroads

ACSES Advanced Civil Speed Enforcement System

AD Axiomatic Design

AREMA American Railway Engineering Maintenance-of-Way Association

ASFA Anuncio de Señales y Frenado Automático

ATC Automatic Train Control

ATP Automatic Train Protection

ATO Automatic Train Operation

ATS Automatic Train Supervision

AWS Audible Warning System

BIM Building Information Modelling

BNSF Burlington Northern and Santa Fe

BSI British Standards Institution

CAD Computer-Aided Design

CASE Computer-Aided Software Engineering

CBI Computer Based Interlocking

CBTC Communications Based Train Control

C-DAS Connected Driver Advisory System

CSS Cab Signal System

CTC Centralised Traffic Control

CTCS Chinese Train Control System

CV Curriculum Vitae

DAS Driver Advisory System

DM Data Modelling

DMI Driver Machine Interface

DP Design Parameter

E-ATC Enhanced Automatic Train Control

EM Enterprise Modelling

EN Euro Norm

ERD Entity Relationship Diagram

ERTMS European Rail Traffic Management System

ETCS European Train Control System

ETML European Traffic Management Layer

ETMS Electronic Train Management System

EVC European Vital Computer

FAA Federal Aviation Administration

FBD Functional Block Diagram

FFBD Functional Flow Block Diagram

FOS Family Of Systems

FR Functional Requirement

FRA Federal Railroad Administration

FRS Functional Requirements Specification

FSML Framework-Specific Modelling language

FuTRO Future Train Regulation Optimisation

GOA Grade Of Automation 


$\begin{array}{ll}\text { GPS } & \text { Global Positioning System } \\ \text { GSM-R } & \text { Global System for Mobile - Railways } \\ \text { ICAM } & \text { Integrated Computer-Aided Manufacturing } \\ \text { IDEF } & \text { ICAM Definition for Function Modelling } \\ \text { IEC } & \text { International Electrotechnical Commission } \\ \text { IEEE } & \text { Institute of Electrical \& Electronic Engineers } \\ \text { IET } & \text { Institution of Engineering \& Technology } \\ \text { I-ETMS } & \text { Interoperable Electronic Train Management System } \\ \text { IFD } & \text { Information Flow Diagram } \\ \text { IM } & \text { Infrastructure Manager } \\ \text { INCOSE } & \text { INternational Council On Systems Engineering } \\ \text { Inx } & \text { Interlocking } \\ \text { IRSE } & \text { Institution of Railway Signal Engineers } \\ \text { ISO } & \text { International Organization for Standardization } \\ \text { ITC } & \text { Interoperable Train Control } \\ \text { ITCS } & \text { Incremental Train Control System } \\ \text { KRTCS } & \text { Korean Radio-based Train Control System } \\ \text { MATLAB } & \text { MATrix LABoratory } \\ \text { MODAF } & \text { Ministry Of Defence Architecture Framework } \\ \text { NDGPS } & \text { Nationwide Differential Global Positioning System } \\ \text { NR } & \text { Network Rail } \\ \text { NTR } & \text { National Technical Rule } \\ \text { NTSB } & \text { National Transportation Safety Board } \\ \text { LEU } & \text { Lineside Encoder Unit } \\ \text { LU } & \text { London Underground } \\ \text { OCS } & \text { Operational Control System } \\ \text { P\&C } & \text { Points and Crossings } \\ \text { PCB } & \text { Printed Circuit Board } \\ \text { PTC } & \text { Positive Train Control } \\ \text { RBC } & \text { Radio Block Centre } \\ \text { RBTC } & \text { Radio Based Train Control } \\ \text { RCS } & \text { Railway Control \& Safety } \\ \text { RNE } & \text { Rail Network Europe } \\ \text { RP } & \text { Route Performance } \\ \text { RRAUK } & \text { Rail Research Association UK } \\ \text { RSSB } & \text { Rail Safety and Standards Board } \\ \text { RTS } & \text { Railway Technical Strategy } \\ \text { RU } & \text { Railway Undertaking } \\ \text { S\&P } & \text { Safety and Protection } \\ \text { SADT } & \text { Structured Analysis and Design Technique } \\ \text { SIL } & \text { Safety Integrity Level } \\ \text { SOS } & \text { System Of Systems } \\ \text { SRS } & \text { System Requirements Specification } \\ \text { SSI } & \text { Solid State Interlocking } \\ \text { SysML } & \text { System Modelling Language } \\ \text { TMS } & \text { Terrestrial Trunked Radio } \\ & \text { Transport for London } \\ \text { Tric Management System } \\ \text { IFTR }\end{array}$




$\begin{array}{ll}\text { TP } & \text { Train Performance } \\ \text { TPH } & \text { Trains Per Hour } \\ \text { TPWS } & \text { Train Protection \& Warning System } \\ \text { TSI } & \text { Technical Standard for Interoperability } \\ \text { U-DAS } & \text { Unconnected Driver Advisory System } \\ \text { UK } & \text { United Kingdom } \\ \text { UML } & \text { Unified Modelling Language } \\ \text { UNIFE } & \text { Union des Industries Ferroviaires Européennes } \\ \text { USA } & \text { United States of America } \\ \text { V\&V } & \text { Verification and Validation } \\ \text { VDU } & \text { Visual Display Unit }\end{array}$




\section{Introduction}

Traditional railway signalling systems have been based around fixed block train separation and line-of-sight signals to control the movement of trains and ensure collision avoidance. This has historically led to a segregation of both the functionality and the development of sub-systems such as signalling, rolling stock and control centres, with them following a very narrow, sequential \& design-based approach in their development and delivery (Schmid, 2002). (King, 2016)

Recent developments on Radio-Based Train Control (RBTC) systems including the European Rail Traffic Management System (ERTMS) for mainline (Poré, 2003) and Communications Based Train Control (CBTC) systems for metro lines (Scheerer \& Baker, 2003) have resulted in more complex systems with greater sub-system interactions as movement authorities are transmitted over a wireless communications channel between the protection system and the train. This has led to a requirement for a systems engineering based approach to the development and deployment of these complete systems (Moens \& Stokes, 2003). (King, 2016)

The railway industry has at times struggled to embrace systems engineering (Doherty \& Harmon, 2007), as it is perceived to run against the safety-focused design-based approach that rightfully enjoys a high status within the industry (Cooksey, 2001). Many engineers in the industry who are familiar with the traditional design based approach also struggle with relating the new systems to the traditional principles that they are used to (Keseljevic, 2005). (King, 2016)

This research investigates the feasibility of producing a systems engineering framework that can be applied to all forms of Railway Control \& Safety (RCS) systems in order to simplify their development and delivery.

Parts of this thesis have been published in the following papers produced by myself:

- 'Systems Engineering Framework for Railway Control and Safety Systems' IRSE News Issue 218, 2016

- 'Systems Engineering Framework for Railway Control and Safety Systems' 2016 IEEE International Conference on Intelligent Rail Transportation (ICIRT), 2016

- 'Event Report on Systems Engineering for Train Control and Communications' IRSE News Issue 224, 2016

- 'A Systems Engineering Framework for Railway Control \& Safety System: The Mainline Challenge' Stephenson Conference, 2017

- 'Systematic Approach to Command Control Signalling CBTC Projects,' Systems Engineering Community Newsletter, Mott MacDonald, November 2012

- 'Delivering ERTMS Systems,' Systems Engineering Community Newsletter, Mott MacDonald, March 2013 
Parts have also been utilised for a paper entitled 'Railway Control \& Safety Systems as a Closed Loop Negative Feedback Control System' that has been submitted for the IET International Conference on Railway Engineering (ICRE) 2018.

Short quotations in this thesis from other texts are shown in quotation marks "'; longer quotations are indented.

\subsection{Overview of Thesis}

The structure of this thesis is broken up into 3 main parts:

A. Chapters $1 \& 2$ introduce the thesis's main concepts, as well as the main literature review detailing the academic background, including the basics of systems engineering, as well as the history of RCS systems and how they are currently developed and delivered.

B. Chapters 3, 4, 5, 6, $7 \& 8$ look at the unique challenges of RCS systems and how systems engineering tools and techniques could improve their development \& delivery, including from a project management perspective.

C. Chapter 9 details the findings of this research and recommendations for future work that could follow on from it.

\subsection{Reason for Research}

Traditional signalling based on fixed lineside signals is becoming increasingly redundant as the railway industry embraces modern systems such as the ERTMS and CBTC. With the change to these complex systems of systems also comes a change in the way in which the industry must develop and deliver what were traditionally 'signalling' projects. (King, 2016)

The industry must move away from what has traditionally been a very process-driven design to a systematic one that delivers functionality across a series of sub-systems. (King, 2016)

However, the design principles required by these systems will remain fundamentally the same as those of conventional signalling, requiring traditional signalling design engineers to work closely with modern system engineers who often use different approaches, methods and terminology.

This research was therefore proposed to determine if a common system engineering framework could be developed that would apply to all forms of modern (and potential future) RCS systems that could be understood by both signalling design engineers and RCS systems engineers.

\subsection{Academic Questions}

The aim of this research was to investigate the following questions:

1. How are complex systems of systems like RCS traditionally modelled and developed?

2. What are the past and present concepts of RCS?

3. Can a systems model be produced that is representative of all forms of RCS?

4. How would specific RCS systems map onto the generic model?

5. Is there a systematic method to develop and deliver any type of RCS system? 


\subsection{Research Methodology}

The research was predominantly carried out in a desktop environment by extensive reading of academic papers and text, as well as drawing significantly on my own experiences within the railway industry. For this reason, a copy of my Curriculum Vitae (CV) is provided in Appendix A.

I started by conducting a literature review into the developments of the most common RCS systems and how they are delivered, before further reading up on the latest developments in systems engineering, particularly relating to the areas of systems of systems and systems modelling.

I then started to investigate the fundamental requirements of any RCS system and from that developed a generic model that any RCS system could be mapped on to, before investigating how this model could be used to model the functionality of an RCS system to assist with design and development.

Finally, I looked into the delivery models and organisational structures often utilised within the industry for developing and delivering RCS systems and investigated if approaching the development of these structures systematically could improve how we develop and deliver RCS projects.

\subsection{Scope of Research}

The scope of this research covers the application of recognised systems engineering tools and techniques to modern forms of RCS on both mainline and metro railway systems.

This will include:

- Systems based around fixed light indications (hereafter referred to as 'conventional signalling). Predominantly based around the signalling principles of the United Kingdom (UK) that the author is most familiar with.

- Communication Based Train Control (CBTC). The most common form of modern train control and protection utilised on Metro railways.

- European Rail Traffic Management System (ERTMS). The European standard for modern mainline railway train control and protection.

- Positive Train Control (PTC). The United States of America (USA) standard for modern mainline railway train control and protection.

In terms of fundamental system engineering, (Faulconbridge \& Ryan, 2014) define four recognised main stages of the systems engineering lifecycle, namely:

$\begin{array}{ll}\text { - } & \text { Pre-acquisition } \\ \text { - } & \text { Acquisition } \\ \text { - } & \text { Utilisation } \\ \text { - } & \text { Retirement }\end{array}$

This research predominantly covers the Acquisition and Utilisation phases of RCS projects. (Faulconbridge \& Ryan, 2014) breakdown of the four activities is shown in Fig. 1-1.

(King, 2016) 


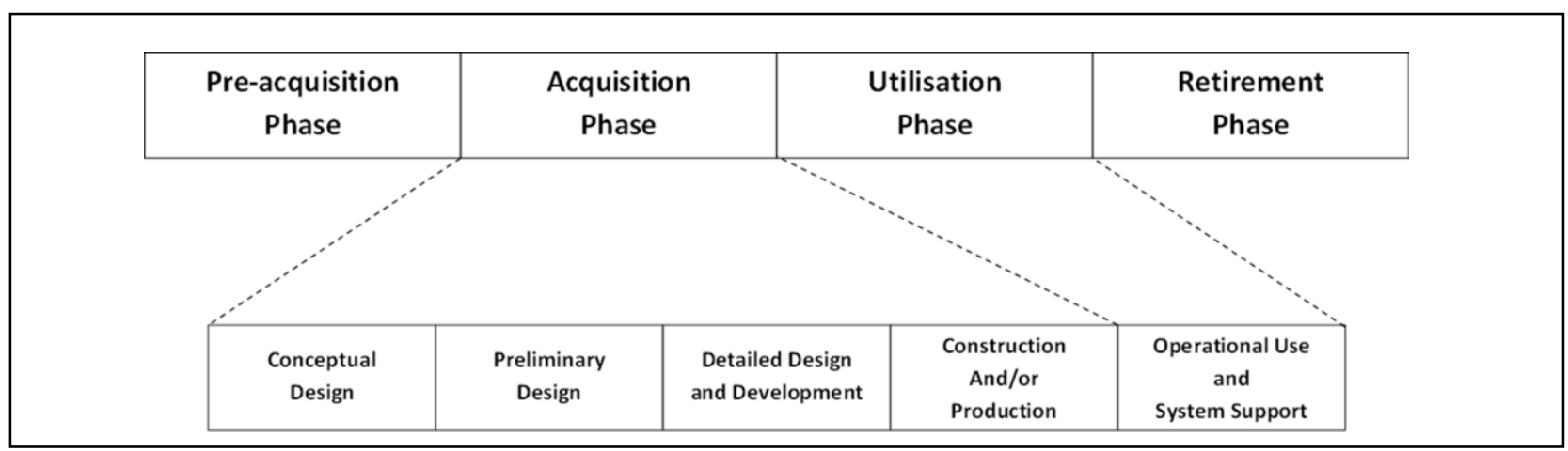

Fig. 1-1 Systems Engineering Lifecycle (Faulconbridge \& Ryan, 2014)

The main activities associated with the Acquisition Phase and their associated major milestones and outputs are defined by (Faulconbridge \& Ryan, 2014) as per the diagram in Fig. 1-2. (King, 2016)

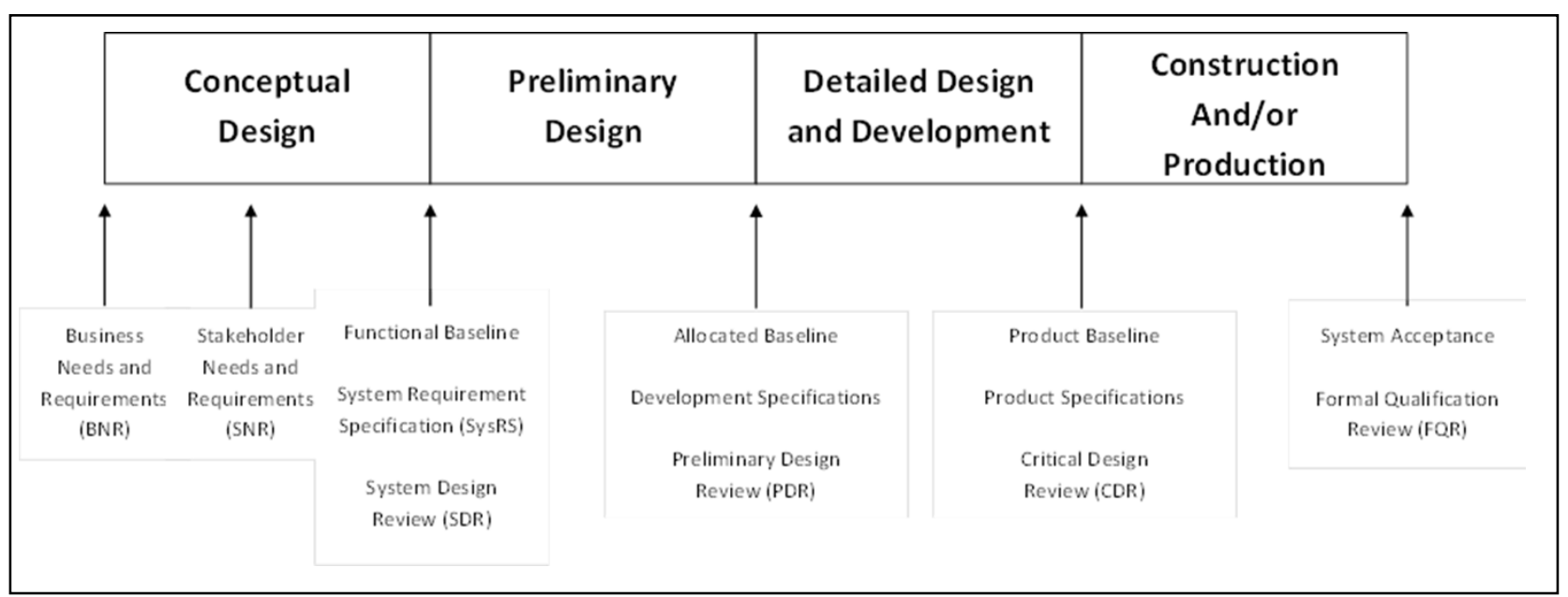

Fig. 1-2 Activities in the Acquisition Phase (Faulconbridge \& Ryan, 2014)

From discussions with a colleague who has extensive systems engineering management experience (Williamson, 2015), I propose that there are three key aspects to successful project development and delivery:
1. Process
2. Technology
3. People 


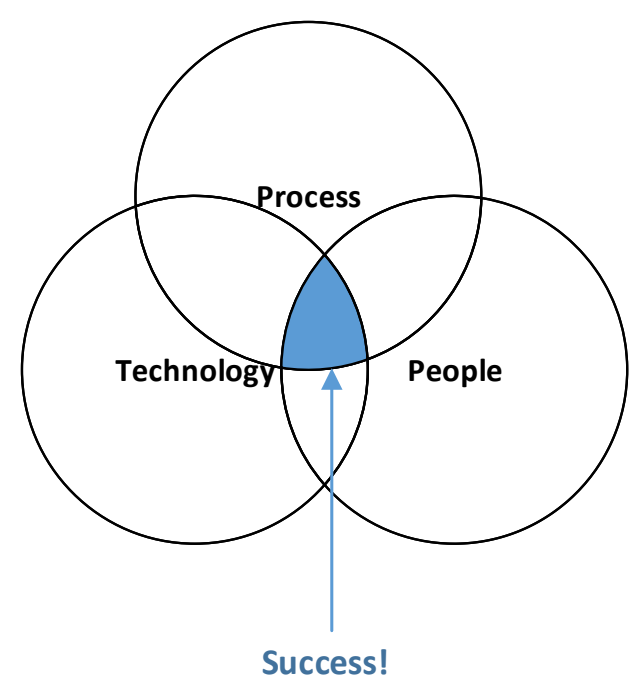

Fig. 1-3 Aspects of Project Delivery That Must be Integrated (Williamson, 2015)

It is only when all three of these aspects or components are developed and aligned correctly as shown in Fig. 1-3 that a project is successful. It is in the investigation of successfully bringing these three elements together for the development and deployment of RCS systems that this research was carried out.

(King, 2016)

\subsection{Requirements for RCS Systems}

RCS is a complex System Of Systems (SOS) and therefore requires careful planning and extensive development work for its implementation. It is my opinion that the development and requirements of RCS should be approached from the top-down waterfall model method of Systems Engineering (Faulconbridge \& Ryan, 2014). In other words, start with the business (or industry) needs and from these develop fundamental requirements for the system which lead to system requirements which lead to sub-system requirements etc.

If we start at the top level, the industry needs of RCS are usually to move $x$ amount of passengers and/or $y$ amount of freight product within timeframe $z$ and achieve this completely safely.

From these needs, it can be derived that there are three fundamental requirements to any RCS system:

A. Ensure safe running of trains

B. $\quad$ Route trains around the network efficiently

C. Have each train run at its optimal performance

We can map these requirements onto normal working operations where:

1. The Signaller will request a route through the Control System.

2. The Control System will request this route from the Interlocking System.

3. The Interlocking System determines that the route can be set safely. 
4. The Interlocking System transmits the permitted movement authority to the Train by setting the appropriate signal indications for the route selected.

5. The Driver will interpret these signals to drive their individual train safely and efficiently.

(King, 2016)

This complete flow can be shown in the model in Fig. 1-4.

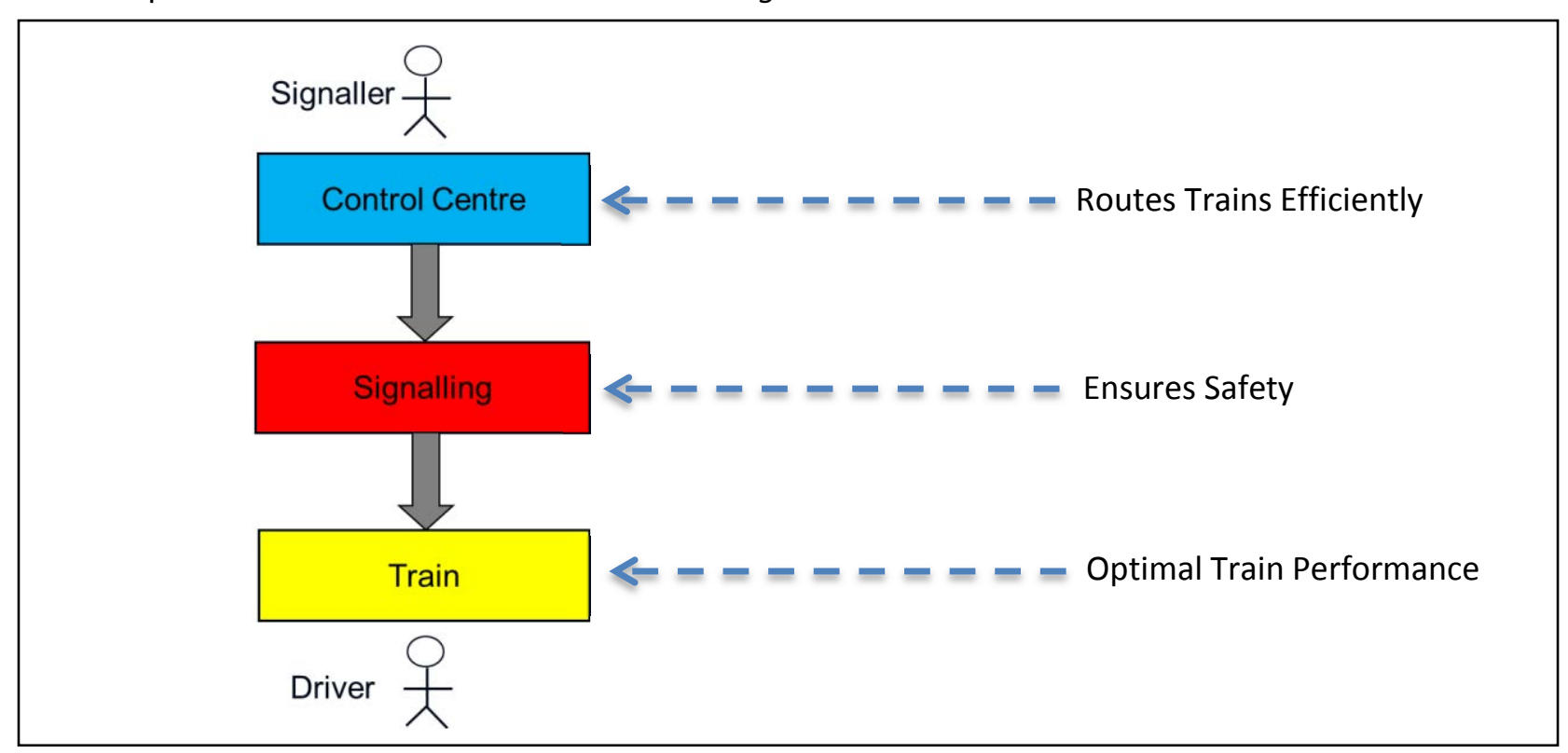

Fig. 1-4 Common Sub-systems of Conventional Signalling (King, 2016)

\subsection{Types of RCS Systems}

Modern RCS systems vary greatly depending on if they are for Metro or Mainline applications and where they are deployed in the world, as different countries have different standards. However, there are 4 broad categories of RCS system that can (potentially) be applied worldwide, as described in Section 2.5:

1. Conventional Signalling

2. CBTC

3. ERTMS

4. PTC

The Sections of this Chapter will define each of these systems in more detail.

\subsubsection{Conventional Signalling}

There are literally hundreds of different railway signalling systems currently implemented throughout the world which utilise different principles of design and safety legislation, most of which is based on historical legislation and the culture within different countries. However, they are all based on the fundamental safety principles of:

1. Ensuring safe separation between trains

2. Ensuring safety of trains at junctions and crossings 
As shown in Sections 2.4.2 \& 2.4.3, most modern railways achieve these through the use of:

1. Block-section train detection (using either axle counters or track circuits)

2. An interlocking system (either relay or computer based)

3. An ATP system (either intermittent or continuous)

Most of these railways are based around utilising indications from the lineside to the driver (often in the form of multiple-aspect colour-light signals).

They are also generally controlled from some form of modern control centre that utilises a server-based electronic control system with Visual Display Unit (VDU) terminals. Though some do still utilise other systems such as lever locks and push-button panels, these will be excluded for the purposes of this research as they are being gradually phased out.

Therefore, for the purposes of this research, conventional signalling shall be defined as a railway that utilises a system comprising of the following sub-systems as shown in Fig. 1-5:

1. Operational Control System (OCS)

2. Block-based Train Detection

3. Interlocking system

4. ATP

5. Multi-aspect signals

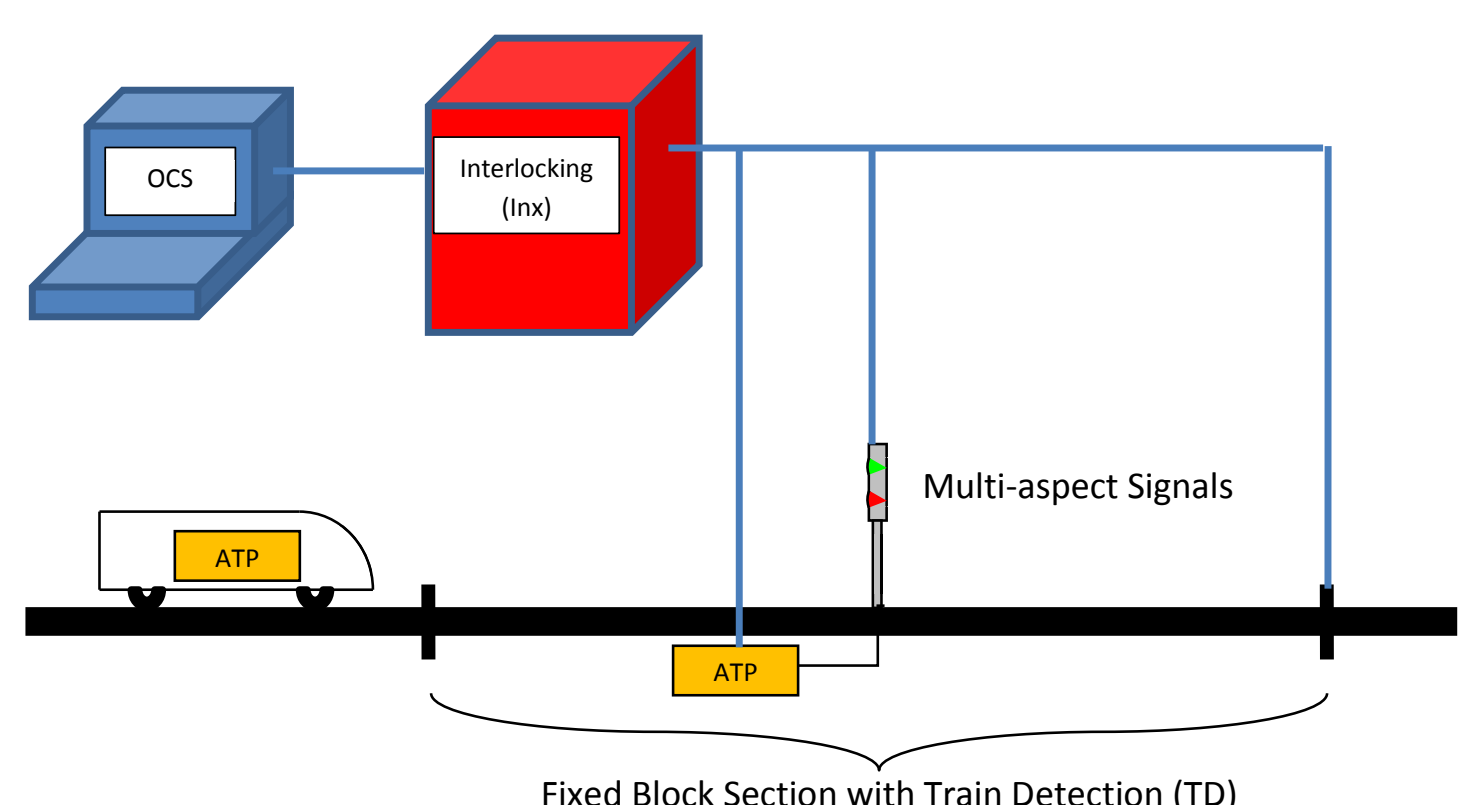

Fixed Block Section with Train Detection (TD)

Fig. 1-5 Conventional Signalling System

\subsubsection{CBTC}

CBTC is defined by IEEE standard 1474.1 as, "The use of a Communications channel to relay Safety Critical Train Control Information between the Signaller and the Train Operator." (IEEE, 2011) 
From this, any modern form of RCS, including ETCS, PTC and certain ATP systems, can all be defined as CBTC. However, CBTC has also become a byword for the fully automated railway signalling deployed on (predominantly) metro railways. This Section (1.7.2) will look exclusively at these metro systems and how they are built up.

\subsubsection{Fixed Block Systems}

Most modern metro CBTC systems utilise Automatic Train Control (ATC) that comprises of two main parts: Automatic Train Operation (ATO) and Automatic Train Protection (ATP), as shown in Fig. 1-6.

\begin{tabular}{|c|c|c|c|}
\hline ATC & $=$ & ATO & ATP \\
\hline $\begin{array}{l}\text { Automatic } \\
\text { Train Control }\end{array}$ & & $\begin{array}{c}\text { Automatic Train } \\
\text { Operation }\end{array}$ & $\begin{array}{c}\text { Automatic Train } \\
\text { Protection }\end{array}$ \\
\hline
\end{tabular}

Fig. 1-6 Automatic Train Control Sub-Systems

ATO is responsible purely for performance (i.e. driving trains between designated stop points), while ATP is responsible for maintaining safety (ensuring collision avoidance, etc.). This is because the ATO is a simple unit with two inputs and two outputs; as shown in Fig. 1-7, all it needs to know is:

- The limit of its movement authority (LMA)

- What speed the train is going at in order to apply the required motoring or braking

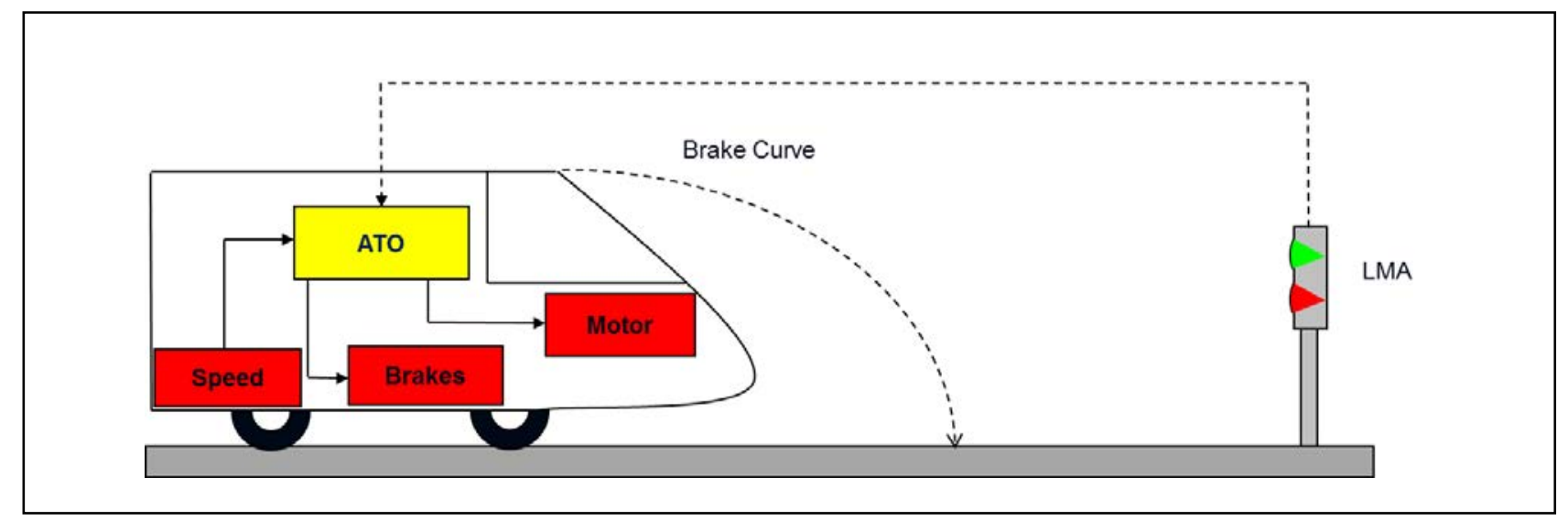

Fig. 1-7 Principles of ATO

If all trains on the line are fitted with ATC, there is no need for traditional line of sight signals as shown in Fig. 1-8. 


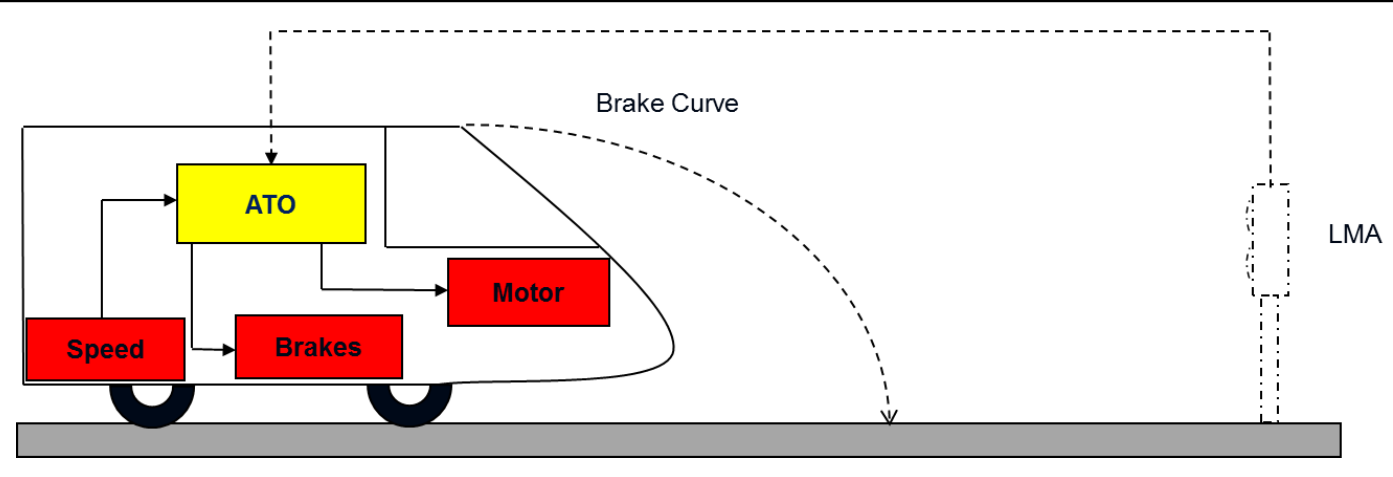

Fig. 1-8 Fixed Block ATO

\subsubsection{Moving Block Systems}

What is generally known as CBTC in terms of metro systems (see introduction of Section 1.7.2) is the addition of Automatic Train Supervision (ATS). ATS is a set of functionality that automates things such as route setting to enable a more efficient service very similar to the Traffic Management System (TMS) for mainline systems (see Section 1.7.5.1).

\begin{tabular}{|c|c|c|c|c|c|}
\hline CBTC & $=$ & ATO & + & ATP & ATS \\
\hline $\begin{array}{c}\text { Communications } \\
\text { Based Train } \\
\text { Control }\end{array}$ & & $\begin{array}{c}\text { Automatic Train } \\
\text { Operation }\end{array}$ & & $\begin{array}{c}\text { Automatic Train } \\
\text { Protection }\end{array}$ & $\begin{array}{c}\text { Automatic Train } \\
\text { Supervision }\end{array}$ \\
\hline
\end{tabular}

Fig. 1-9 CBTC Sub-systems

By continuously detecting each train's exact position on the line (usually achieved by every train registering regular fixed points from the infrastructure and continuously updating a central system of its position using its odometer), it is possible for these systems to run every train as close as possible to the subsequent train by means of a closed loop control system. This is known as Moving Block and is illustrated in Fig. 1-10.

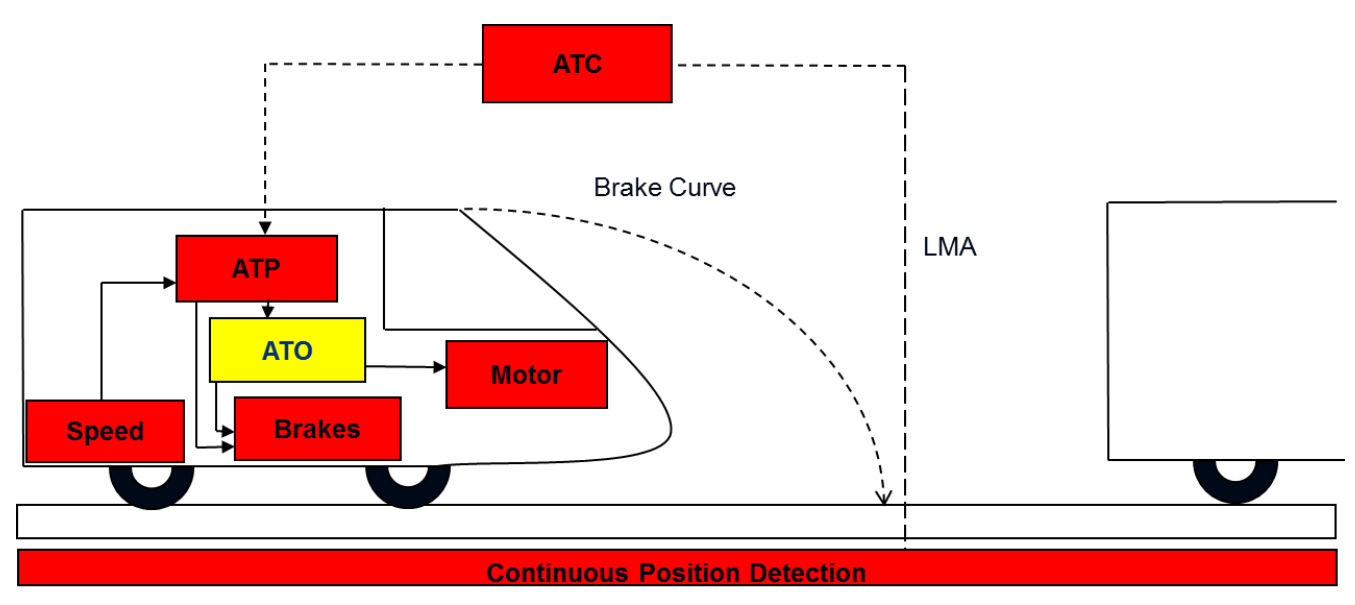

Fig. 1-10 Moving Block ATO 


\subsubsection{ERTMS}

The European Rail Traffic Management System (ERTMS) is the new standard for interoperable railway systems within Europe. It is made up of three main parts as shown in Fig. 1-11.

\begin{tabular}{|c|ccc|}
\hline $\begin{array}{c}\text { Standard } \\
\text { Interoperable } \\
\text { Railway System }\end{array}$ & $\begin{array}{c}\text { Standard } \\
\text { Communications } \\
\text { Infrastructure }\end{array}$ & $\begin{array}{c}\text { Interoperable } \\
\text { Train Protection }\end{array}$ & $\begin{array}{c}\text { Optimised } \\
\text { Traffic } \\
\text { Management }\end{array}$ \\
\hline ERTMS & GSM-R & ETCS \\
\hline $\begin{array}{c}\text { European Rail } \\
\text { Traffic } \\
\text { Management } \\
\text { System }\end{array}$ & $\begin{array}{c}\text { Global System } \\
\text { for Mobiles - } \\
\text { Railways }\end{array}$ & $\begin{array}{c}\text { European Train } \\
\text { Control System }\end{array}$ & $\begin{array}{c}\text { European Traffic } \\
\text { Management } \\
\text { Layer }\end{array}$ \\
\hline
\end{tabular}

Fig. 1-11 ERTMS Sub-Systems

The Global System for Mobiles - Railways (GSM-R) is to be the standard radio communications system for railways, providing both voice and data.

The European Traffic Management Layer (ETML), combined with the European Operating Rules, are a standard set of operating principles to provide optimised traffic management, utilising tools such as automatic route setting, etc.

The European Traffic Management System (ETCS) is to be the standard train protection system for Europe. ETCS can be delivered in one of three levels; in all levels, the driver has a display in their cab known as a Driver-Machine Interface (DMI) which tells them their permitted Movement Authority (MA) in the form of a target speed that they must drive to. If the driver goes over this permitted speed, then the system intervenes and automatically applies braking. An overview of each of the 3 levels is given in the following sub-sections of this Section.

\subsubsection{ETCS LeVel 1}

Level 1 acts as an overlay for existing conventional schemes and utilises radio beacons known as balises embedded in the 4-foot connected to the interlocking via a Lineside Equipment Unit (LEU). These balises transmit the permitted MA to the train as it passes over them, though the MA remains the signal indication, not the balise. 


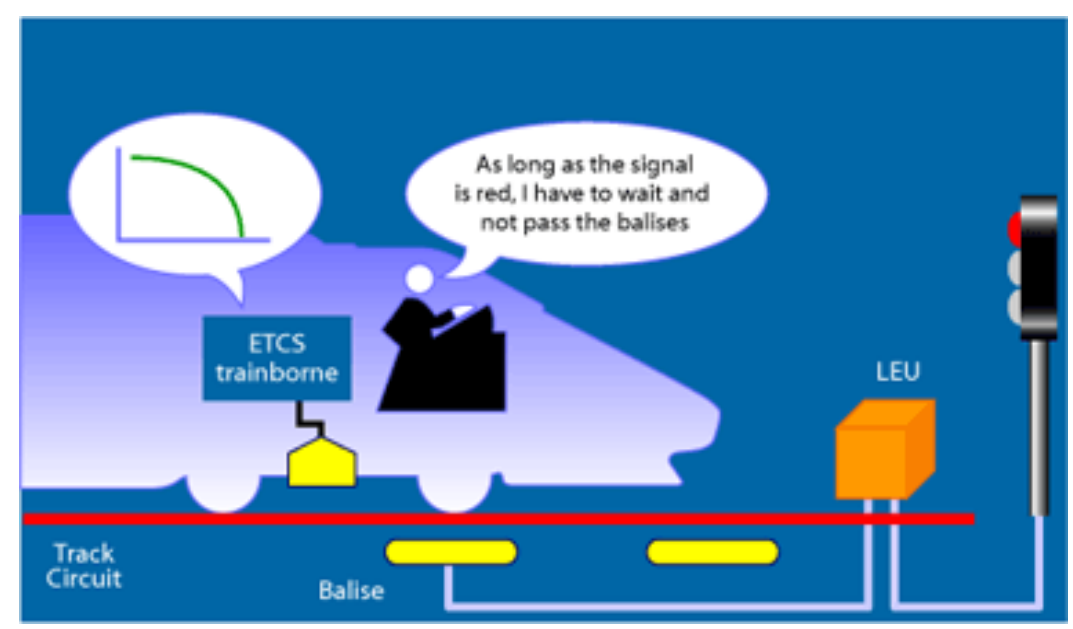

Fig. 1-12 ETCS Level 1 (without infill) (UNIFE, 2013)

It is also possible to make use of an infill loop or radio infill between balises to update the MA more continuously, thus enabling the driver to have earlier indication of a signal change.

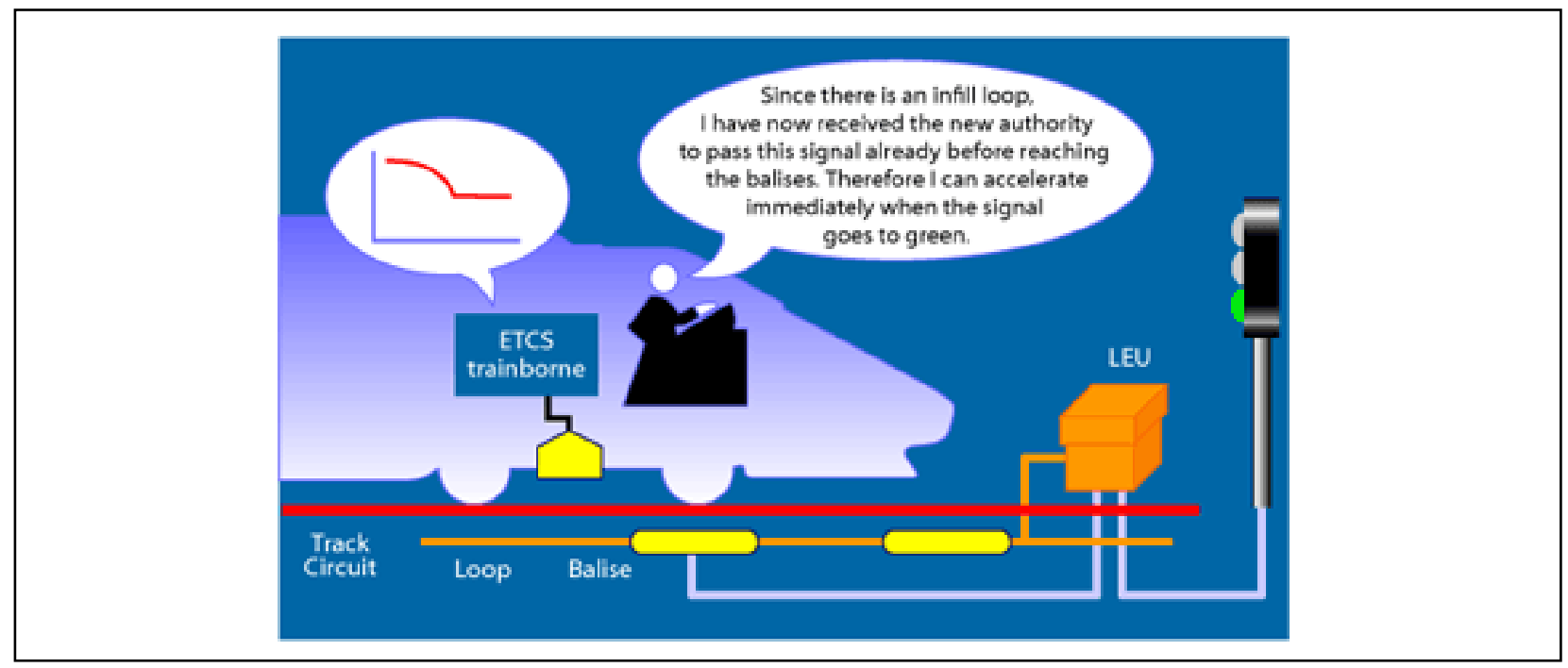

Fig. 1-13 ETCS Level 1 (with infill) (UNIFE, 2013)

\subsubsection{ETCS Level 2}

Level 2 utilises the GSM-R system to continuously transmit the MA to the train via a Radio Block Centre (RBC) which is connected to the interlocking, meaning that there is no longer a need for lineside signals. Balises are still used but now act as autonomous position references only. 


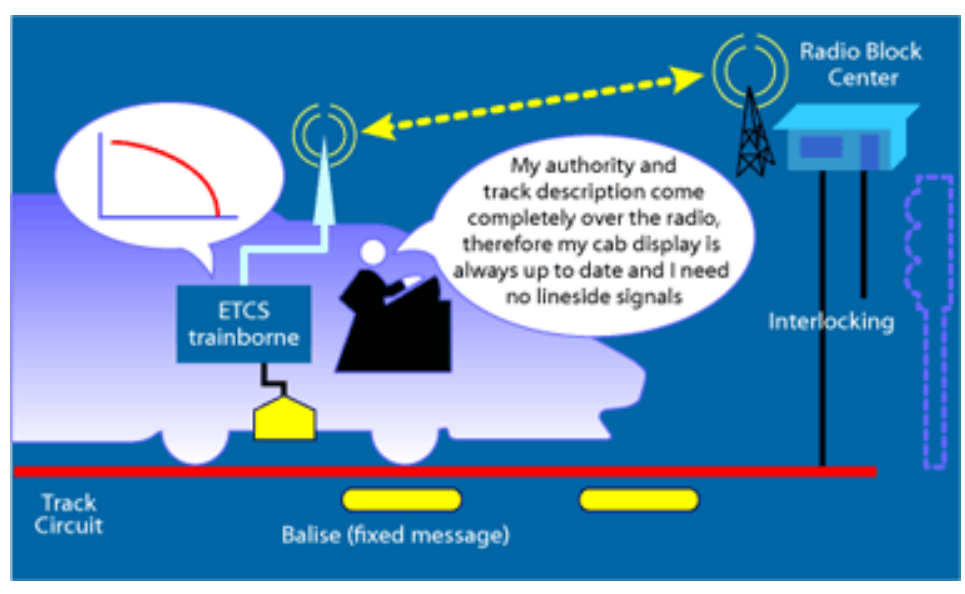

Fig. 1-14 ETCS Level 2 (UNIFE, 2013)

\subsubsection{ETCS Level 3}

In Level 3, conventional forms of train detection (such as axle counters or track circuits) are removed and the train maintains its own integrity, allowing the train to run within virtual blocks or on moving block.

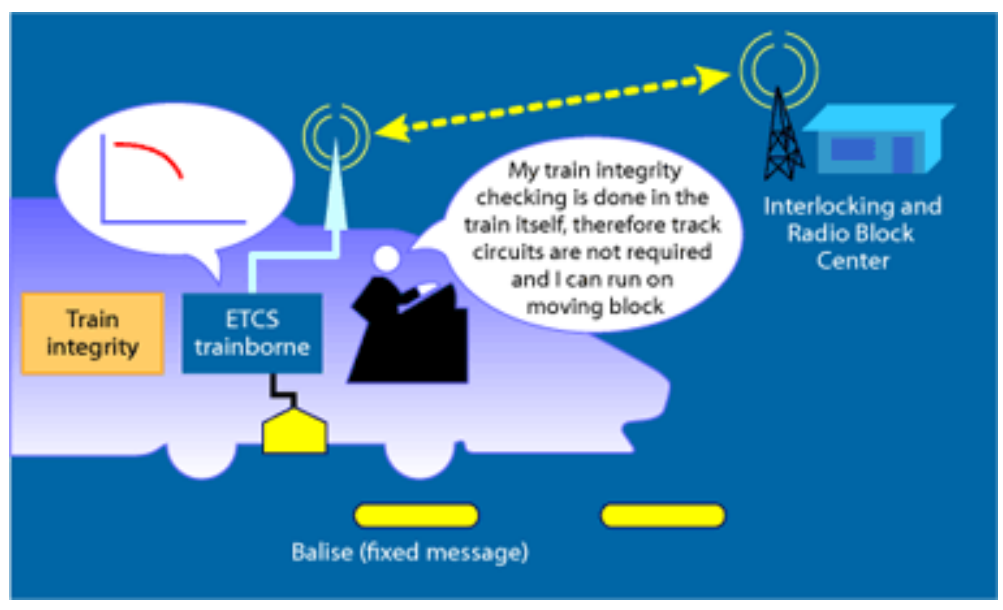

Fig. 1-15 ETCS Level 3 (UNIFE, 2013)

\subsubsection{PTC}

The Federal Railroad Administration (FRA) states that, "PTC is a system of functional requirements for monitoring and controlling train movements as an attempt to provide increased safety" (FRA, 2008). It has been defined by the United States of America (USA) to increase safety across its railway networks.

The American Railway Engineering and Maintenance-of-Way Association (AREMA) describes Positive Train Control as having the following primary characteristics:

1. Train separation or collision avoidance

2. Line speed enforcement

3. Temporary speed restrictions

4. Rail worker wayside safety 
The main concept in PTC (as defined for North American Class I freight railroads) is that the train receives information about its location and where it is allowed to safely travel, also known as movement authorities. Equipment on board the train then enforces this, preventing unsafe movement. PTC systems may work in either dark territory or signalled territory, and may use GPS navigation to track train movements.

(AREMA, 2009)

The FRA has listed among its goals:

To deploy the Nationwide Differential Global Positioning System (NDGPS) as a nationwide, uniform, and continuous positioning system, suitable for train control. Various other benefits are sometimes associated with PTC such as increased fuel efficiency or locomotive diagnostics. These are benefits that can be achieved by having a wireless data system to transmit the information, whether it is for PTC or other applications.

(AREMA, 2009).

According to Amtrak:

A typical PTC system involves two basic components:

1. Speed display and control unit on the locomotive

2. A method to dynamically inform the speed control unit of changing track or signal conditions.

Optionally, three additional components may exist:

1. An on-board navigation system and track profile database to enforce fixed speed limits

2. A bi-directional data link to inform signalling equipment of the train's presence

3. Centralized systems to directly issue movement authorities to trains

(Amtrak, 2007)

There are numerous versions of PTC that have been developed throughout North America. Some of these systems are based on existing technologies that have been 'upgraded' to meet the standard for PTC, whilst others are completely new systems that have been developed from first principles based on the new PTC requirements. An example 'generic' system is shown below in Fig. 1-16. 


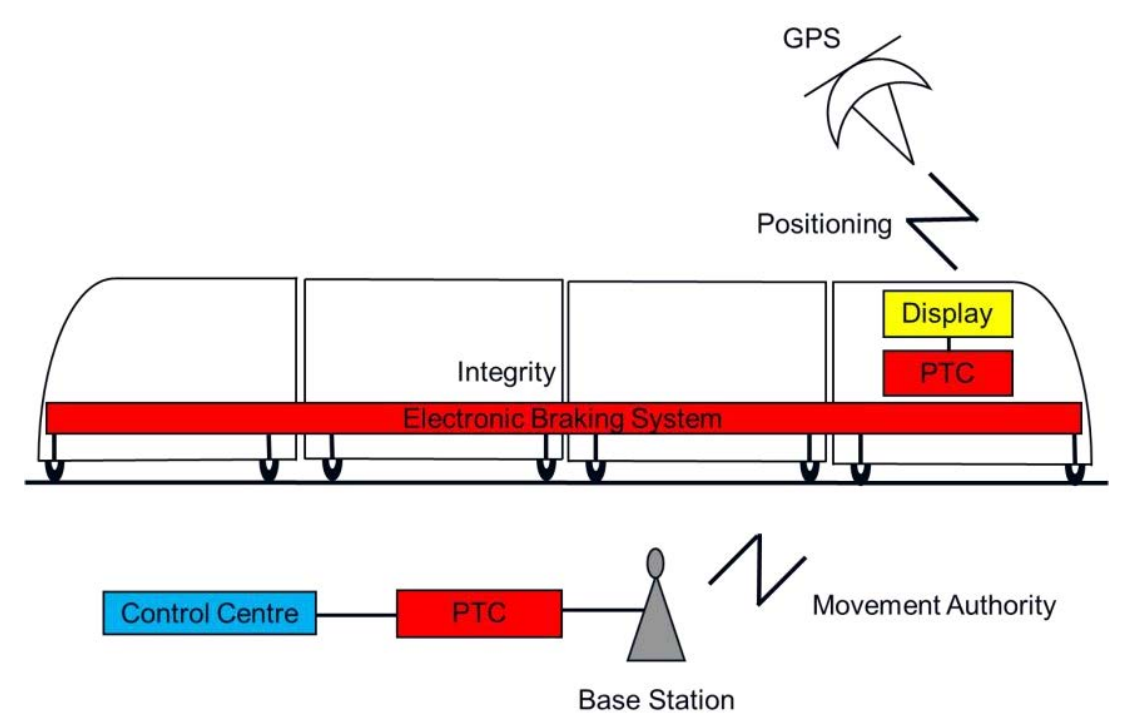

Fig. 1-16 Example PTC System

In the example shown in Fig. 1-16, the train utilises an electronic braking system to ensure its integrity and is also fitted with a Global Positioning System (GPS) transceiver. A centralised electronic interlocking system creates 'virtual' blocks on the track that exist in its memory only. Each train relays its location back to the central interlocking, which in turn grants each train its movement authority to enter whichever virtual block it is safe to do so.

The following sub-sections summarise some of the main PTC systems currently being implemented in the USA as defined by AREMA.

\subsubsection{Advanced Cïvil Speed Enforcement System (ACSES)}

"A transponder-based system, in use on Amtrak's Northeast Corridor." (AREMA, 2009)

\subsubsection{Electronic Train Management System (ETMS)}

"A GPS and communications-based system being deployed by Burlington Northern and Santa Fe (BNSF) Railway." (AREMA, 2009)

\subsubsection{Interoperable Electronic Train Management System (I-ETMS)}

"A GPS and communications-based system, not yet ready for deployment" (AREMA, 2009)

\subsubsection{Incremental Train Control System (ITCS)}

"A GPS and communications-based system used by Amtrak on its Michigan line" (AREMA, 2009)

\subsubsection{Enhanced Automatic Train Control (E-ATC)}

A system that uses an underlying ATP system (referred to as ATC in North America), in conjunction with other "enhanced" features or systems to achieve the core required functionalities of PTC.

These systems are often integrated with underlying Cab Signal Systems (CSS) and Centralised Traffic Control (CTC) systems, in addition to other signal or train control system enhancements the railroad elects to make to meet the full requirements of PTC. (AREMA, 2009) 


\subsubsection{Other Systems}

It may be clear from the previous Sections of this Chapter, that the two main new deployments of RCS on the mainline (ETCS and PTC) are predominantly analogous to the ATP element of CBTC. However, there are separate sub-systems that have been developed for the mainline that achieve functionality analogous to the ATS and ATO functions of CBTC. The two main systems of this type that are currently being deployed and under development, Traffic Management Systems (TMS) and Driver Advisory Systems (DAS), are defined in this Section.

\subsubsection{Traffic Management Systems}

Traffic Management Systems (TMS) have been developed to support line controllers with the efficient routing of trains and management of service. One of the main suppliers of TMS, Hitachi, defines it as providing some or all of the following features:

\section{Traffic Planning}

Creates train and staff rosters based on the traffic plan prepared, together with actual diagrams for the day's operations, and provides this information to the Operation Management System and operating companies.

\section{Operation Management System}

Automatically controls and sets routes for trains based on the train diagrams from the traffic plan. In the event of operational disruption, it continues Route Performance based on train diagrams changed using commands.

\section{Power Supply and Infrastructure}

Provides centralised management from a central power-supply control centre of the operational status of the electric railway substations and station power-supply facilities. Power-supply facilities are monitored and controlled based on the information processed.

4. Information for Passengers

Provides passenger information (display, announcement) relating to train departures and arrivals. Also provides accurate information based on information from the Operation Management System in the event of disruptions.

\section{Operation Information for Staff}

Provides station staff, maintenance staff, and train staff with the necessary working information regarding train operation status and the latest diagrams in real time.

Provides support for the creation of maintenance schedules. Maintenance work is carried out safely and efficiently on-site, using portable wireless terminals to keep track of scheduling.

\section{Maintenance Support}

Provides station staff, maintenance staff, and train staff with the necessary working information regarding train operation status and the latest diagrams in real time.

\section{Driver-Only and Driverless Operation}

Provides systems supporting driver-only and driverless operation by linking the Operation Management System with platform gates and Automatic Train Operation (ATO) systems.

(Hitachi, 2013) 
TMS systems therefore form an intrinsic part of modern control centre systems providing functions such as automatic route-setting and real-time train diagram alterations using path manipulation to regulate the network efficiently. An example TMS architecture is shown in Fig. 1-17.

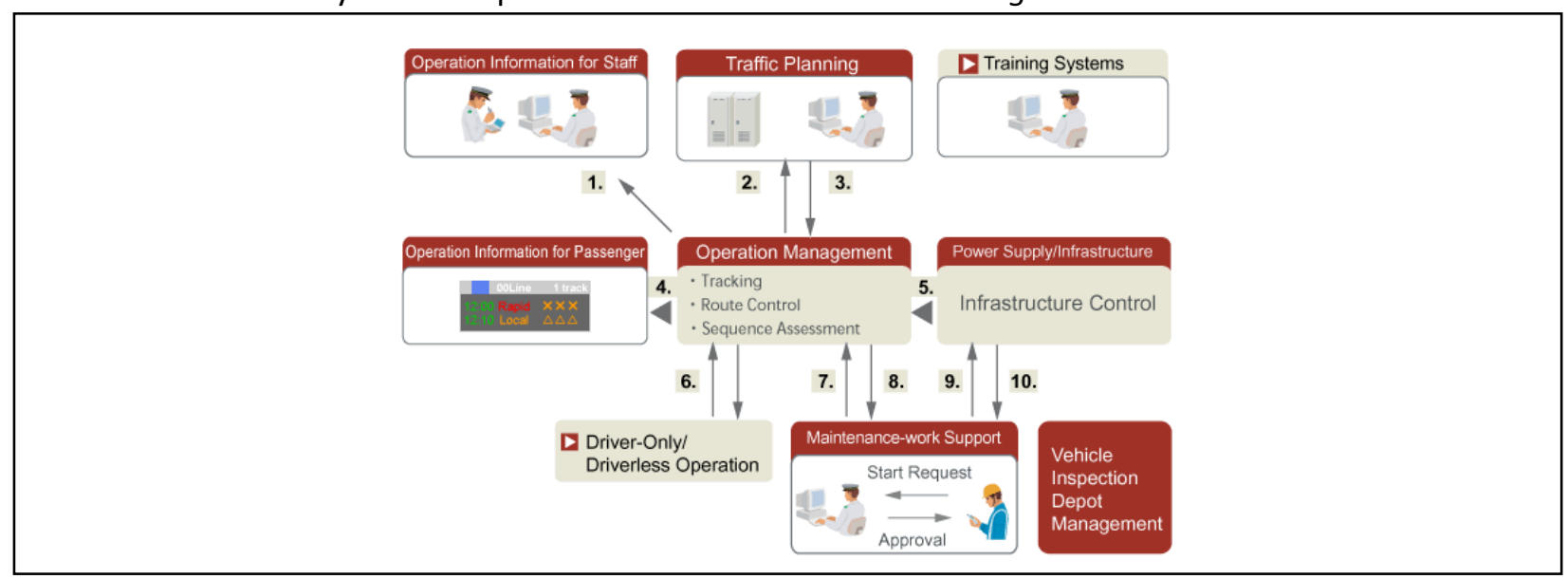

Fig. 1-17 Example TMS System (Hitachi, 2013)

\subsubsection{Driver Advisory Systems}

Zhu, et al. defines that:

Driver Advisory Systems (DAS) are designed to provide train operators with advisory information that lead to improved performance with less locomotive wear, higher energy efficiency and better service quality. DAS does not have a direct interface as such with the existing train control system; instead it is more concerned about train operators' actions and human factors. (Zhu, et al., 2016)

Many train operating companies have started to develop DAS systems that monitor the performance of the rolling stock systems and then provide guidance to the driver via an in-cab display on the best way to drive the train (i.e. level of motoring and braking) in order to optimise the fuel consumption efficiency. Such systems are sometimes referred to as Unconnected Driver Advisory Systems (U-DAS).

Several operators and infrastructure managers are now expanding these systems by utilising a central infrastructure-based system that works with the TMS and other infrastructure systems to relay information to the trains about current trackside conditions whilst also receiving information on the trains' current performance. The on-board DAS system can utilise all this information to provide the driver with guidance on not only how to optimise fuel efficiency, but also optimally drive the train for improved service performance. Systems such as this are often referred to as Connected Driver Advisory Systems (C-DAS).

An example DAS display in shown in Fig. 1-18. 


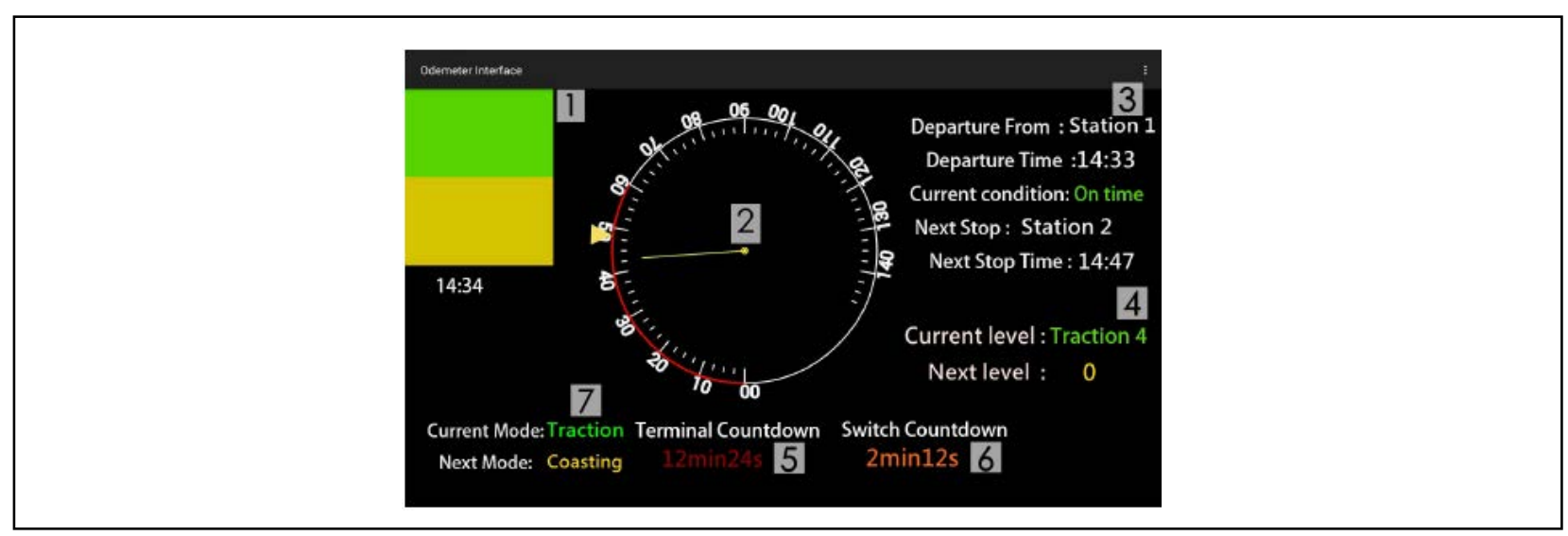

Fig. 1-18 Example DAS In-cab Display (Zhu, et al., 2016) 


\section{Literature Review}

A recent paper (Bouch \& Roberts, 2013) highlighted the need to develop a better understanding of systems engineering within the UK railway industry.

This paper recommends utilising the British railway group standards to identify systems interfaces and from these elicit models from a top-down systems engineering approach.

Although this paper looks at this from a high-level point of view of the entire railway system, it does not go into detail for individual disciplines such as signalling and rolling stock.

Also in the same publication was a paper (Liu, et al., 2013) that demonstrated a different approach to the development of train control. Utilising a classic railway junction as an example, the paper proposed utilising a 'fault-tolerant approach to the scheme design' as opposed to the usual conservative method of design. This would still achieve an acceptable level of safety, as well as achieve greater performance through the flexibility of the design. Utilising a systematic approach to the development of RCS systems may enable this sort of approach to be adopted more easily and reap the benefits of more flexible faulttolerant design.

In 2012, the Rail Safety and Standards Board (RSSB) published (on behalf of the industry) the technical strategy (RSSB, 2012) for the British railways over the next 30 years. In 2013, an Academic Response (RRAUK, 2013) to this strategy was produced by the Rail Research Association UK on behalf of UK academia. Both of these publications endorse the strategy of taking the railway as a whole system along with embracing more innovative solutions to problems. The strategy also specifies in its Control, Command \& Communications section the vision for in-cab signalling and intelligent traffic control systems for efficient, safe and optimised train services. The Academic Response (RRAUK, 2013) states that through the Future Train Regulation Optimisation (FuTRO) programme, the UK is developing complete solutions that will utilise traffic management systems, ERTMS, automation and driver advisory systems to achieve this vision. All of these systems will need to work together as part of the complete train control system; hence a high-level system engineering framework of how these sub-systems will work together will be extremely useful to assist in achieving the strategy's vision.

A recent thesis (Woodland, 2004) lays down an overview of the fundamentals of ATP systems (which are in turn the basis for all RBTC systems) and discusses both the perception of them being expensive and some of the blockers that have historically prevented them from being widely adapted in the UK.

This thesis provides an excellent high-level model of a complete railway system and also derives the major requirements of Train Control Systems. However, it does not investigate how to further develop these requirements into relevant sub-systems, nor does it explore the feasibility of segregating key functions such as safety, route optimisation and train performance.

The thesis does, however, demonstrate how to utilise these different systems in order to optimise the performance of the railway onto which they are installed. However it does not consider how to develop and deliver these systems efficiently and achieve all requirements, which will be the fundamental basis 
for my thesis. Another key aspect of my work will be that a Train Control System is in fact a 'System of Systems', which is also not covered in the aforementioned thesis.

\subsection{Systems of Systems}

The International Council of Systems Engineers (INCOSE) published a paper (DeRosal, et al., 2008) as part of their Systems Engineering Vision 2020. In this paper, they defined some of the key concepts for System of Systems (SOS) engineering for large complex systems, including train control systems for railways. Though the paper acknowledges that there is 'no universally agreed set of principles' for systems engineering, it does make the following assertions:

1. There are classes of problems that require complex systems to deal with them.

2. The engineering of a complex system is itself a complex problem.

3. Complexity science can be used to inform the understanding and solution of such problems, including the development of enterprise systems engineering methods and tools.

4. There are gaps in our scientific understanding of complexity, and in our ability to apply it, which if filled, would significantly expand the power and utility of our methods and tools for enterprise systems engineering.

(DeRosal, et al., 2008)

The paper goes on to discuss some of the common assumptions that are made in complex enterprise systems. The key message is that system engineering tools used for one industry or application may not be appropriate for another. This links in with my theory that it would be extremely useful to develop systems engineering tools and frameworks specifically for the railway industry.

Another paper (Rebovich, 2008) goes on to explore how systems engineering, despite still being a fairly new discipline, has evolved over the years. It defines 3 stages that systems engineering has currently gone through:

1. Classical Systems Engineering

2. System of Systems Engineering

3. Enterprise Systems Engineering

(Rebovich, 2008)

The author describes Classical Systems Engineering as being that defined in the INCOSE (ANSIIEIA 632) Systems Engineering process, that of, "A sequential, iterative development process used to produce systems and sub- systems." (Rebovich, 2008)

In terms of System of Systems Engineering, the author starts with what he terms the classical approach, which involves utilising "an executive oversight agency that aligns and synchronises the development of individual sub-systems to develop a larger system whose functionality is greater than the sum of its parts." (Rebovich, 2008) He then goes on to describe how this approach does not lend itself to systems that are not built from scratch and rely on 'overlay' over existing systems and practises. This is certainly in-line with most railway applications. 
What he then defines as Enterprise Systems Engineering is the requirement to have interactions with systems owned by different organisations. This is a new discipline of systems engineering and again very relevant to the railway industry, where the infrastructure is generally owned and operated by Infrastructure Managers (IMs), while the rolling stock is generally operated and maintained by Railway Undertakings (RUs). The paper goes on to discuss some of the challenges of implementing such systems, using the development of the banking ATM system as an example, ending with the conclusion that part of Enterprise Systems Engineering scope should be to identify technology trends and manage the interactions between different organisations. This will be a key issue in the development of any system engineering models for the railway industry, with its large number of multiple stakeholders.

A later paper (Boxer, et al., 2008) expands on the concepts of how to deal with multiple organisations by proposing four layers of 'interoperability' when describing how machines are used by organisations:

- Layer 4: Organisational Interoperability (shared understanding of organisational processes)

- Layer 3: Semantic Interoperability (shared understanding of meaning)

- Layer 2: Syntactic Interoperability (language syntax)

- Layer 1: Machine Level Interoperability (lexis)

(Boxer, et al., 2008)

This is useful for understanding how multiple organisations such as IMs and RUs will have to interact.

Another paper (Lewis, et al., 2008) offers an alternative view that looks at a proposed Systems of Systems lifecycle and how Systems Of Systems (SOS) can be shown on simple diagrams of Collaboration against Response. Though it is not clear how these could relate to the application of Train Control Systems, the paper also provides an excellent diagram on the overview of what it calls Capabilities Engineering, showing how it can be used to gather end user needs and develop them into system requirements.

Another view is presented in a paper (Clark, 2008) that examines how to derive a model for a System of Systems (or "Family Of Systems (FOS)" (Clark, 2008) as the author calls them) based around the traditional systems engineering $\mathrm{V}$-cycle and block diagrams. This method is to have a top-level block diagram representing the full system and then have a series of nested block diagrams to represent each sub-system. Each of these nested sub-systems has an associated V-cycle of their own, which in turn feed-up to an overall V-cycle.

Although this approach seems fairly simple, it could potentially lead to extremely complex diagrams for systems made up of large numbers of sub-systems.

A simpler model is shown in another paper (Yoon, et al., 2008) in which the authors use the ISO/IEC15288:2002 system life cycle model to derive a "hierarchical structure of a system-of-interest" (Yoon, et al., 2008), which can in turn be mapped onto a single V-model. 


\subsection{Railway Systems}

In a paper produced as part of the Railway Signalling and Control Systems Professional Development Course for the IET in 2010 (Booth, 2010), the author details the history and development of train protection for fixed block systems and how it evolved into ATP.

He then discusses the differences between intermittent and continuous ATP before exploring the development of in-cab signalling, which leads on to the development of ERTMS/ETCS. This is an excellent paper on the history of train protection systems and the basics of ERTMS.

Another paper (Peng, 2011) provides a very good overview of CBTC systems, detailing how they are utilised to automate train movements yet still provide a safe method of operation.

A recent interesting paper (Hossein, et al., 2015) looks at the original development of the UK railway network in the 19th Century and how it evolved into a complex SOS built and run by numerous private companies. It then goes on to talk about the nationalisation and later privatisation of the network and what impact this had on the system. The paper then discusses the modern railway as a System of Systems (though points out that technically it has always been such). It then compares the system to the US Department of Defence SOS Classification and concludes that the UK rail network "started as an accidental SOS and has moved to being a collaborative SOS" (Hossein, et al., 2015). The paper then

further examines the system in terms of the UK MoD System of System Approach (SOSA) which consists of 9 principles split across three categories:

Coherence:

P1. Unifying the [Defence] Enterprise.

P2. Driving Business and Operational Effectiveness.

P3. Minimising Diversity.

Reuse:

P4. Designing for Reuse.

P5. Building with Proven Solutions.

P6. Ensuring Commonality of Services across the Enterprise.

Interoperability:

P7. Designing for Flexible Interoperability.

P8. Adopting Open Standards.

P9. Treating Planning, Design and Configuration Information as an Asset.

(Hossein, et al., 2015)

It concludes that from its development from the 18th to the 21st Century, the UK railway can be considered a complex System of Systems, some of which has evolved and some of which has been inherited. 


\subsection{Systems Engineering for Railways}

One of the most important aspects of this research will be how Systems Engineering can best be utilised within the railway industry in order to deliver the best possible train control system efficiently. This Section therefore looks at several papers that have investigated this subject.

A paper presented by Schmid at the IRSE technical meeting in 2002 (Schmid, 2002) looked at the development and future of train control systems. It discusses a 'jigsaw' model of train control systems, showing how all the important elements of the system interact together and talks about research being undertaken to improve Network and Capacity Management, Dependability of Railway Systems \& Train Control and Signalling (Safety Layer). One of its key discussions is the importance of how the safety layer fits into a train control system as well as the layers of development required to build up a train control system. It goes on to look at the requirements of the radio system and the importance of education within the railway industry of both operational and engineering requirements. It concludes with an analysis of the future requirements for academic railway research.

A paper produced in 2013 (Beckford \& Dora, 2013) imagines what the railway may look like in the future. It first looks at the history of the railway in Britain and how it has gradually been developed through an almost reactive process following serious incidents, though the current operation has not changed fundamentally since 1950. It also discusses the issue that 'sub-systems' have traditionally worked in 'silos' with as limited interaction with each other as possible. It then goes on to show how this must change to a systems-based approach as the industry faces greater integration of technology that traditionally crosses different discipline boundaries. It also looks at several examples, including traffic management, of how this systematic approach will be required in order to deliver a vision of how the railway must operate in the future in order to deliver the level of capacity required.

A paper published in issue 202 of IRSE news (Mohan, 2014) considers the options for future methods of detecting train positions, some based on wayside detection, others using satellites and some using radio communications systems. What is common across all the options shown is that they require elements that make up a much larger system.

Issue 204 of IRSE News contains an article (Free \& Marshall, 2014) that looks into the proposed project to 'resignal' the Great Western main line in the UK. This large project will not only require the existing Class B ATP system to be upgraded to ETCS (the first upgrade of its kind in the UK) but will also involve the upgrade of the entire line to overhead electrical power line pantographs. In order to deliver such a large comprehensive programme, it is clear that a systematic approach will be required to control and manage the scope of the changes. Another article in issue 205 of IRSE News (Noffsinger, 2014) looks at the same issues in relation to the upgrade of the present protection systems in the USA to PTC.

An interesting article was found on the Carnegie Mellon University website (Firesmith, 2013) which examined the use of multiple $\mathrm{V}$-models as well as dual and tri V-models for software engineering verification \& validation. These models were developed to assist with the issue of how testers of software often had multiple types of requirements, some part of the generic software and other particular to specific applications. This is very much the same paradox faced by developers and testers 
of railway control and safety systems so a similar approach could potentially be used to manage the development and delivery of railway system projects. However, the embedded nature of the diagrams proposed may not be appropriate to the railways environment, where different organisations potentially perform different tasks, so something more sequential may be required.

\subsection{History of the Development of RCS Systems}

Modern railways are complex integrated SOS (Hossein, et al., 2015) that have evolved over many years out of the primitive mining installations of the 17th century. Until the 1970s, train consists were controlled by drivers and the infrastructure was managed by signallers, generally responsible for relatively small parts of the network. Drivers and controllers of today's mainline networks benefit from much better technology, while modern integrated metro systems are almost fully automated and often utilise wireless communications. Human interactions are limited and large networks are managed by control centres, with a level of automation.

However, the development of these integrated systems has not always followed a well-structured path, with differing and potentially incompatible solutions being developed in isolation by different stakeholders of the overall system. A lack of international standards in the field of railway control systems has led to potential confusion in relation to the terminology used to describe these systems, with similar terms and acronyms having different meanings for different members of the railway community.

The story of the development of railway control systems within the railway industry is very much the story of the development of the railway itself. Although the fundamental requirements placed on the industry have always remained the same, i.e. to move large numbers of passengers and goods safely and efficiently between different locations, what have evolved over the years are the requirements for higher levels of safety and maximizing the capacity available on networks. This has resulted in the evolution of railway control systems which enable more trains to be operated more efficiently on lines with enhanced safety. They allow railways to deliver faster, more frequent and safer services for customers and staff.

\subsubsection{Development of Railways}

Railways were born out of the use of guided carts utilised in the 17th Century to transport product out of mines (Lewis, 2001). This technology was eventually re-imagined for more general use in transporting people and goods, becoming the first commercial tram roads. These early tram roads of the 17th and 18th centuries, whether powered by gravity, animals or people, operated by line of sight at low speed.

When faster and more powerful steam traction was introduced for what became known as railways, it was initially considered acceptable practice to ensure safe separation of trains by timing the departure of trains into sections of tracks. This meant that there were no fixed indications or method for notifying the driver of a train of the status of the line ahead. Generally, trains were dispatched from a fixed point (such as a station), then allowed to travel for a fixed length of time before the following train was permitted to proceed. The timing was ensured by so-called railway policemen (May, 2000). 


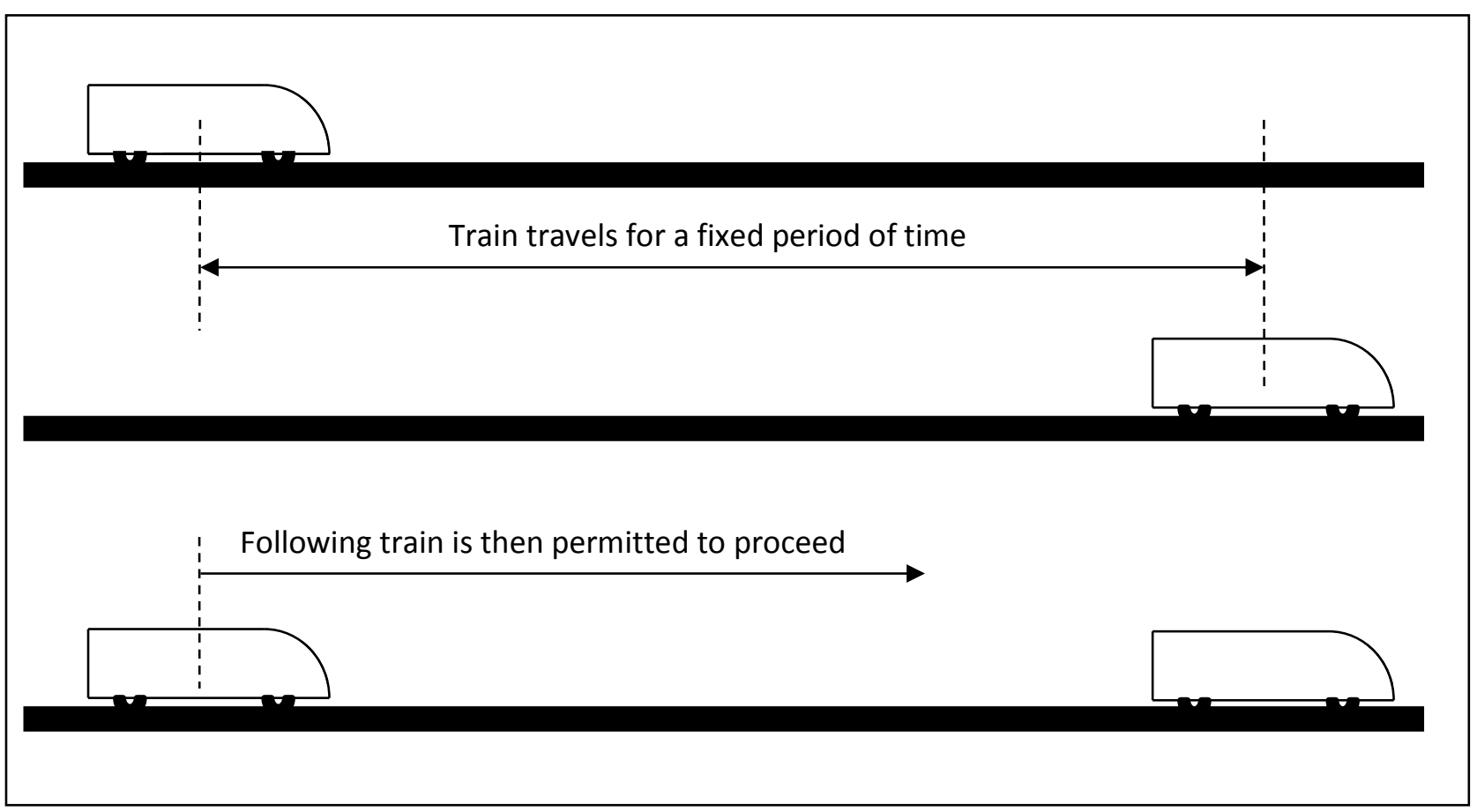

Fig. 2-1 Time-delayed Separation

Since there was no form of communication with the driver of the first train, there were serious safety issues if a train was forced to slow down or stop before reaching its next waypoint as the following train had no way of knowing that it could not reach its next designated stop before encountering the train in front. This inevitably led to several tragic collisions as the railways grew in size, speed of operation and service intensity (Colburn, 2013).

\subsubsection{Development of Signalling}

In order to ensure the safe separation of trains, the concept of 'block working' was introduced, where the railway line was divided into sections to be used by one train at a time. This approach utilised fixed location signals, with mechanical arms, coloured balls and colour lights to indicate to the driver whether to stop or proceed. Initially, the operation of these signals was entirely manual, based on the observation of the passing trains and their tail-lights, on the exchange of tokens and the use of the telegraph, negotiating the passage of trains from one 'block' to the next by Morse code or bell-codes (Colburn, 2013). The introduction of electric track circuits associated with each block section both increased the level of safety and allowed a limited level of automation (Colburn, 2013). They allowed the remote detection of the location of trains. The electric circuits would be connected to signals protecting the sections. When trains entered a block section, they would short out the track circuit and cause the preceding signal to change to the stop indication, so that drivers of following trains would know the section was occupied and would stop their trains in good time. 


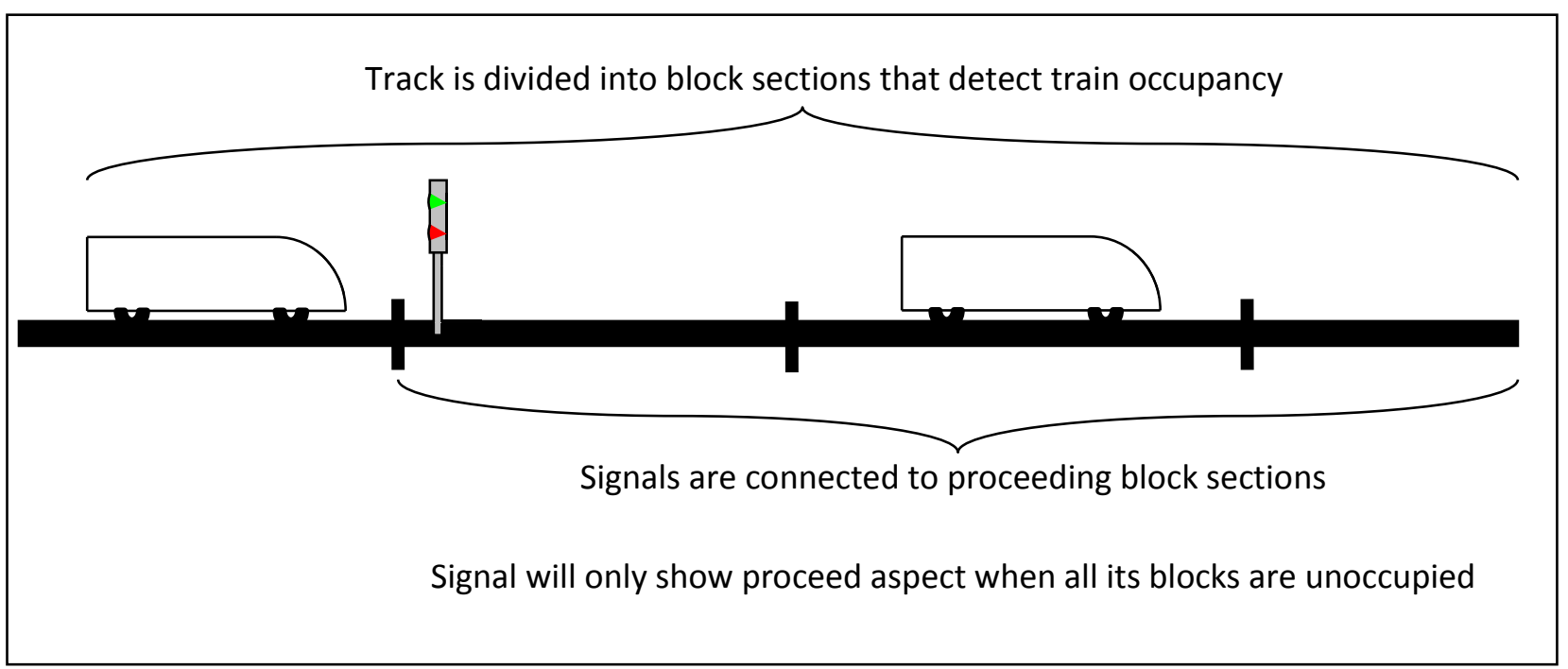

Fig. 2-2 Block Separated Signalling

Although this significantly reduced the risk of collisions between trains following each other on plain line, there was still a danger of collision at points and crossings where conflicting routes could be set and, hence, opposing trains might be running on the same track. In order to overcome this problem, the levers used to control the points, at that time often located in local signal boxes, were interconnected so that when a route was set by one lever, the other levers were locked mechanically, preventing conflicting routes from being set. This approach became known as interlocking.

Modern fixed block signalling systems still adhere to these fundamental principles, although they may use more complicated audio-frequency track circuits or axle counters for the train detection, as well as modern interlocking systems that are based on safety critical electronic hardware with in-built redundancy and validated software to ensure safety.

\subsubsection{Development of Train Protection}

Even though the introduction of block working with lineside signals had greatly reduced the number of collisions that occurred on the railway, the system was limited in that it required the driver to acknowledge the signal aspect and then act as required by the command. This was not always the case with drivers missing signals due to distraction, illness or poor visibility. Although rare, such incidents resulted in a number of very severe collisions, e.g., the Southall accident in Britain in 1997. The concept of automatic train protection emerged as a consequence of these incidents, where an additional safety system is overlaid on the signal indication that prevents the train from passing the signal if it is set at danger. In its simplest form, this was achieved by fitting a lever known as a tripcock to the undercarriage of the trains, which applied the emergency brake when activated. A device known as a trainstop was installed next to the signal, which raised a mechanical arm to activate the tripcock if the signal was set to danger. The mechanical interface is replaced with magnetic and inductive methods of activation in newer versions of trainstop systems. However, to protect trains fully, this type of system requires a clear space beyond the signal that is as long as a full braking distance, from line speed. Typical examples are the German Indusi, the Spanish Anuncio de Señales y Frenado Automático (ASFA) and the Swiss Signum systems. 
Modern forms of train protection all work on the same basic principle of stopping a train before a danger point, but utilise various methods, often based around wireless communication, either to stop the train as quickly as possible or to slow it down gradually. Most of the modern systems supervise the train's speed continuously and also often first give an audio and / or visual indication to the driver before intervening. In some regions, the ATP functionality is referred to as Automatic Train Control (ATC).

An example absolute ATP system that stops the train immediately if it passes a signal set at danger is shown in Fig 2-3.

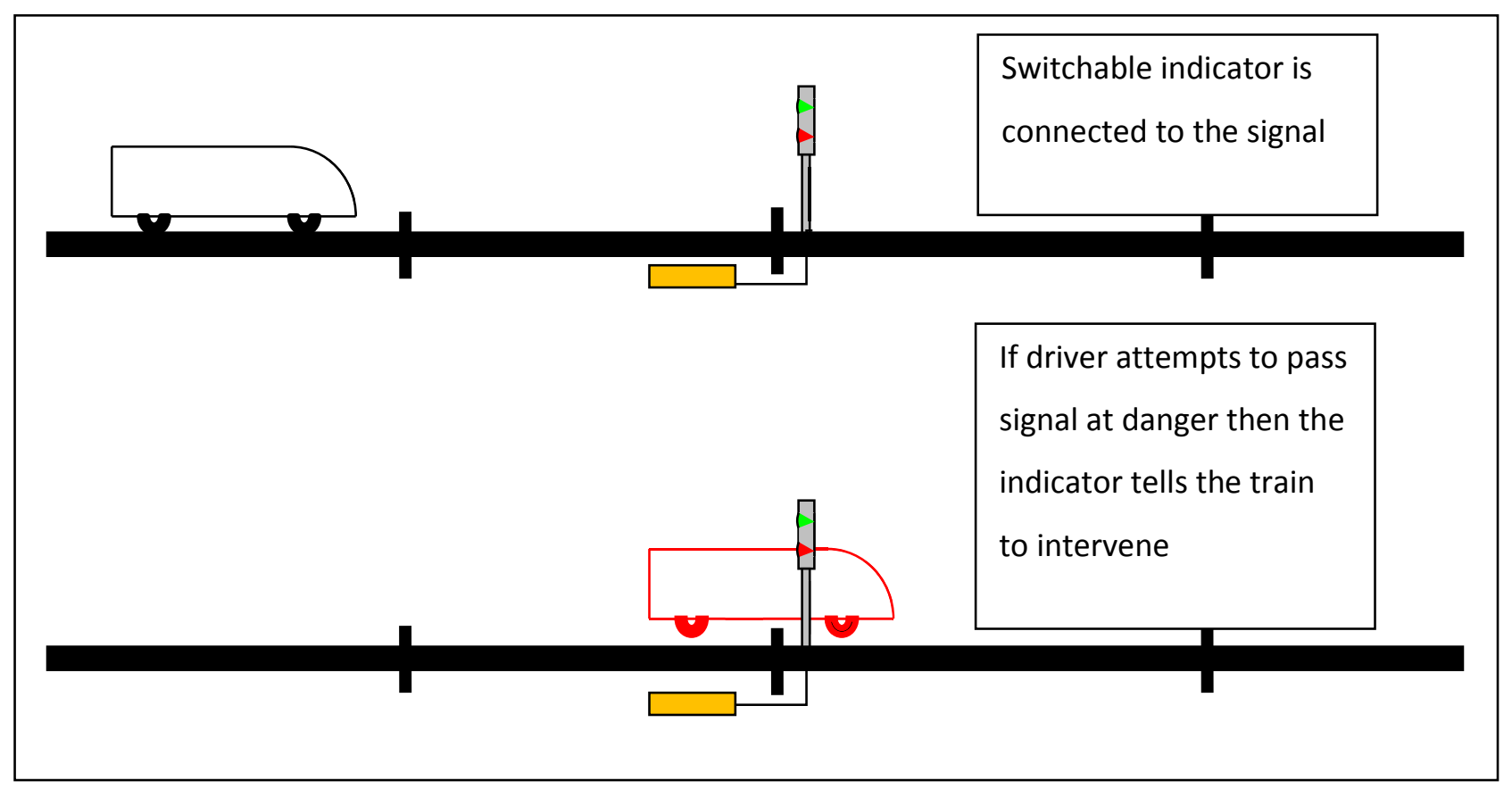

Fig. 2-3 Example Absolute Automatic Train Protection System

\subsubsection{Development of Automation}

As technology has developed, it has become possible to automate many further aspects of the operation of the railway, including the routing of trains and even the control of the movement of trains. Unlike many earlier enhancements of the railway system, these new developments do not usually provide any safety benefits, but are instead intended to improve the efficiency of the railway and to increase the capacity of the network.

\subsubsection{Route Automation}

Today, the routing of trains is often handled by centralized control centres that utilise computer systems to enable operators to set routes for entire lines. These systems provide no direct safety functionality, but can be used to control vast areas of a railway or a complete metro network, e.g., BNSF's Network Operations Centre at Fort Worth in Texas, which controls nearly 35,000 miles of railway across the entire USA (BNSF, n.d.) or London Underground's new Control Centre at Northumberland Park, which now controls the entire Victoria Line (TfL, 2015). Developments have also been made on producing 
computer systems for these control centres that automate key functions such as the routing of the trains based on the timetable or schedule.

\subsubsection{Train Automation}

One of the most significant advancements in the development of metro systems in recent years has been that of Automatic Train Operation (ATO), where trains are no longer controlled by a driver but drive themselves between designated stopping points, usually stations. ATO is actually quite a simple system, as it only requires four inputs and acts on two outputs. The system merely needs to know:

- The timetable

- The aspect of the next signal

- The position of the train

- The train's current speed

The last two of which are both available from the odometer, though this does not provide the greatest level of position accuracy on its own and some form of error correction (usually through the use of fixedposition reference beacons throughout the track) is also required.

From these inputs, the ATO can calculate what speed profile the train must adopt in order to reach its next stopping point at the correct time. It therefore needs to have outputs to:

- The train's traction

- The train's braking systems
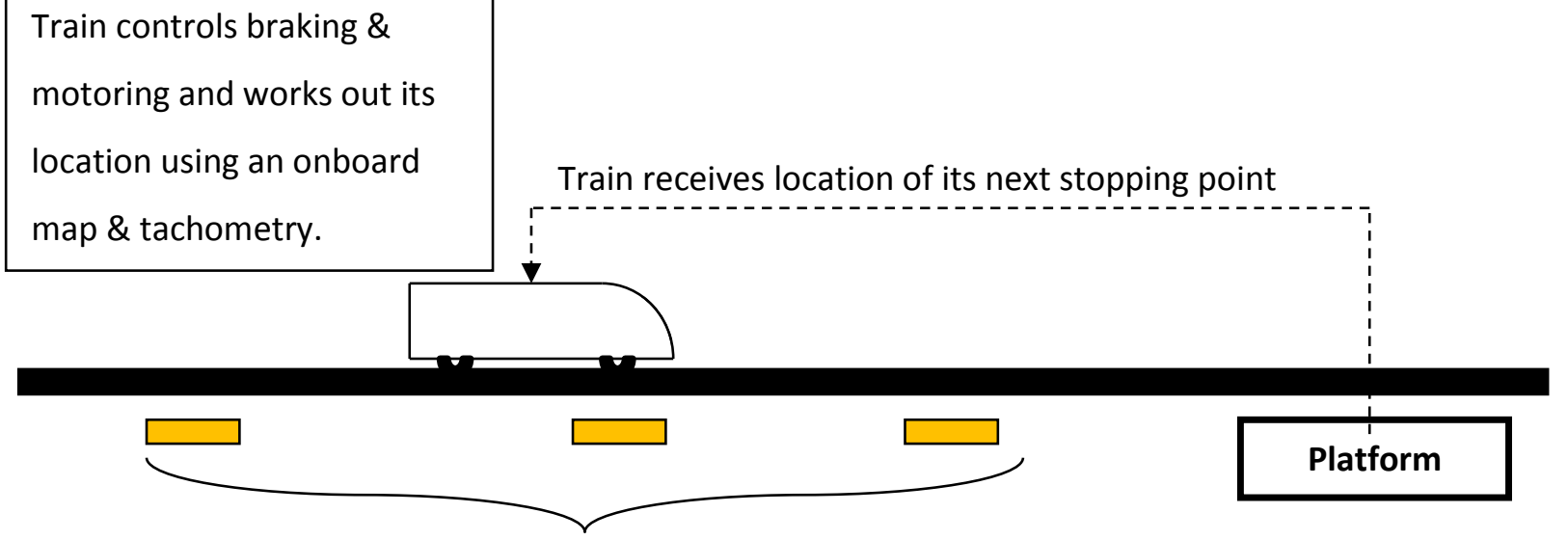

Platform

Position references are provided in the trackside for the train

Fig. 2-4 Basic ATO Functionality

Since the ATO is only responsible for moving the train to its next stopping point, it is not designed to a safety critical standard and, therefore, ATO must always be used with Automatic Train Protection (ATP). The combination of these two elements is known as Automatic Train Control (ATC) in Europe. 
Standard EN 62290-1:2006 (BSI, 2013) has defined five main Grades Of Automation (GOA) for train control, as per Table 2-1: 


\begin{tabular}{|c|c|c|c|c|c|c|}
\hline \multirow{2}{*}{\multicolumn{2}{|c|}{ Basic functions of train operation }} & $\begin{array}{l}\text { On-sight train } \\
\text { operation }\end{array}$ & $\begin{array}{c}\text { Non-automated train } \\
\text { operation }\end{array}$ & $\begin{array}{l}\text { Semi automated } \\
\text { train operation }\end{array}$ & $\begin{array}{c}\text { Driverless train } \\
\text { operation }\end{array}$ & $\begin{array}{c}\text { Unattended train } \\
\text { operation }\end{array}$ \\
\hline & & GOA0 & GOA1 & GOA2 & GOA3 & GOA4 \\
\hline \multirow[t]{3}{*}{$\begin{array}{l}\text { Ensure safe } \\
\text { movement of } \\
\text { trains }\end{array}$} & Ensure safe route & $\begin{array}{c}\mathrm{x} \\
\text { (points } \\
\text { command/control in } \\
\text { system) }\end{array}$ & system & system & system & system \\
\hline & Ensure safe separation of trains & $\mathrm{x}$ & system & system & system & system \\
\hline & Ensure safe speed & $\mathrm{x}$ & $\begin{array}{c}\mathrm{x} \\
\begin{array}{c}\text { (partly supervised by } \\
\text { system) }\end{array} \\
\end{array}$ & system & system & system \\
\hline Drive train & Control acceleration and braking & $\mathrm{x}$ & $\mathrm{x}$ & system & system & system \\
\hline \multirow{2}{*}{$\begin{array}{l}\text { Supervise } \\
\text { guideway }\end{array}$} & Prevent collision with obstacles & $\mathrm{x}$ & $x$ & $\mathrm{x}$ & system & system \\
\hline & Prevent collision with persons on tracks & $\mathrm{x}$ & $\mathrm{x}$ & $\mathrm{x}$ & system & system \\
\hline \multirow{3}{*}{$\begin{array}{l}\text { Supervise } \\
\text { passenger } \\
\text { transfer }\end{array}$} & Control passengers doors & $\mathrm{x}$ & $\mathrm{x}$ & $\mathrm{x}$ & $\mathrm{x}$ & system \\
\hline & $\begin{array}{l}\text { Prevent injuries to persons between cars or } \\
\text { between platform and train }\end{array}$ & $\mathrm{x}$ & $\mathrm{x}$ & $\mathrm{x}$ & $\mathrm{x}$ & system \\
\hline & Ensure safe starting conditions & $\mathrm{x}$ & $\mathrm{x}$ & $\mathrm{x}$ & $x$ & system \\
\hline \multirow[t]{2}{*}{ Operate a train } & Set in/set off operation & $\mathrm{x}$ & $\mathrm{x}$ & $\mathrm{x}$ & $\mathrm{x}$ & system \\
\hline & Supervise the status of the train & $\mathrm{x}$ & $\mathrm{x}$ & $\mathrm{x}$ & $\mathrm{x}$ & system \\
\hline $\begin{array}{l}\text { Ensure detection } \\
\text { and management } \\
\text { of emergency } \\
\text { situations }\end{array}$ & $\begin{array}{l}\text { Perform train diagnostic, detect fire/smoke and } \\
\text { detect derailment, detect loss of train integrity, } \\
\text { handle emergency situations (call/evacuation, } \\
\text { supervision) }\end{array}$ & $\mathrm{x}$ & $\mathrm{x}$ & $\mathrm{x}$ & $x$ & $\begin{array}{l}\text { system and/or } \\
\text { staff in OCC }\end{array}$ \\
\hline
\end{tabular}

Table 2-1 Grades of Automation (BSI, 2013)

Permission to reproduce extracts from BS EN 62290-1:2006 is granted by BSI. British Standards can be obtained in PDF or hard copy formats from the BSI online shop: www.bsigroup.com/Shop or by contacting BSI Customer Services for hardcopies only: Tel: +44 (0)20 8996 9001 , Email: cservices@bsigroup.com. 


\subsection{Modern Systems}

Modern RCS systems can generally be divided into two types, namely, those utilised on mainline railways and those used on metro networks. Most modern systems rely on some form of radio or inductive transmission of data from the infrastructure to the train and vice versa.

\subsubsection{Mainline Systems}

There are two main systems of radio based train control currently being implemented on mainline operations throughout the world: ERTMS and PTC.

ERTMS (European Rail Traffic Management System) is the European Union's initiative to standardize all forms of train operation within Europe. It consists of three main parts:

- Global System for Mobile communications - Railways (GSM-R), which is a standard communications system

- European Traffic Management Layer (ETML), which will standardize traffic management operations

- European Train Control System (ETCS), which will provide standard train protection for Europe.

ETCS utilises wireless communication to provide in-cab signalling and can be implemented in one of three main levels as defined by the Union des Industries Ferroviaires Européennes (UNIFE):

- Level 1 acts as an overlay for existing conventional schemes and utilises radio beacons known as balises embedded in the 4-foot connected to the interlocking via a Lineside Equipment Unit (LEU). These balises transmit the permitted MA to the train as it passes over them

- Level 2 utilises the GSM-R system to continuously transmit the MA to the train via a Radio Block Centre (RBC) which is connected to the interlocking, meaning that there is no longer a need for lineside signals. Balises are still used but now act as autonomous position references only

- Level 3 is a conceptual level where conventional forms of train detection (such as axle counters or track circuits) are removed and the train maintains its own integrity, allowing the train to run on moving block

(UNIFE, 2013)

The Chinese Train Control System (CTCS) is very similar to the ETCS system (Ning, et al., 2004) but with the levels defined slightly differently as shown in Table 2-1.

\begin{tabular}{|c|c|}
\hline CTCS Level & Equivalent ETCS Level \\
\hline 1 & Local Protection System \\
\hline 2 & 1 \\
\hline 3 & 2 \\
\hline 4 & 3 \\
\hline
\end{tabular}

Table 2-2 Equivalent CTCS \& ETCS Levels 
As CTCS architecture is therefore almost identical to ETCS architecture, it will not be considered separately as part of this research.

PTC (Positive Train Control) is the standard developed in North America as their new in-cab signalling standard. It is based around four main objectives set by the USA Federal Railroad Administration (FRA) (FRA, 2008):

- Train separation or collision avoidance

- Line speed enforcement

- Temporary speed restrictions

- Rail worker wayside safety

(FRA, 2008)

There are currently five types of system that have been defined as PTC by the FRA (FRA, 2008) and the definitions are quoted below:

- ACSES (Advanced Civil Speed Enforcement System).

- A transponder-based system, in use on Amtrak's Northeast Corridor (Type Approved and Certified by FRA.)

- ETMS (Electronic Train Management System).

- A GPS and communications-based system being deployed by BNSF Railway. (Type Approved and Certified by FRA for restricted use.)

- I-ETMS (formerly called Vital Electronic Train Management System).

- A GPS and communications-based system, not yet ready for deployment. (Type Approved by FRA.)

- ITCS (Incremental Train Control System).

- A GPS and communications-based system used by Amtrak on its Michigan line

- Authorized for passenger train speeds up to $110 \mathrm{mph}$, originally put into use by the specific requirements of an FRA-approved waiver.

- ITCS certification through Amtrak's request for expedited certification process is pending successful resolution of a few remaining issues prior to FRA approval for certification.

- Enhanced Automatic Train Control (E-ATC).

- A system that uses an underlying automatic train control (ATC) system, in conjunction with other "enhanced" features or systems to achieve the core required functionalities of PTC.

- These systems are often integrated with underlying cab signal systems (CSS) and centralized traffic control (CTC) systems, in addition to other signal or train control system enhancements the railroad elects to make, to meet the full requirements of PTC.

(FRA, 2008)

These systems are discussed in greater detail in Sections 1.7.3 and 1.7.4. 


\subsubsection{Metro Systems}

Modern metro networks utilise systems known as Communications Based Train Control (CBTC), with Communications referring to some form of wireless communication that is utilised to transmit authority to the train to proceed; though sometimes CBTC is defined as Computer Based Train Control due to the fact that it relies heavily on computer-based processing.

CBTC generally combines Automatic Train Control (ATC) that consists of Automatic Train Protection (ATP) and Automatic Train Operation (ATO), with another function known as Automatic Train Supervision (ATS). These functions are defined in more detail in Section 1.7.2.

CBTC can also utilise some form of continuous train detection, whether by means of current loops or balises and odometers, which enable a central system connected to the interlocking to know the position of every train on the network accurately and thus allow trains to run closer to each other than is possible with fixed block separation. This method of control, where trains are separated by a braking distance and a safety gap, is known as moving block. These systems are discussed in greater detail in Sections 1.7.3 and 1.7.4.

\subsection{System Modelling Tools}

There are a large number of software tools that can be utilised to model complex systems and even complex SOS. The majority of these tools have been designed for other industries or as a generic tool that can be applied to any industry. However, some tools have been developed especially for the railway industry.

A recent MSc thesis by an employee of Thales (Farrell, 2015) investigated if the use of modelling and simulation of external systems and their interface to CBTC would reduce risks to CBTC's implementation on projects such as the 4 Lines Modernisation Programme currently taking place on London Underground (LU). The author concluded that:

The use of modelling and simulation can be used at the design stage using an existing simulation tool, and at the early implementation stage using a proven concept simulation tool, and would reduce risk. Risks were determined to be to people involved in testing activities and also those associated with the cost of rework following design error. He also concluded that there were commercial benefits both in terms of monetary savings from reduced resources and equipment needed to undertake testing activities and also intangible benefits, such as enhanced reputation through the use of innovative approaches to testing. (Farrell, 2015)

The 2012 Railway Technical Strategy (RTS) (RSSB, 2012), which defines the UK's future vision for the railway industry, has technology at its core and a recent study (Sharpe, et al., 2015) investigated how the strategy's vision could be applied to a current major network upgrade, namely the capacity improvements programme between Woking and Waterloo. The study promoted the use of systems thinking and modelling tools to monitor and control the complex interdependent requirements of the programme. 
A recent paper (Li \& Zhang, 2015) investigated the benefits of modelling a modern CBTC system using Architecture Analysis \& Design Language (AADL) in the development and delivery of such systems, whilst another paper (Hossein, et al., 2015) utilised various abstract models to simulate the Bay Area Rapid Transit (BART) system in California. They showed how this effectively enabled systems to be tested prior to building in order to limit the risks of malfunctions on implementation.

\subsection{Resilience Engineering}

A recent white paper produced for the aviation industry (Leonhardt, et al., 2009) discusses the importance of Resilience Engineering to Air Traffic Management (ATM) systems. These systems have many similar challenges to RCS systems, so this approach could be a useful analysis tool to examine the appropriateness of these proposed RCS models and how they should be utilised for developing and delivering RCS systems.

Leonhardt et al define Resilience Engineering as, "The intrinsic ability of a system to adjust its functioning prior to, during, or following changes and disturbances, so that it can sustain required operations under both expected and unexpected conditions." (Leonhardt, et al., 2009)

They go on to explain that:

Since humans are indispensable in all situations involving change, Resilience Engineering naturally has strong links with Human Factors and Safety Management. It is based on the following premises:

1. Performance conditions are always underspecified. Individuals and organisations must therefore adjust what they do to match current demands and resources. Because resources and time are finite, such adjustments will inevitably be approximate.

2. Some adverse events can be attributed to a breakdown or malfunctioning of components and normal system functions, but others cannot. The latter can best be understood as the result of unexpected combinations of performance variability.

3. Safety management cannot be based exclusively on hindsight, nor rely on error tabulation and the calculation of failure probabilities. Safety management must be proactive as well as reactive.

4. Safety cannot be isolated from the core (business) process, nor vice versa. Safety is the prerequisite for productivity, and productivity is the prerequisite for safety. Safety must therefore be achieved by improvements rather than by constraints.

Adopting this view creates a need for an approach that can represent the variability of normal system performance, and for methods that can use this to provide more comprehensive explanations of accidents as well as identify potential risks.

(Leonhardt, et al., 2009)

In comparison to traditional risk analysis and safety management, the authors state that, "Resilience engineering is not only to prevent things from going wrong, but also to ensure that things go right, i.e., to ensure normal outcomes." (Leonhardt, et al., 2009) 
Leonhardt et al demonstrate this concept on a diagram where, "The $x$-axis describes predictability, ranging from very low to very high, and the $y$-axis describes the value of the outcome, ranging from negative to positive" (Leonhardt, et al., 2009) as shown in Fig. 2-5.

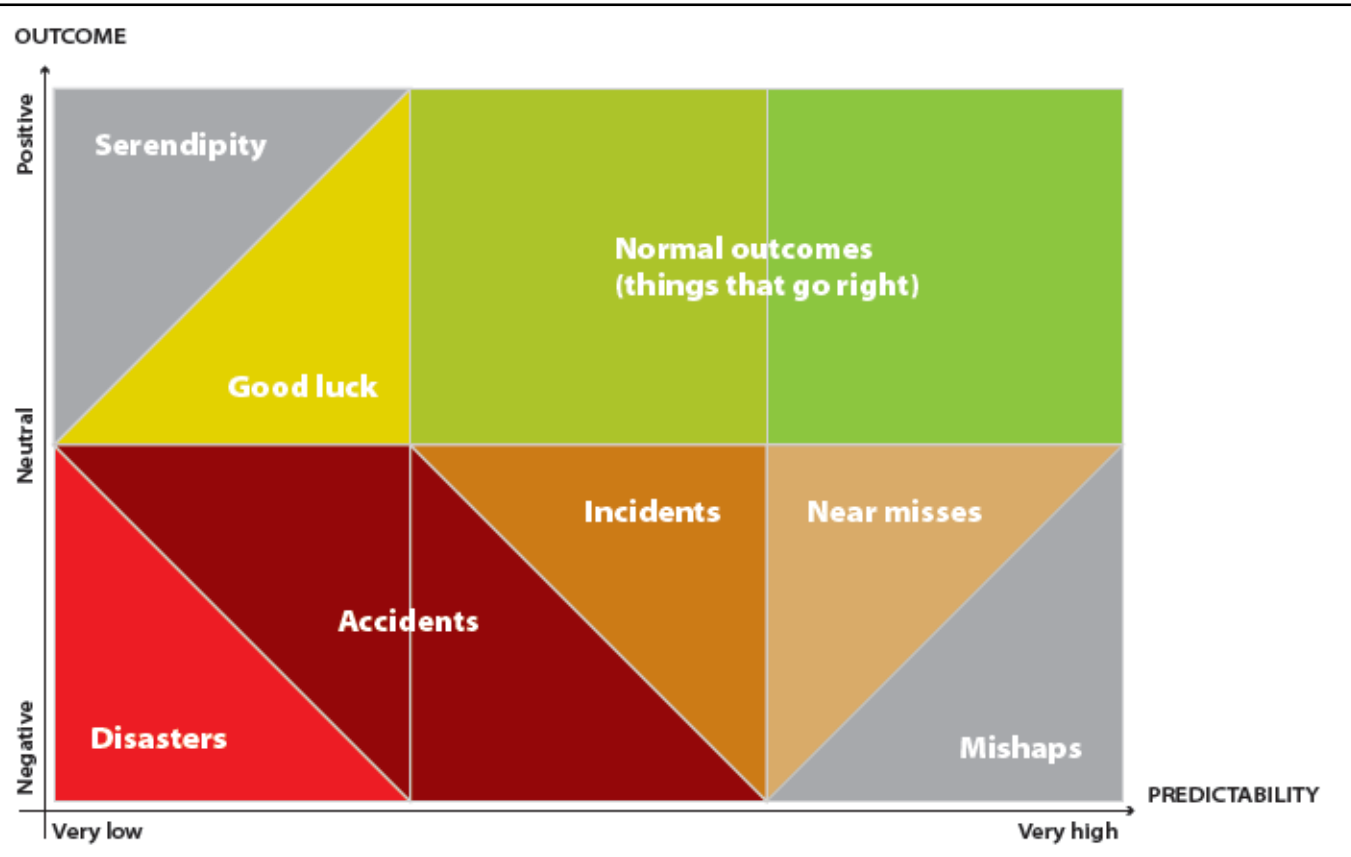

Fig. 2-5 Resilience Engineering set of possible outcomes (Leonhardt, et al., 2009)

The authors go on to talk about the importance of performance variability in resilience engineering. This is the study of how the performance of systems is bound to vary significantly due to a number of factors as demonstrated in Fig. 2-6.

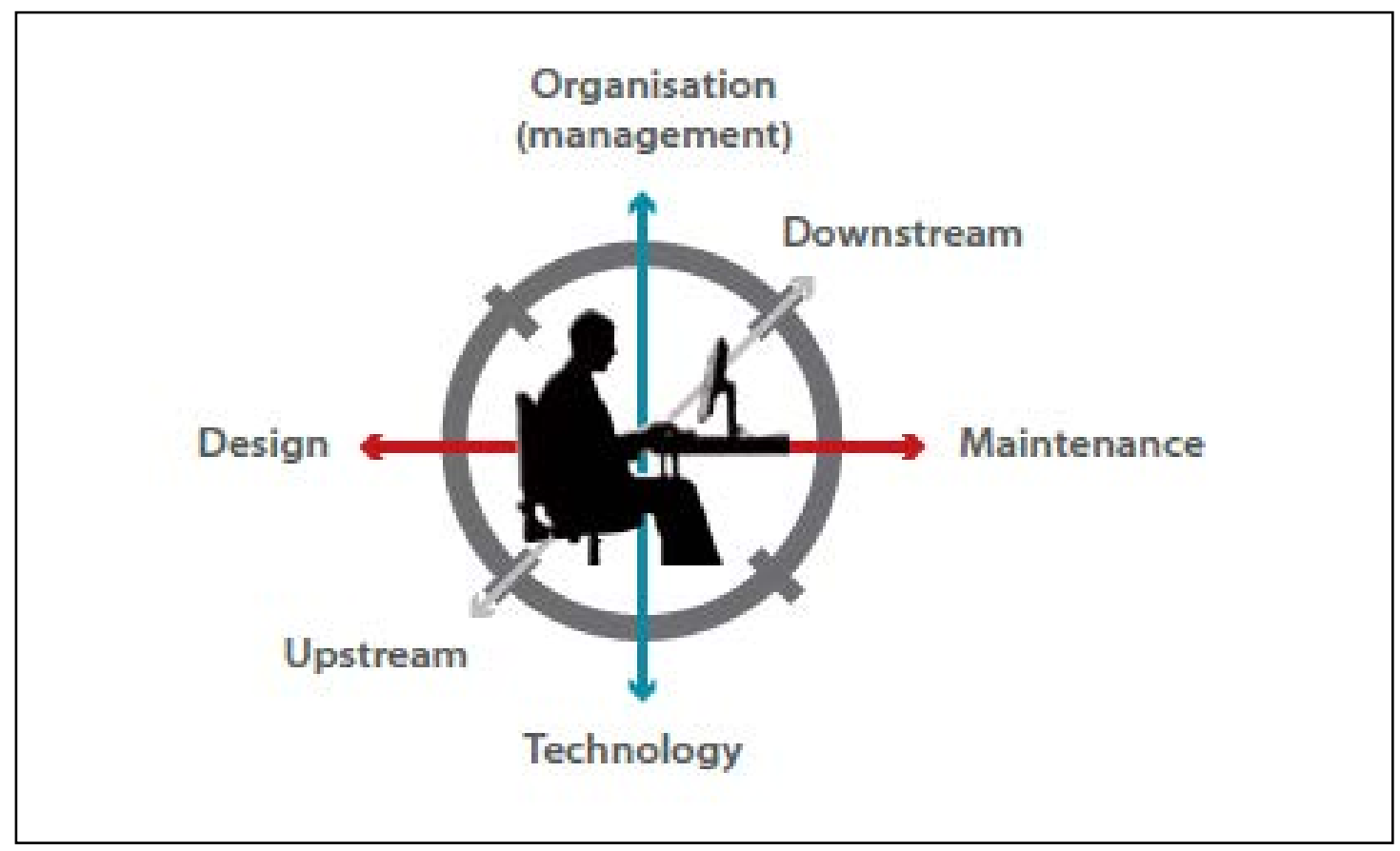

Fig. 2-6 Safety Focus anno 2009 (Leonhardt, et al., 2009)

The authors then introduce the concept of upstream-downstream and the importance of its integration into a company's business. They state that, "There are dependencies to what 
went before (upstream) and what comes after (downstream) in any particular process at a given point in time." (Leonhardt, et al., 2009) There is also a very good analogy of how situations can develop from multiple flaws in the system, which it calls the 'Swiss Cheese' Model. This basically shows how situations do not usually develop from one big flaw but from a number of small flaws (in other words the holes of the cheese) all lining up at the same time:

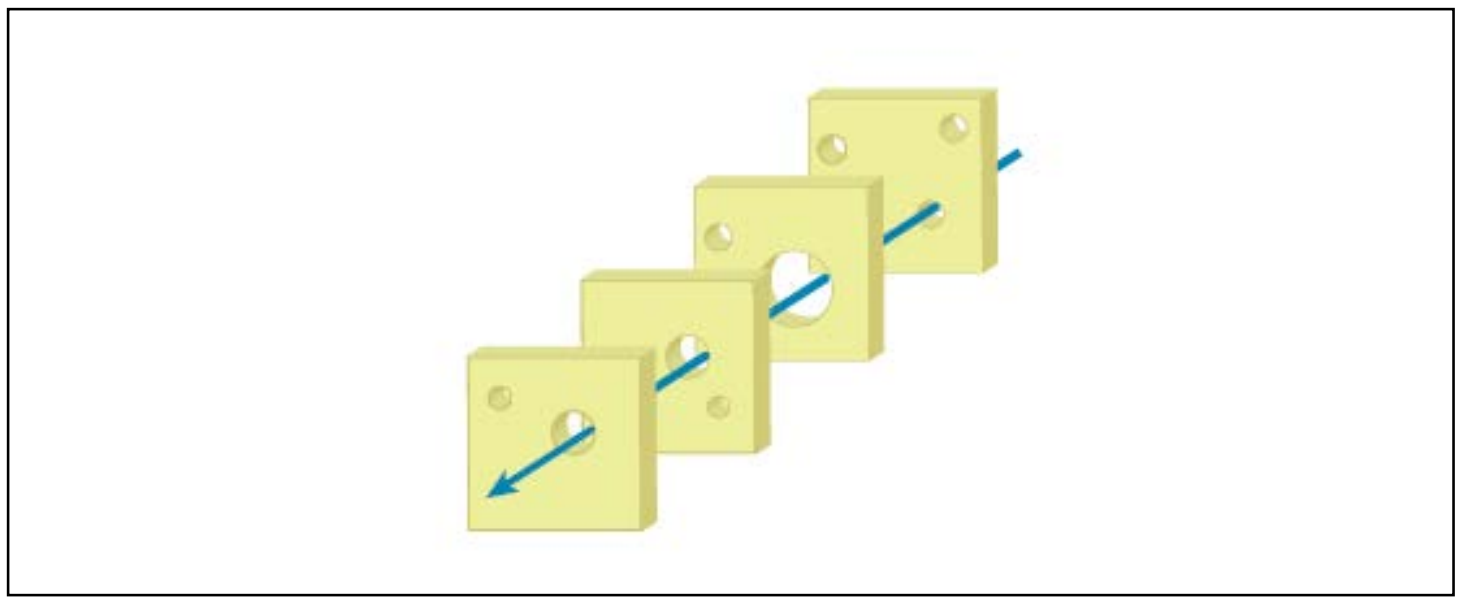

Fig. 2-7 'Swiss Cheese' Model (Leonhardt, et al., 2009)

This approach of resilience engineering has been demonstrated for use on the railway by (Collis, et al., 2013), who applied it retrospectively to an incident that occurred on the Channel Tunnel in 2009, when bad weather caused the failure of several trains. The incident resulted in the pile-up of several trains that required rescuing. The paper examines the response of the operator, who seems to have been unprepared for such an incident. One of the key aspects that the paper raises is the importance of anticipation and planning of events. The paper re-iterates one of the key aspects of resilience engineering: that it is not only identifying potential issues that could affect a system, but also determining how to prevent them.

This approach can be applied to the RCS system models to show how they are important to the development of a RCS system and how they can be utilised to control and prevent risk in the programme development.

As stated previously, the key to the operation of a RCS system is accurate end-to-end communication of safety critical information between two key personnel (the Line Controller and the Train Operator). It is vital that the upstream and downstream of this data is maintained under all possible scenarios. We utilise the Safety \& Protection layer as defined in the functional model to ensure that this is the case. However, as the system is developed and migrated, there is significant risk of loss in integrity if the system is not developed or implemented correctly. It is therefore essential that change control is monitored and controlled carefully as the system is developed and that these changes are implemented correctly when the system is installed onsite.

Therefore, I would say that there are two fundamental issues that we should constantly consider in the development of any RCS system: 
1. Maintain the integrity of both the new system and any existing system during development and migration

2. When the system is in operation, the integrity of the safety-critical data must be maintained at all times

Both of these items can be ensured through using appropriate systems engineering tools such as:

- Requirements Management

- Interface Management

- Configuration Management

\subsection{Current RCS Systems Design and Delivery}

The development and delivery of modern RCS systems varies greatly depending on the type of RCS system and where it is deployed in the world, as different countries have different standards. However, they can be broadly grouped into the four categories that shall be defined in Section 1.7.

\subsubsection{Conventional Signalling}

There have been several papers produced into the developments and applications of conventional signalling technology as it continues to be widely utilised worldwide. Some of the best examples are described in this Section.

A recent paper by P. Booth for the Railway Signalling and Control Systems Professional Development Course provided by the Institution of Engineering and Technology in June 2010 (Booth, 2010) defines the basics of train protection for mainline railways and explains how conventional signalling is designed in the UK.

Another recent paper by Wang \& Goverde (Wang \& Goverde, 2016) investigates how to optimise the train trajectory of conventional signalling systems, particularly in relation to the ATP. It also explores how the performance can be further improved by the introduction of Driver Advisory Systems (DAS).

Recent research (Wang, et al., 2016) makes the point that even conventional signalling consists of sub-systems such as ATP, CBI and centralised control, all of which are themselves self-disciplined control systems. The paper talks about the different requirements on the design of the safety critical systems such as ATP and CBI which typically have a Safety Integrity Level (SIL) (IEC, 2010) rating of 4, whilst the less safety-critical centralised control systems are generally SILO-2.

\subsubsection{CBTC}

There have been several papers that have looked into the developments and applications of CBTC technology for use on predominantly metro systems. Some of the best examples are described in this Section.

A paper published by Yelloz in 2012 (Yelloz, 2011) describes the development and implementation of the Siemens CBTC system that was installed on Line 9 of the Barcelona Metro as the first driverless train in Spain. The paper gives an excellent example of how the requirements of the implemented system were derived from the unique operational environment of the Barcelona Metro and how they adapted their experiences on the Paris 
Metro to this system. The paper goes on to explain how it derived General, Functional and Availability requirements, as well as Degraded Modes and Maintenance requirements. It then explains how the Siemens system meets these requirements and how the functionality is divided between the On-board and Wayside equipment. It also outlines the communications system and Automatic Train Supervision capabilities before detailing the benefits the new system brings to passengers and operators. It is interesting to note that these benefits do not always relate directly to the identified requirements. What this paper does not discuss is what methods were used to ensure that all requirements were met or how the generic products were adapted to the specific application of the Barcelona Metro.

Another paper published by Oh. et al in 2013 (Oh, et al., 2013) discusses how Korea has developed its Korean Radio-based Train Control System (KRTCS) as its standard for CBTC. The paper details the system's functionality from a generic point of view, independent of any specific application. It presents a good high level view of the architecture and how its functionality works, particularly in the interactions between the wayside and on-board systems. It does not go into any details of how the system's functionality relates to industry needs nor how it can be applied to specific applications.

A recent paper from Ferrai et al in 2014 (Ferrai, et al., 2014) investigates the issues for standardising CBTC specifications. It provides a very good description of both Fixed Block and Moving Block operation and an excellent high level overview of various CBTC architectures, before going on to develop a global feature diagram showing common elements of CBTC systems in simplified tree diagram. It then shows how this can be derived into example sequence diagrams for train moves for specific technologies. It also shows traceability of how functionality can be derived from the standards (but not from business needs or requirements) and then goes onto scenarios to develop appropriate architecture.

A different take on this is provided in a paper from Siemens (Schmelzer, 2010), which looks at potentially utilising the ETCS standards to standardise CBTC development. It particularly relates to the Siemens CBTC system, which utilises switchable balises in a similar way to ETCS, enabling quite a direct comparison. It goes on to explain the difference between continuous ATC utilising CBTC standards and intermittent ATC using ETCS standards. Its main analysis is on how standardising CBTC with ETCS could be utilised to improve mixed traffic operation, but it does not show how such a system would be developed and applied to a specific application.

A final paper produced by Hitachi (Tazaki, et al., 2012) explores how their CBTC system (previously only utilised in Japan) was developed for Chongqing in China. Though it gives a brief overview of how the system was developed for global markets, it does not go into great detail about how the system was developed, nor how it is applied to the specific applications.

\subsubsection{ERTMS}

Since ERTMS was developed as the standard solution for train control within Europe, there have been many papers written on it. Some of the best examples which investigate the development and implementation of its architecture are provided in this Section. 
A paper produced by the French Institute of Sciences and Technology for Transport (Ghazel, 2014) gives a very good overview of the entire ERTMS system, including its current level of deployment and basic levels of operation. It then goes on to discuss the challenges it introduces in its development and deployment, particularly the management of transitions and demonstrates the use of UML to depict this pictorially. However, it does not investigate the process for developing and delivering the ERTMS system either generically or for specific applications.

Another paper (Qiu, et al., 2014) further shows how railways can be modelled using state charts and investigates how these charts can be applied to ERTMS systems in order to determine the availability that the system will bring to a particular railway. It then utilises ETCS Level 2 to show how the system is broken down at a high level and the interactions of the main sub-systems. Again, it does not investigate how the system will be developed or implemented.

An article (Smith, et al., 2012) looks into the lessons learnt from the implementations of ERTMS that have taken place so far. It provides an excellent detailed diagram of the ERTMS architecture as well as a good overview of the known Class B systems within Europe. It then goes on to talk about the amount of ERTMS deployed across Europe and some of the mistakes made. It mainly details problems with operational procedures and issues with human factors in relation to the drivers' interactions to the system. It could be inferred from this that there has not been correct gathering of end-user requirements and a general lack of systems engineering during the development and implementation of these projects.

Another paper (Cimatti, et al., 2012) conducts an excellent investigation into the validation of requirements for safety critical systems using ETCS as an example. It utilises a graphical approach based on UML to examine ETCS in terms of hybrid evolution. It then proposes a long and quite complex process based around informal analysis, formal analysis, formalisation and formal validation to prove requirements are met by an implemented system. The output is a new language called OTHELLO, which is expressive enough to represent various domains of interest, yet allows efficient procedures for checking. A limitation of this paper is that it only looks at the software elements of ETCS and does not explore its implementation in a specific application.

A final paper (Thompson, et al., 2012) carried out an ergonomics study into the implications of the fitment of ETCS to existing UK rolling stock. It pays particular attention to the human factors issues of the integration of the current class B systems (TPWS \& AWS) with the ETCS DMI in the cab. It examines this in a desktop environment, utilising simulation and cab mock-ups to determine the main issues the end users will face. The paper looks into the potential implications of these fitments on real rolling stock and how they can be achieved, but does not investigate how the on-board system fits into the complete ERTMS system.

\subsubsection{PTC}

The challenges of implementing PTC are very similar to those of ERTMS but with the added complication that there are numerous variations of the 'system'. 
This was particularly highlighted in a paper produced for IRSE news (Noffsinger, 2014) where the author goes into detail about the whole programme. The paper starts with the history of PTC, including how the FRA first began rulemaking proceedings in the late 1990s to set technical standards for electronic systems on railways; a debate that became moot after the high profile collision in Chatsworth, California in July 2008 with 25 fatalities and 100 injured.

Directed by Congress to override the cost/benefit test, FRA set about developing and issuing regulations requiring railways to implement and commission PTC by the statutory deadline of 31 December 2015.

The paper (Noffsinger, 2014) goes on to define the four core requirements of PTC as defined in Section 1.7.4 before looking at the scope of the required programme to fit the entire USA network, including the challenges of:

- Upgrading the communications infrastructure

- Modifying the existing railway infrastructure and signalling

- Achieving approval through the regulation process

- The different types of PTC (as defined in Section 1.7.4)

(Noffsinger, 2014)

The paper (Noffsinger, 2014) concludes how the challenges made it unlikely that any railroad would meet the 31 December 2015 deadline for PTC implementation, a fact acknowledged by the FRA, who provided some leeway in PTC Final Rule in August 2014 on the implementation targets. This temporary relief provision expires on 31 December 2017, which provides some flexibility for a two-year period. 


\section{System Development \& Delivery of RCS Systems}

In terms of fundamental system engineering, (Faulconbridge \& Ryan, 2014) define four recognised main stages of the systems engineering lifecycle as:

- Pre-acquisition

- Acquisition

- Utilisation

- Retirement

This research predominantly covers the Acquisition and Utilisation phases of RCS projects. Faulconbridge \& Ryan describe the breakdown of this as shown in Fig. 3-1.

(King, 2016)

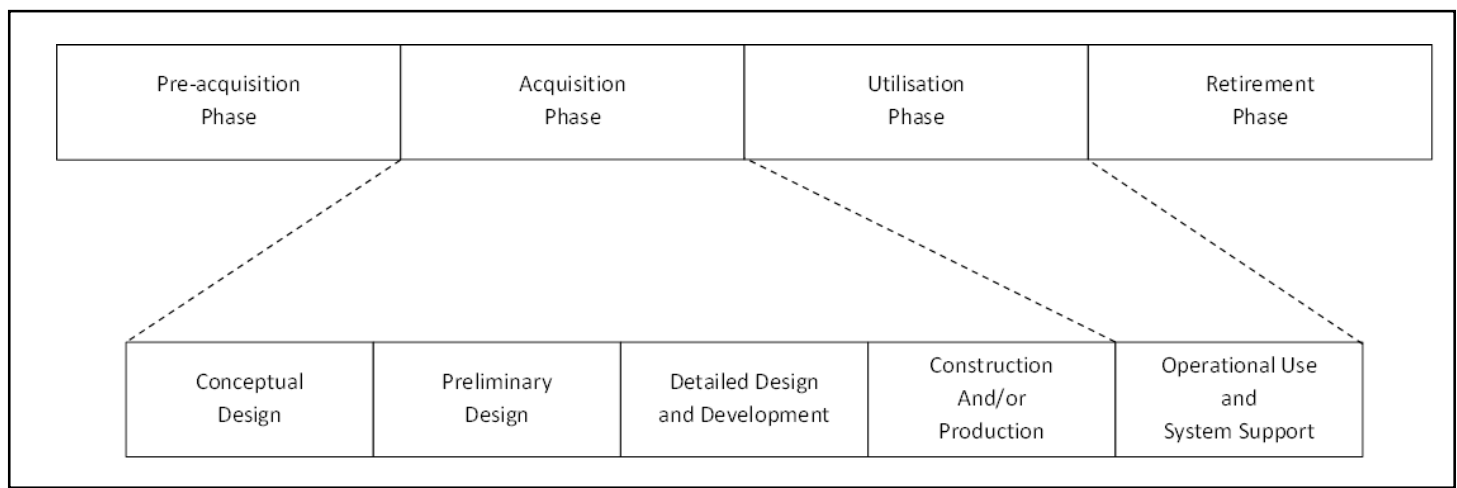

Fig. 3-1 Activities in the Acquisition and Utilisation Phases of the system lifecycle (Faulconbridge \& Ryan, 2014)

The main activities associated with the Acquisition Phase and their associated major milestones and outputs are defined by (Faulconbridge \& Ryan, 2014) as shown in Fig.

3-2. (King, 2016)

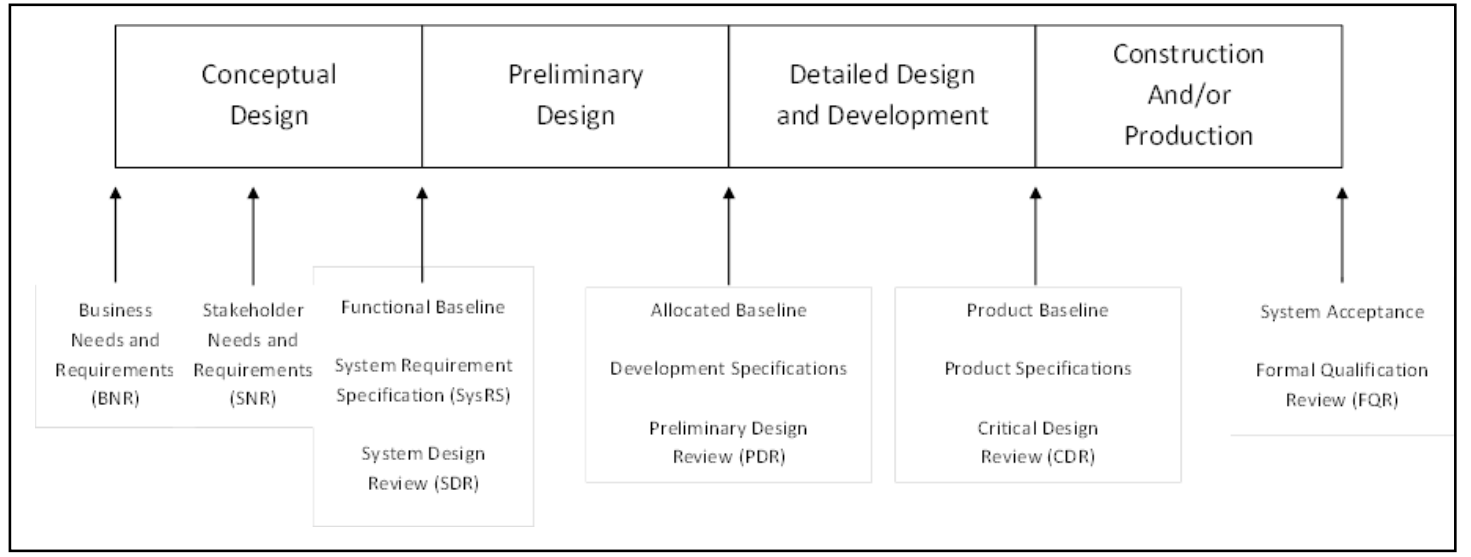

Fig. 3-2 Acquisition Phase activities and the major artefacts and reviews associated with each (Faulconbridge \& Ryan, 2014)

There are a number of systems engineering models that have been developed to manage the development and delivery of systems from Acquisition to Utilisation. The most popular is the V-lifecycle model, which was originally developed for software systems but has been adapted over time for complex multi-disciplinary systems (Blanchard \& Fabrycky, 2011) including RCS systems.

Although the $V$-lifecycle model is starting to be used extensively throughout the railway industry for both the development and deployment of RCS, there is 
considerable confusion about how it should be applied and even what it is fundamentally being used for (Sharpe, et al., 2015). One of the issues is that there is not so much a 'standard' $V$-lifecycle model for all forms of systems, so there are multiple $V$-models that are used for different types of systems.

(Bruegge \& Dutoiyt, 2010) defines the original V-lifecycle model as being developed for Software Engineering from the waterfall model to incorporate feedback and ensure defined requirements are met by software code. This model is now generally utilised for most forms of product development. (Blanchard \& Fabrycky, 2011) show how this model has been developed by INCOSE to manage the requirements of large complex systems such as aviation and industrial control systems.

Further complications arise from a lack of understanding within the railway industry of the difference between Generic Systems and Specific Applications. These will therefore be defined in the following Sections of this Chapter. (King, 2016)

\subsection{Generic System}

Suppliers of RCS technology tend to develop Generic systems based on global market requirements from the industry. This enables them to develop adaptable systems that can be sold to different local markets throughout the world (Bourne \& Clark, 2007). To develop these systems, they tend to follow a $V$-lifecycle model very similar to the adapted waterfall model utilised for product development as shown in Fig. 3-3. (King, 2016)

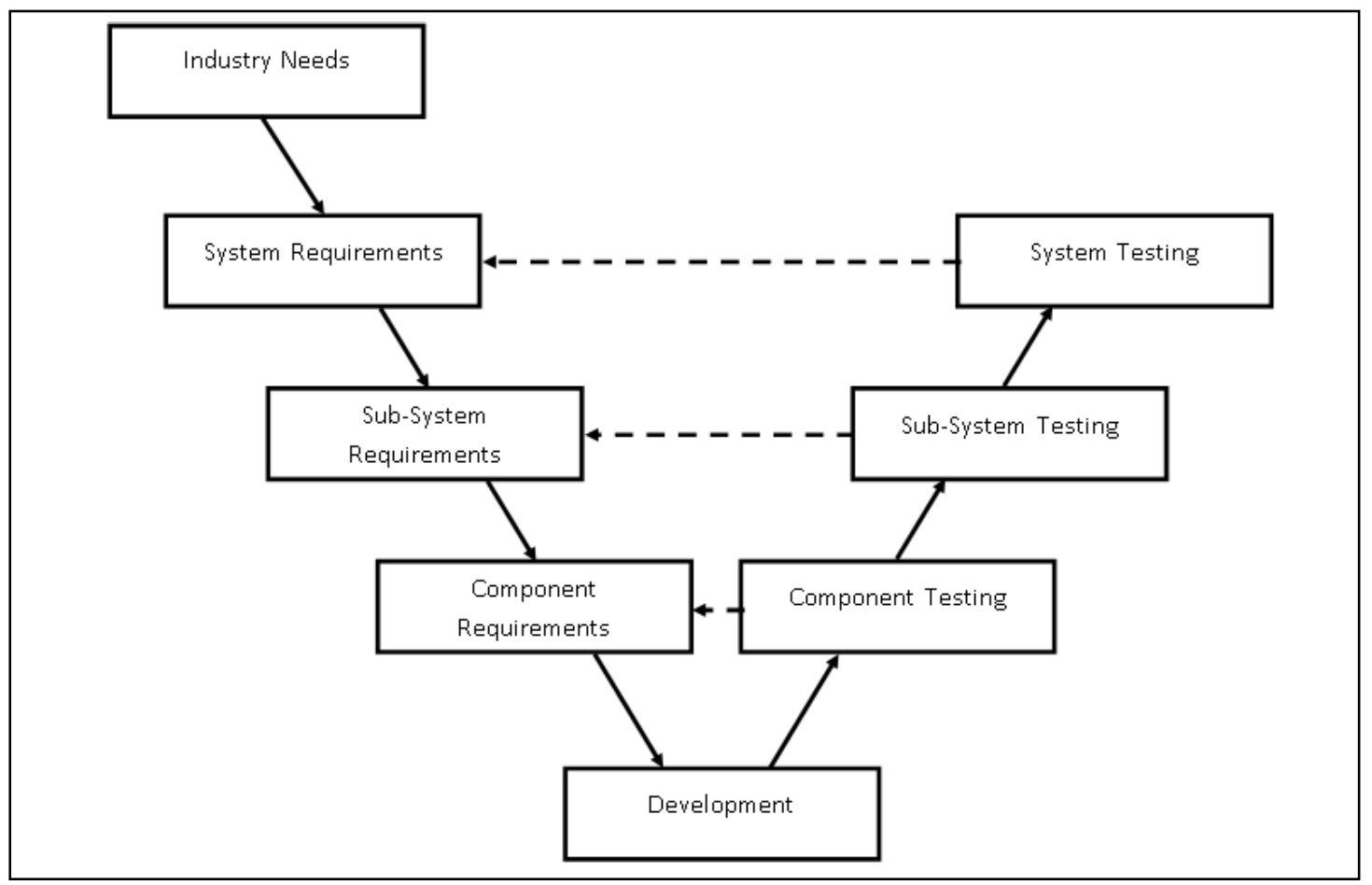

Fig. 3-3 Typical Supplier V-Cycle for Developing RCS Systems (King, 2016)

The supplier will take common needs that railways throughout the world have and use these to develop a system platform that will be made up of various sub-systems that will in turn be made up of hardware \& software components. They will then develop the system to take to market. (King, 2016) 


\subsection{Specific Application}

Railway operators will generally have identified business needs for an RCS system and develop a Concept of Operations before going to market to identify a system that will meet these needs (Bourne \& Clark, 2007). They will then follow a V-lifecycle model more akin to the INCOSE version of the V-lifecycle developed for complex systems as shown in Fig. 3-4. (King, 2016)

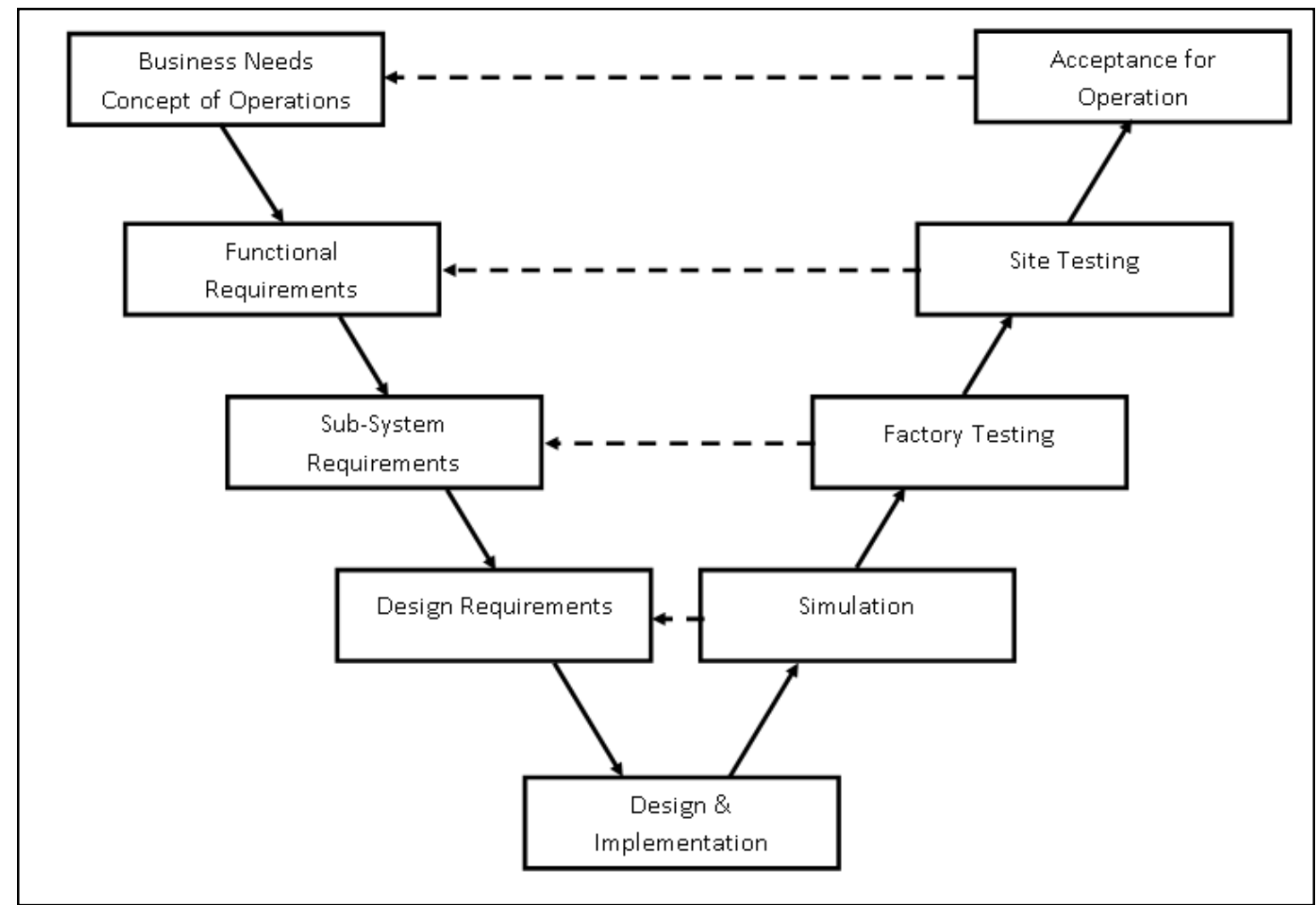

Fig. 3-4 Typical V-Cycle for Delivering RCS System on a Specific Railway (King, 2016)

The operator will contract the supplier to deliver the system to the concept of operations it has developed. The supplier will determine what functional requirements their generic system will need in order to deliver the operator's needs, including specifics such as the geographic layout of the line and particulars of station interfaces. These will inevitably lead to required modifications to their sub-systems. They will then need to design the implementation of the system (scheme layout, etc.) which will in turn be simulated and factory tested to prove the concept before being installed and tested on site to be accepted for operation by the operator. (King, 2016)

\subsection{RCS System W-Model}

The development of the Generic System and Specific Application actually each tell half the story of the RCS system development. What is really needed is a 'W-model' showing all the stages and which entity is responsible for them. As part of this research, I have produced such a diagram and it is proposed in Fig. 3-5. (King, 2016) 


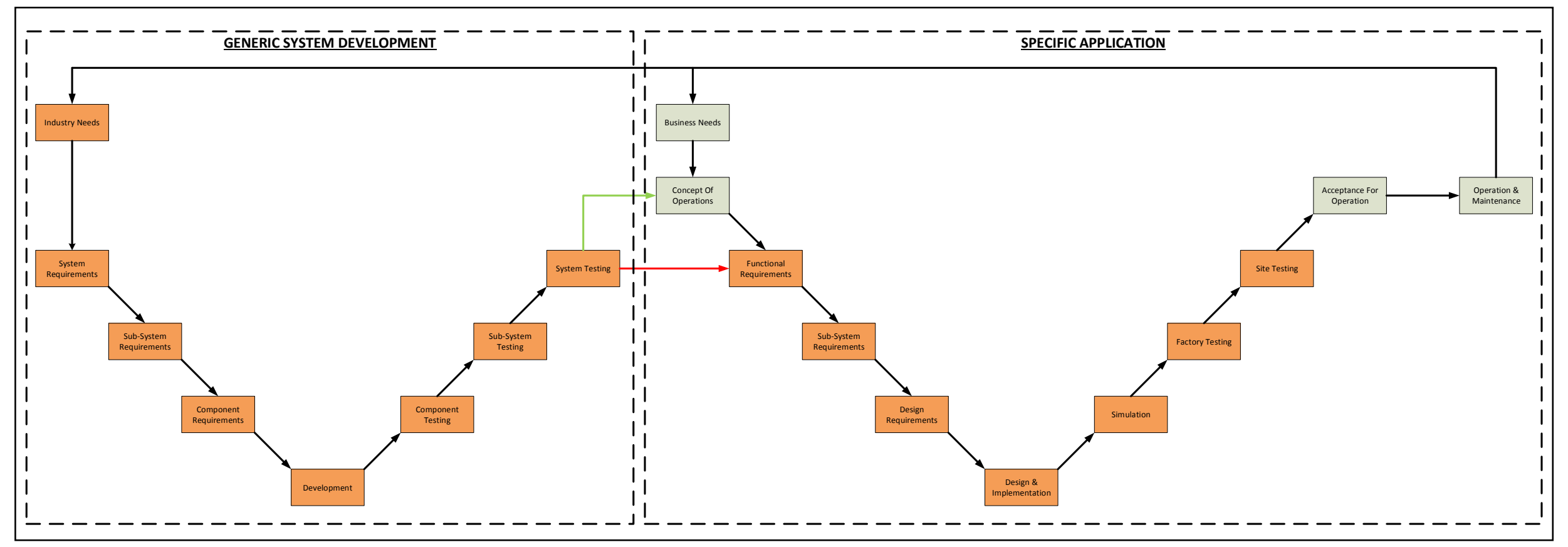

Fig. 3-5 Proposed W-Cycle for Complete RCS Development \& Implementation (Single Source Supplier) (King, 2016) 
As can be seen in Fig. 3-5, the supplier will develop their generic system based on the industry's needs as described in Section 3.1.

When an operator identifies business needs for an RCS system as described in Section 3.2, they will then produce a Concept of Operations (Faulconbridge \& Ryan, 2014) that will define how the new system will function and the key human-machine interactions that will take place, both in terms of operations and maintenance.

The Operator (or an Engineering Consultancy representing them) will then produce an output-specified Invitation To Tender (ITT) that will go out to suppliers to provide a system that meets their requirements.

The suppliers will bid for this work proposing a system based on their generic systems that they developed using the process described in Section 3.1.

The operator will choose the system most appropriate to their needs and then contract the relevant supplier to deliver this system to their specific requirements as shown in Section 3.2.

Once the system has been accepted for operation, it will then enter the utilisation phase of Operations \& Maintenance until the business needs require a new RCS system. At the same time, suppliers will be observing the utilisation of all railways to determine new innovations for their generic system development.

(King, 2016)

However, even this model can be somewhat over simplistic, as it makes the fundamental assumption that a single-source supplier shall be utilised for the complete system (i.e. the same supplier shall provide all sub-systems and integrate them into a complete system). This is becoming increasingly unlikely on many mainline networks, where separate development programmes are taking place for traffic management and train control technology in order to maximise competition within the supplier market. Therefore, an operator may want to purchase separate TMS, ATP and DAS systems and then integrate them into a complete system on their railway. In this case, there will be multiple generic system V-lifecycles that must be integrated in the specific application V-lifecycle as shown in Fig. 3-6. Here there a multiple research and development $v$-cycles being carried out by multiple suppliers to each develop a specific sub-system that must then be integrated by the operator into a complete system to deliver a safe operational railway. 


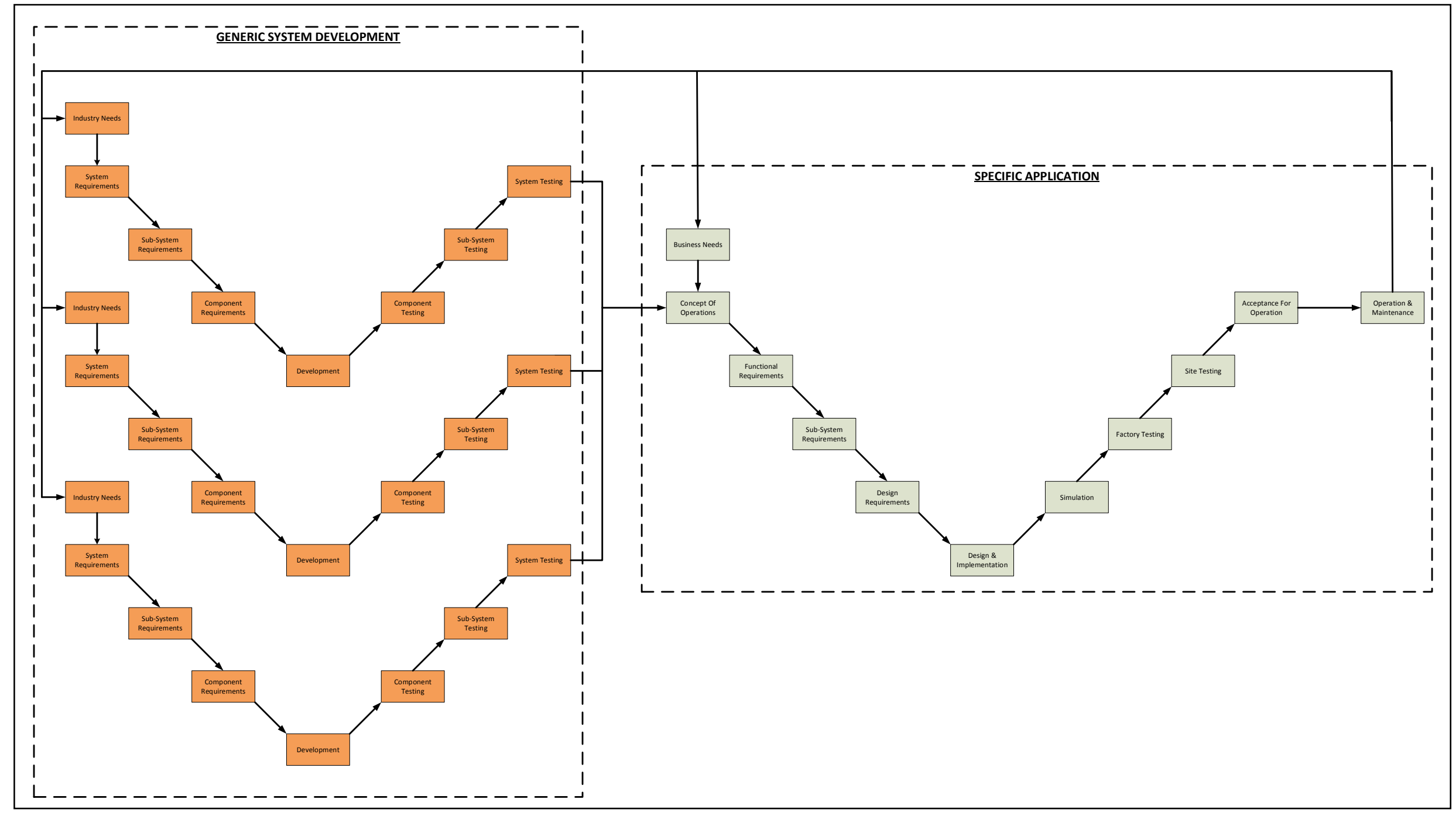

Fig. 3-6 W-Cycle for Complete RCS Development \& Implementation (Multiple Supplier Sub-systems) 


\section{RCS System Model (Generic System)}

This section shall expand upon the idea that it is possible to develop a generic model of a RCS system that works on the principles that all solutions must follow and therefore, any system can be mapped onto it.

\subsection{Functional Model}

If we take the systems model derived from conventional signalling in Fig. 1-4, then also consider that there can be feedback between each sub-system and that there is a direct (voice) communication between the operators, we can extrapolate a more generic model where we can see the requirements as functional layers (as opposed to physical sub-systems) as shown in Fig. 4-1.

(King, 2016)

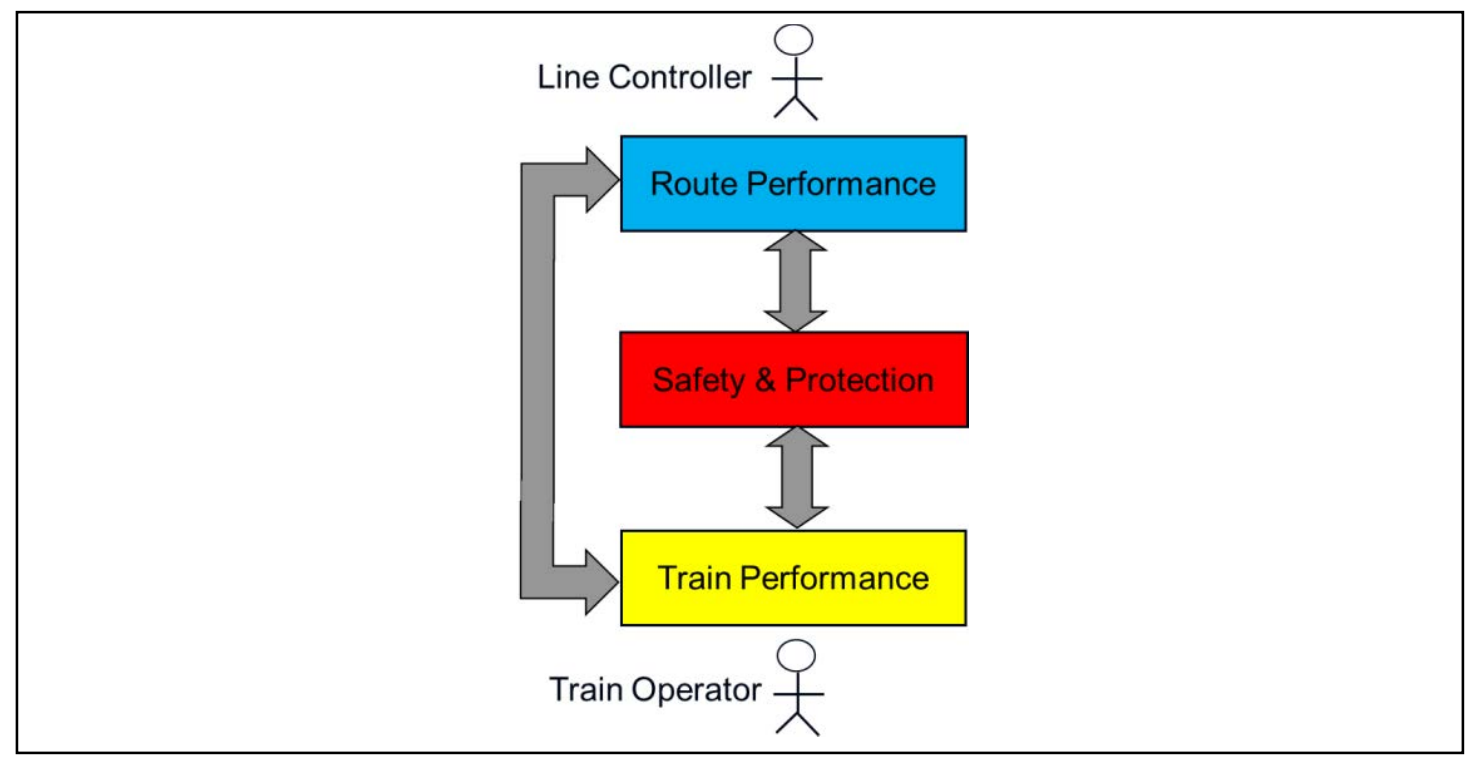

Fig. 4-1 Generic RCS Functional Model (King, 2016)

This model works on the basis of the following rules:

- The Line Controller interfaces to the system through the Route Performance Layer ONLY

- The Train Operator interfaces to the system through the Train Performance Layer ONLY

- NO Operator directly interfaces to the Safety \& Protection Layer

- ALL Safety Critical functions including interlocking, train detection, train protection and points detection are handled in the Safety \& Protection Layer ONLY

- ALL Safety Critical communications MUST pass through the Safety \& Protection Layer

- The Non-vital Communications Path is for voice communications and indications ONLY (for example passenger announcements)

(King, 2016) 


\subsection{Physical Model}

The functional model derived in Section 4.1 can potentially be mapped onto any form of system in order to derive its functional requirements. However, this could potentially be problematic for delivering the system, as equipment can be in different locations and assets spread across different stakeholder owners.

It would therefore be useful to also consider a physical model that shows the locations of equipment across the main locales of the railway in order to deliver the system. This can be complex, as different railways (and the location requirements of different types of RCS and their associated sub-systems) can vary significantly in their geographic requirements. However, I have made a proposal based on my experience of various mainline, metro and mining railways throughout the world for a generic physical model of the main locations usually found on these railways, this is show in Fig. 4-2.

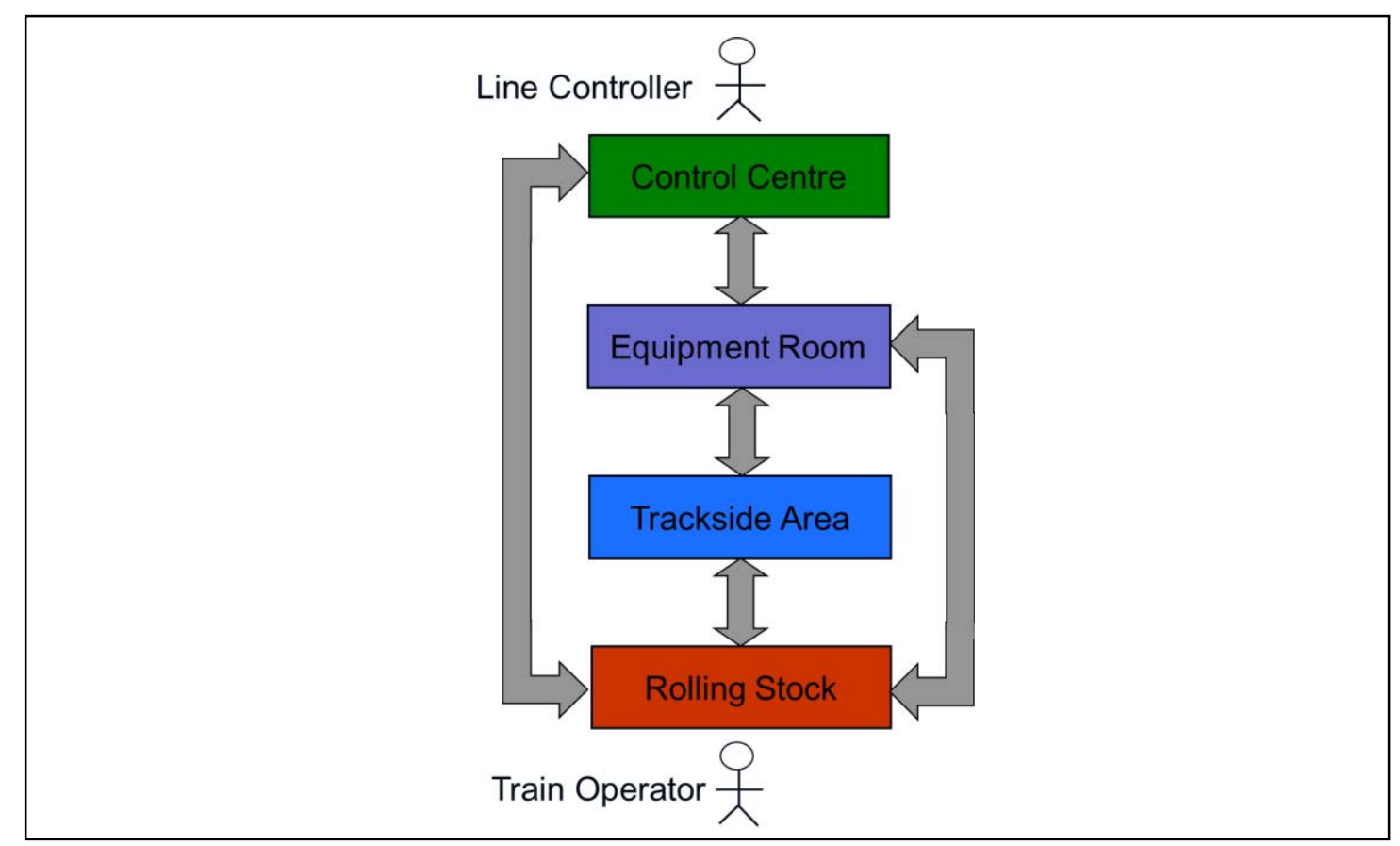

Fig. 4-2 Generic RCS Physical Model

The locations defined in the proposed physical model are:

- Control Centre $=$ The building/location from which the railway is controlled (equipment such as control system, traffic management system, etc. will usually be located here.)

- Equipment Room = Room containing central-processing equipment located either on a station or on-site near track (equipment such as interlocking processor, radio block centre, axle counter evaluator, etc. are usually located in these sort of locations)

- Trackside Area $=$ On or near the track (equipment such as track circuits, axle counter heads, etc. will be located here)

- Rolling Stock = The trains (equipment such as driver machine interface, European vital computer, etc. will be installed on the vehicles)

The model shown in Fig. 4-2 is intended to be as flexible as possible so that it can be applied to any type of railway as required. In order to do this, it has been developed to show all the 
possible (main) locations that could be required for railway operation. However, I acknowledge that certain railways and/or RCS systems may not utilise all the locations. For example, a small railway may only require a single central interlocking processor that could be located in the control centre and hence require no distributed equipment rooms along the route, or a mining railway using a PTC system as defined in Section 1.7.4 may require no trackside elements. If scenarios like these are the case, then the diagram can be easily redrawn with the relevant boxes removed to simplify the design.

\subsection{Stakeholder Interactions}

Though the models derived in Sections 4.1 \& 4.2 appear very similar on paper, they differ significantly in terms of the engagement of the major stakeholders as defined for the majority of mainline operations, namely the Infrastructure Manager (IM) and the Railway Undertaking (RU).

\subsubsection{Physical Stakeholder Boundaries \& Interfaces}

The stakeholder interactions on the physical model are relatively simple as shown in Fig. 4-3, as (generally) the IM owns the buildings that contain the control centre and equipment rooms as well as all of the trackside infrastructure, whilst the RU (usually) owns the trains that it uses to run its service. From the end-user point of view, as IM's are generally responsible for the routing of trains, Line Controllers usually work for them, whilst as RU's are responsible for the delivery of service and Train Operators are often part of their organisation.

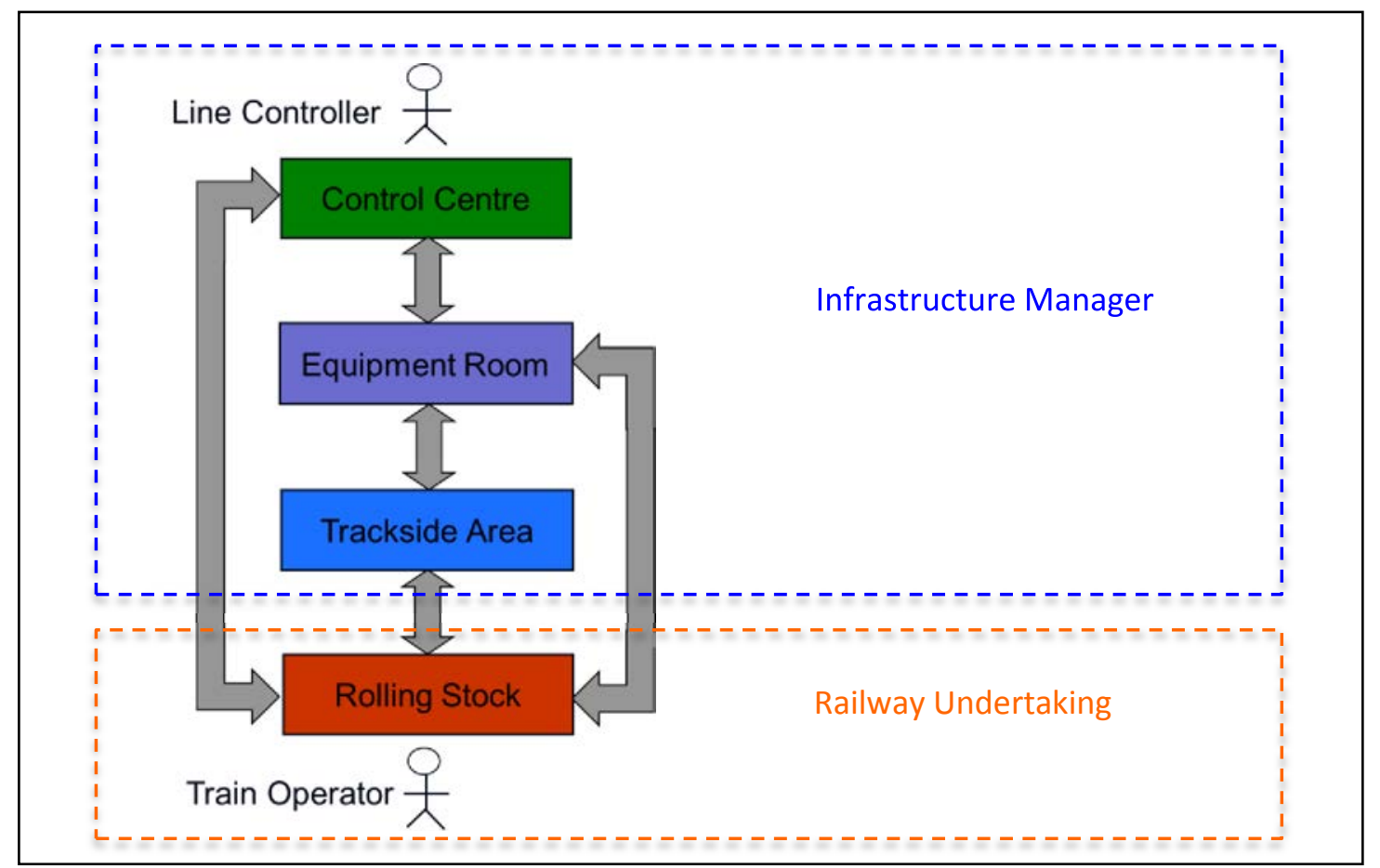

Fig. 4-3 RCS Physical Model Stakeholder Interactions

\subsubsection{Functional Stakeholder Boundaries \& Interfaces}

As shown in Fig. 4-4, the stakeholder interactions on the functional model are somewhat more complicated, as there is significant overlap of responsibility between the IM and RU of at least two of the functional layers, namely Train Performance and Safety \& Protection. 


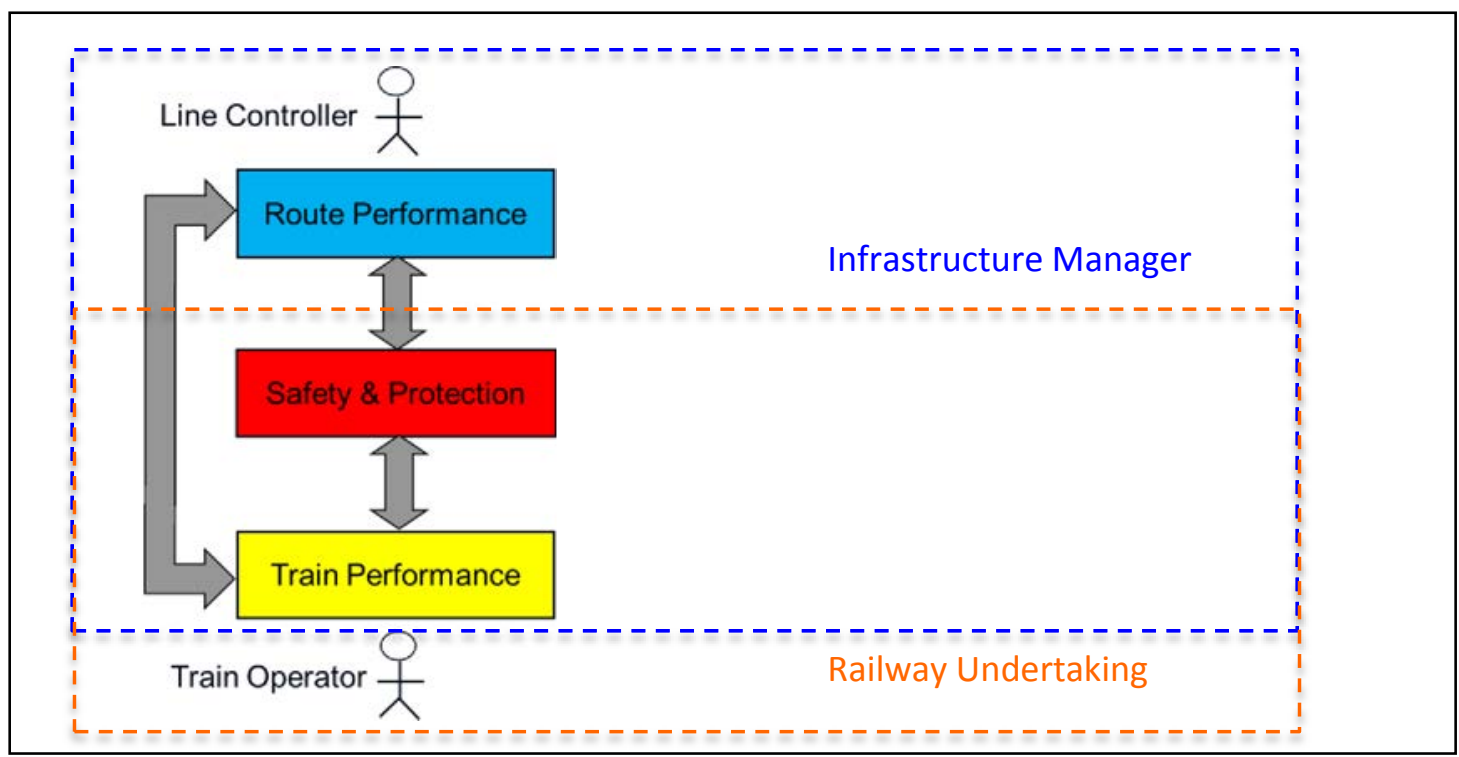

Fig. 4-4 RCS Functional Model Stakeholder Interactions

Route Performance (generally) falls exclusively within the realm of the IM as they are responsible for the allocations of train paths on the network.

Safety \& Protection requires strong interaction between the infrastructure and rolling stock elements (and hence strong interface between the IM and RU), as the safety of where a train can travel is predominantly based around constraints of the infrastructure at a particular point in time, but is also dependent on the performance capability of individual trains. It is also essential to the functionality of systems such as ATP for an intrinsic link between the infrastructure and on-board sub-systems as certain conditions must be met by the infrastructure sub-system in order for the on-board sub-system to intervene in an unsafe situation.

Train Performance will always require an on-board rolling stock element (and hence be the responsibility of the $\mathrm{RU}$ ), but can also require significant input from the infrastructure (and hence the IM) for more advanced functions such as ATO and C-DAS that rely heavily on realtime information about the network from the TMS.

\subsection{Functional to Physical Translation}

When considering the development of RCS systems, we must not only derive the system's functional requirements, but also determine how they will be delivered into the real world; in other words, how the system specified in the functional model relates to the products delivered in the physical model and hence how migration strategies can be developed as shown in Fig. 4-5. 


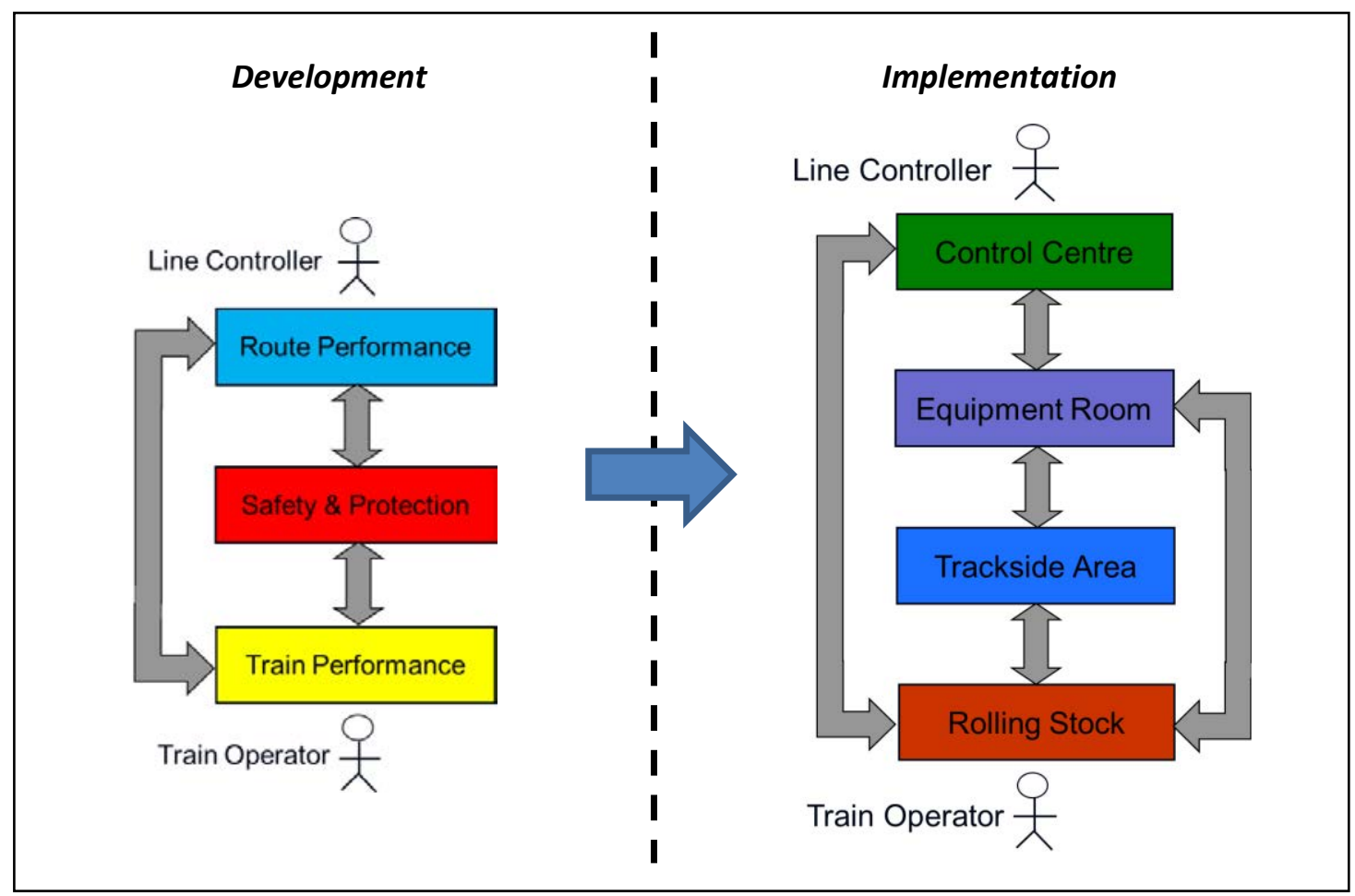

Fig. 4-5 RCS Development \& Implementation

The challenge with developing RCS systems is keeping track of the development of the system from conception through to implementation. This can be further complicated by the fact that we must develop the system based on requirements using a functional model and then implement it using a physical model. What I propose is a simple coding system that allows solutions to requirements to be tracked to individual products easily throughout the complete development and delivery lifecycle.

Firstly, with the functional model, we identify each layer by a single unique letter as shown in Fig. 4-6.

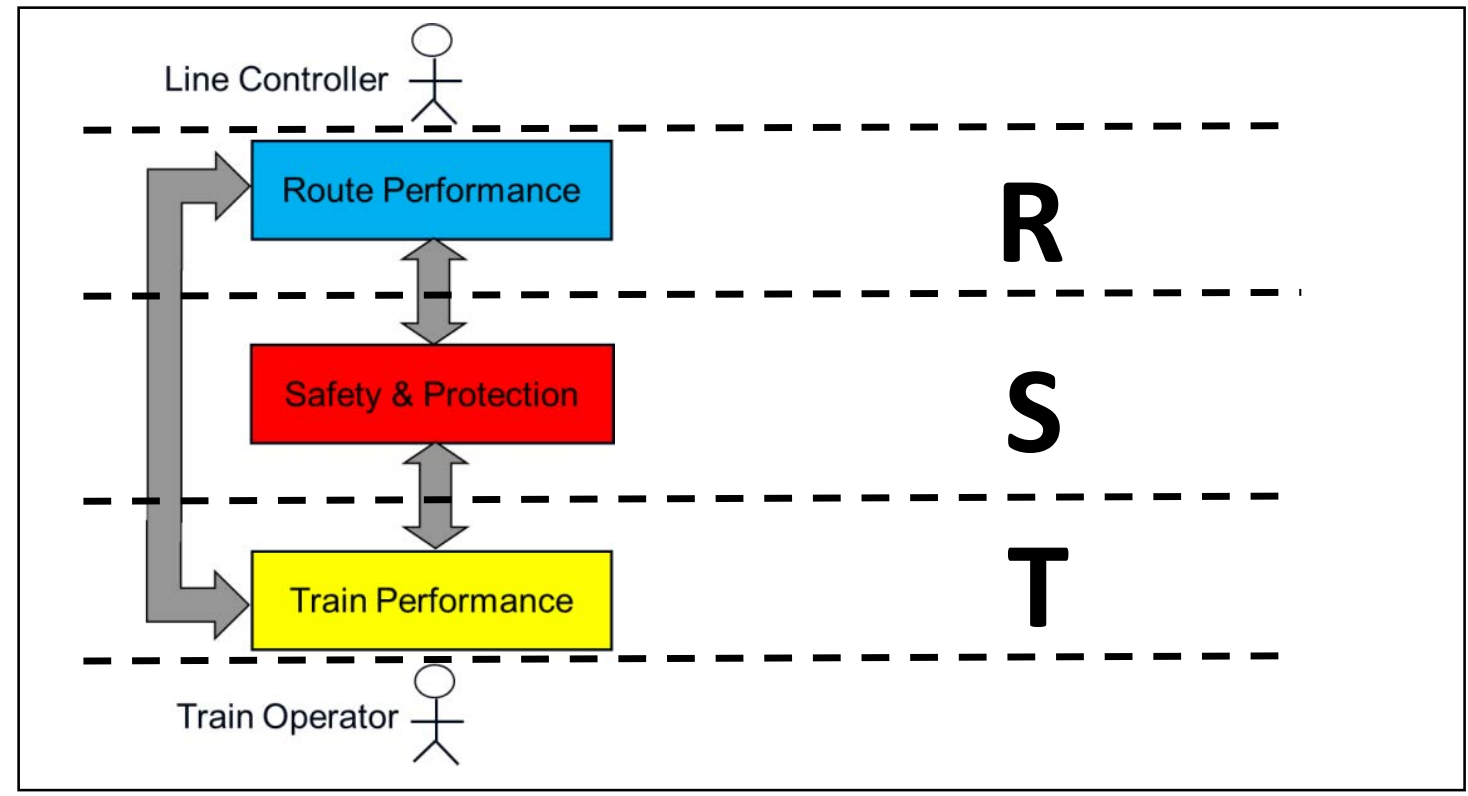

Fig. 4-6 RCS Functional Sub-System Identification 
We can now easily label all our requirements with $\mathrm{R}, \mathrm{S}$ or $\mathrm{T}$ depending on what layer they relate to. For example, if Requirement 1 is "System shall ensure safe separation of trains" then we would label this $1 \mathrm{~S}$ as it is a Safety requirement. If Requirement 2 is "System shall route trains automatically" then we label that $2 \mathrm{R}$ as it is Route Performance, etc.

When we come to the physical model, we likewise label this with a single letter to represent each location, as shown in Fig. 4-7.

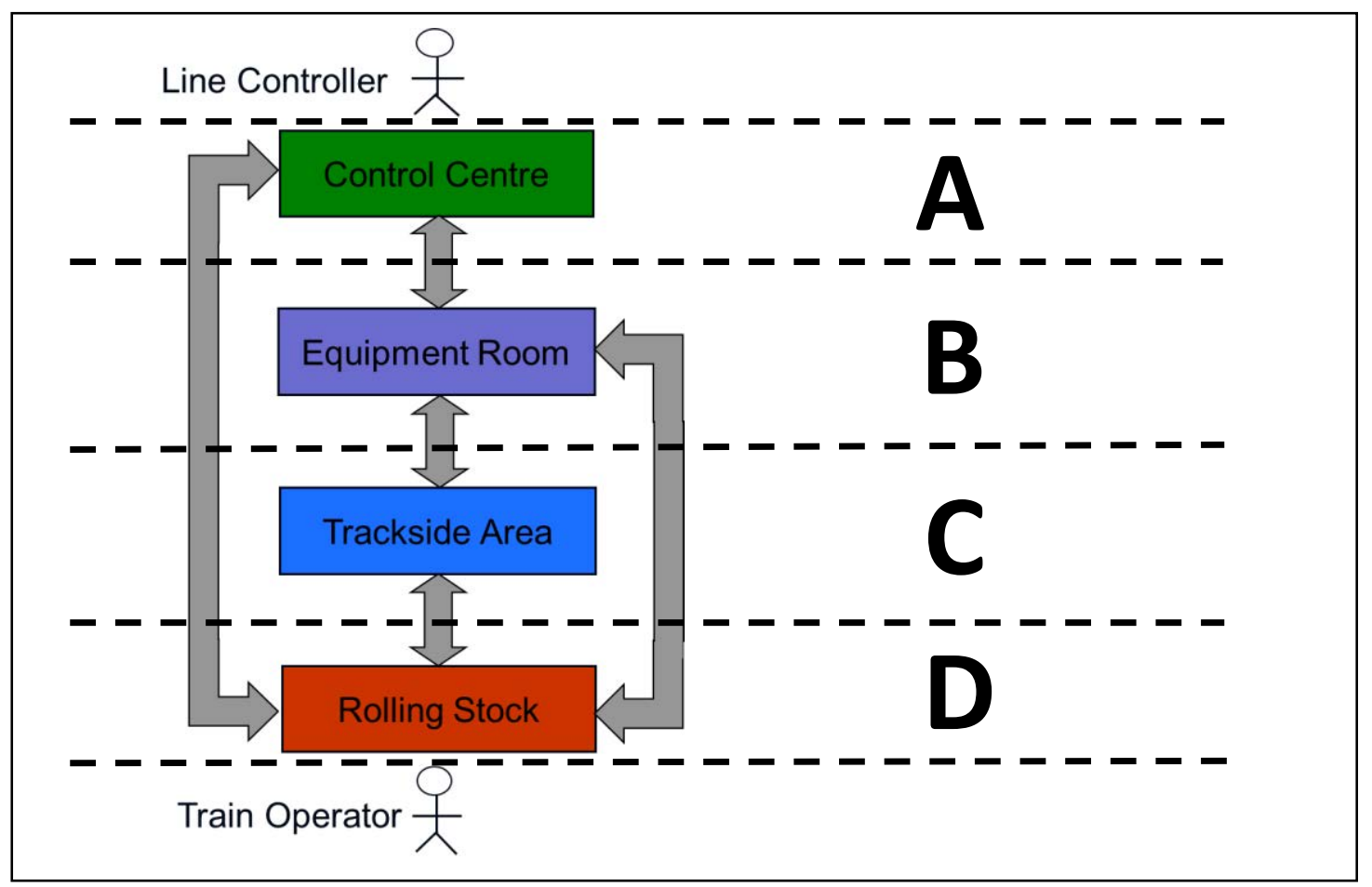

Fig. 4-7 RCS Physical Sub-System Identification

This enables us to now keep track of all sub-systems and products that will make up the completed system architecture and we can combine these with the functional model requirements to determine what functional layer individual products belong to and even what requirements they are fulfilling.

Generally, there are a finite number of relationships between the functional layers and the physical locations. These are shown in Table 4-1.

\begin{tabular}{|l|l|l|l|l|}
\hline & A & B & C & D \\
\hline $\mathbf{R}$ & X & X & & \\
\hline S & X & X & X & X \\
\hline $\mathbf{T}$ & X & & X & X \\
\hline
\end{tabular}

Table 4-1 Possible Physical Locations of RCS Functional Sub-Systems

For examples:

- An interlocking system could be located in an equipment room and be part of the Safety Layer, so would be labelled SB.

- A traffic management system would be part of Route Performance and located in the control centre, so would be labelled RA.

- The ATO box would of course be located on the rolling stock and be part of Train Performance, so would be labelled TD. 


\section{Specific RCS Systems}

This Chapter will explore how the main types of RCS, as defined in Section 1.7, can be mapped onto the generic system model developed in Chapter 4.

\subsection{Conventional Signalling}

The main sub-system elements of conventional signalling (as defined in Section 1.7.1) are the following

- The Operational Control System (OCS)

- The Interlocking (Inx)

- Train (and points) Detection (TD)

- Automatic Train Protections (ATP)

- Signals

Since the OCS is the Line Controller's main interface and is used to route the trains around the network, it is clearly part of Route Performance.

The Inx, TD and ATP are all elements that ensure the safety of the train path and prevent the train from carrying out an unsafe movement. They are therefore all part of Safety \& Protection.

As the signals are the means of informing the Train Operator about their permitted movement (and hence the Train Operator's primary interface to the RCS system), they are part of Train Performance.

We can therefore map the main functional elements for conventional signalling onto the generic model as shown in Fig. 5-1.

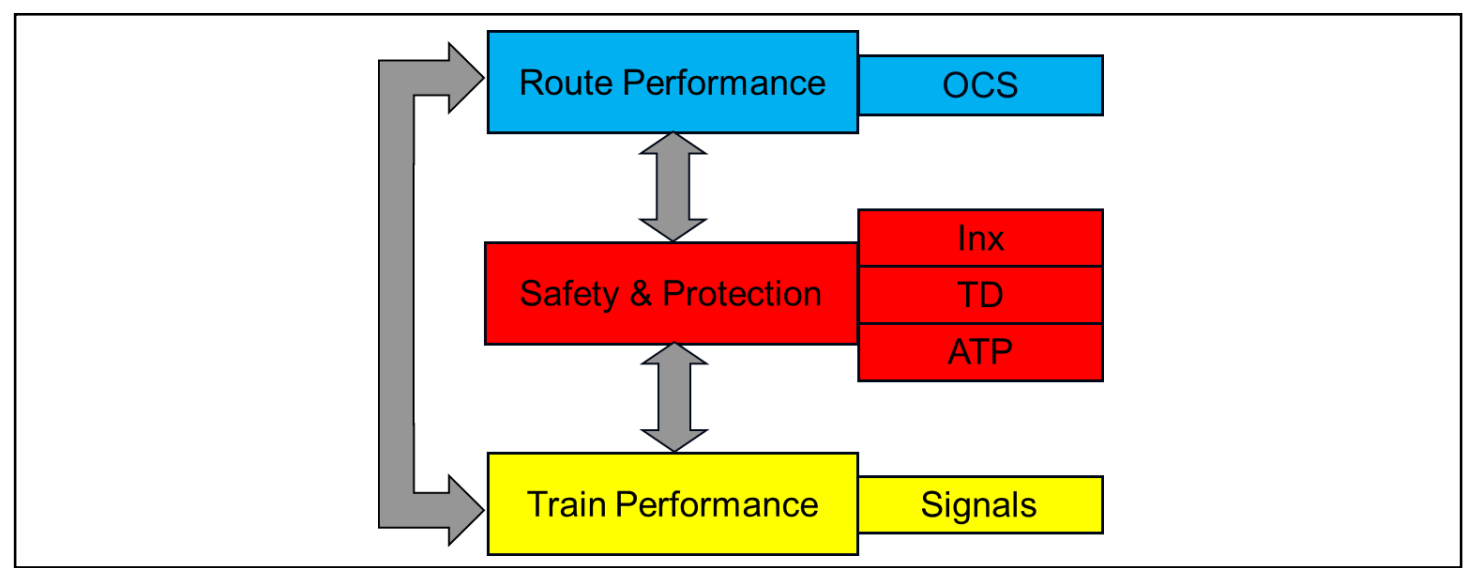

Fig. 5-1 Conventional Signalling Functional Sub-systems

If we then repeat this exercise for the physical model, we can see where these products are (usually) implemented on the railway, as shown in Fig. 5-2. 


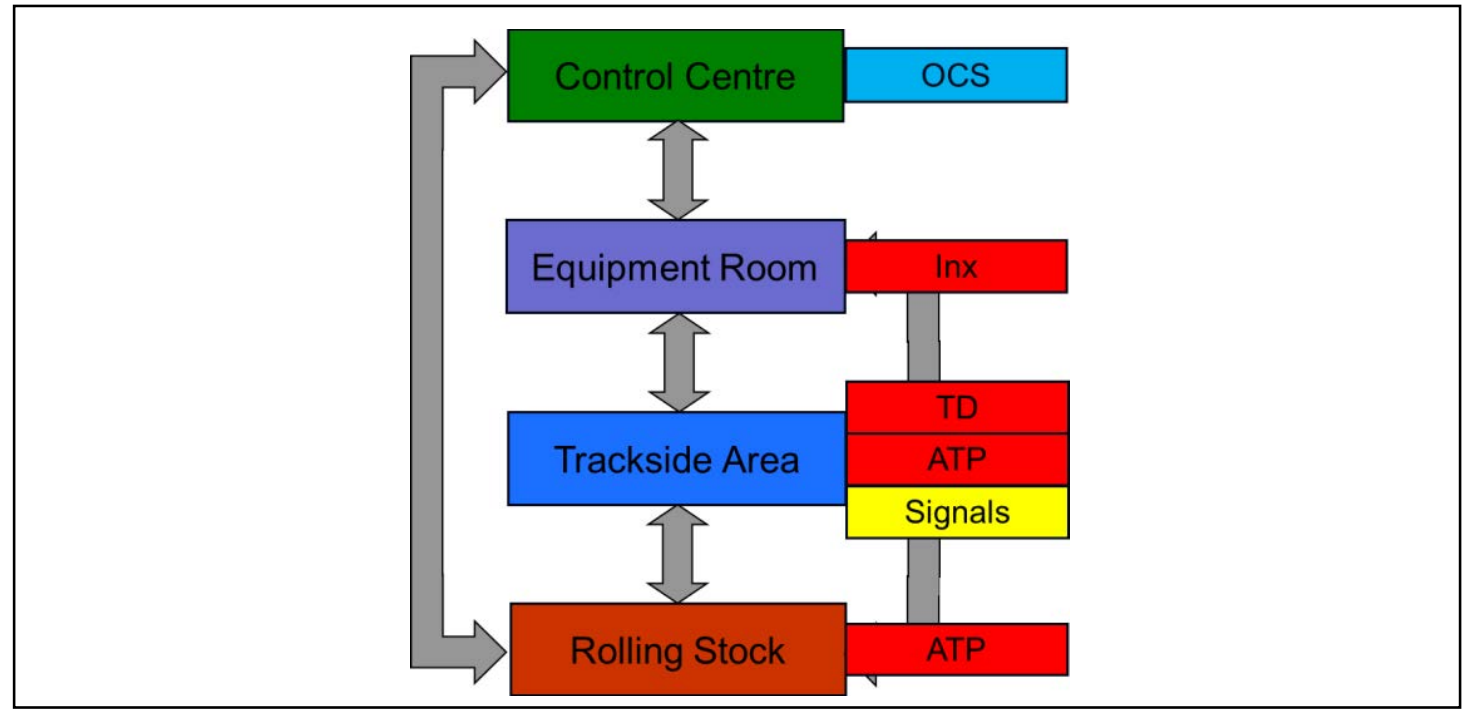

Fig. 5-2 Conventional Signalling Sub-System Physical Locations

From these two models, we can extrapolate the system flow and the products that make up each individual sub-system for generic Conventional Signalling in relation to locations, as shown in Fig. 5-3.

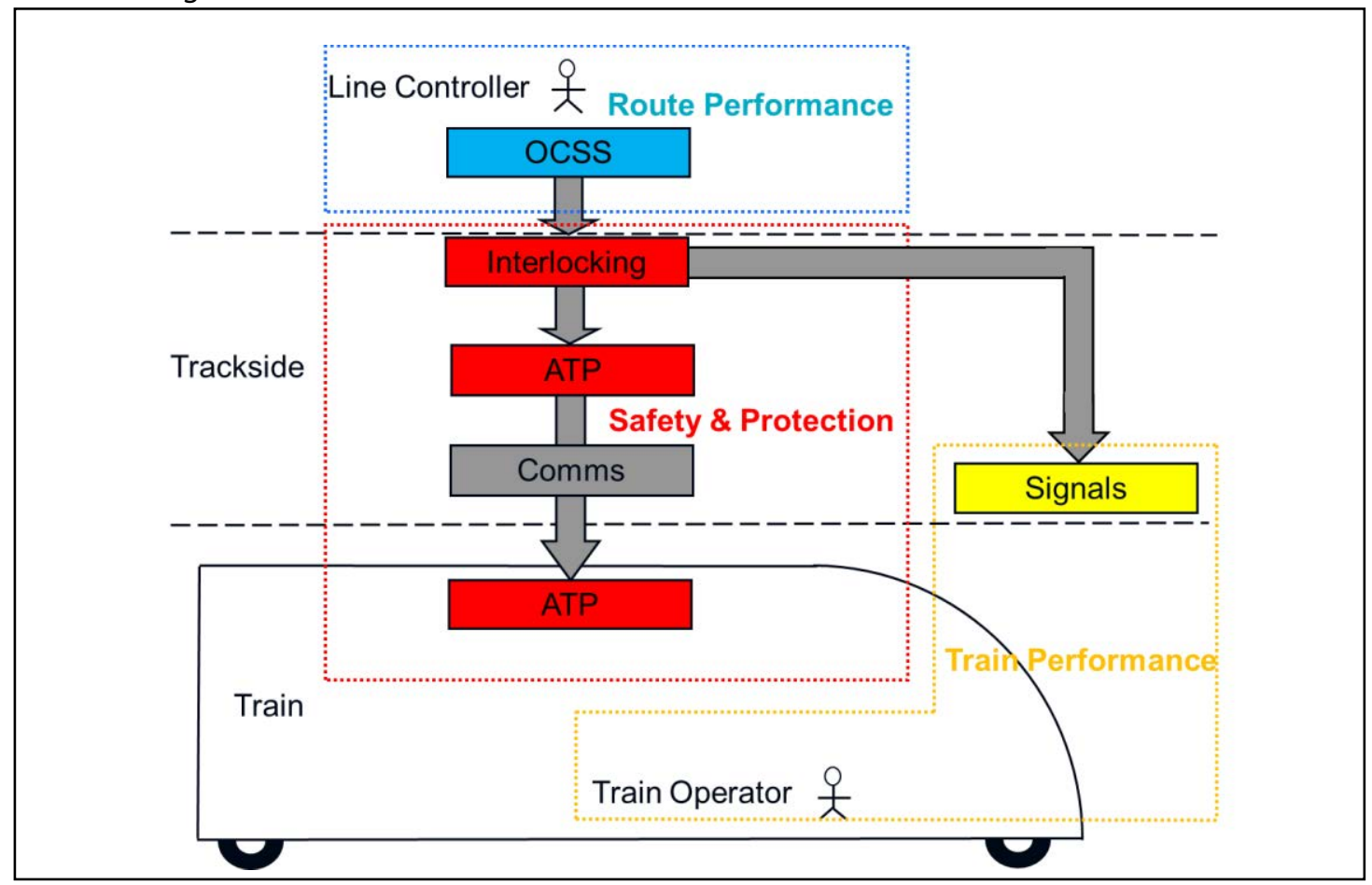

Fig. 5-3 Conventional Signalling System Flow

This then leads to the location map shown in Table 5-1 for Conventional Signalling.

\begin{tabular}{|l|l|l|l|l|}
\hline & A & B & C & D \\
\hline $\mathbf{R}$ & OCS & & ATP(lineside) & ATP(on-board) \\
\hline $\mathbf{S}$ & & In $\mathbf{X}$ & \\
\hline $\mathbf{T}$ & & & Signals & \\
\hline
\end{tabular}

Table 5-1 Conventional Signalling Location Map 
We can therefore define these subsystems with the following suffixes to simultaneously identify their location and functionality:

- OCS-RA

- $\quad$ Inx-SB

- $\quad$ ATP(lineside)-SC

- TD-SC

- $\quad A T P(o n-b o a r d)-S D$

- Signal-TC

\subsection{CBTC}

The main sub-system elements of full moving block CBTC (as defined in Section 1.7.2) are the following:

- Automatic Train Supervision (ATS)

- Automatic Train Control (ATC) which consists of:

- Automatic Train Protection (ATP)

- Automatic Train Operation (ATO)

- Train (and points) Detection (TD)

The ATS automates and regulates the network service as part of the control system, so is therefore part of Route Performance.

The ATC can be thought of as the central infrastructure element of the system (usually located in an equipment room) that works with the TD to determine that trains are safe to move. Both of these elements are therefore part of Safety \& Protection.

The ATP is the on-board element of the system that ensures the train does not overstep its authority. It is therefore also part of Safety \& Protection.

The ATO is responsible for driving the train between designated stopping points; therefore it is part of Train Performance.

We can therefore map the main functional elements of full moving block CBTC onto the generic system model as shown in Fig. 5-4.

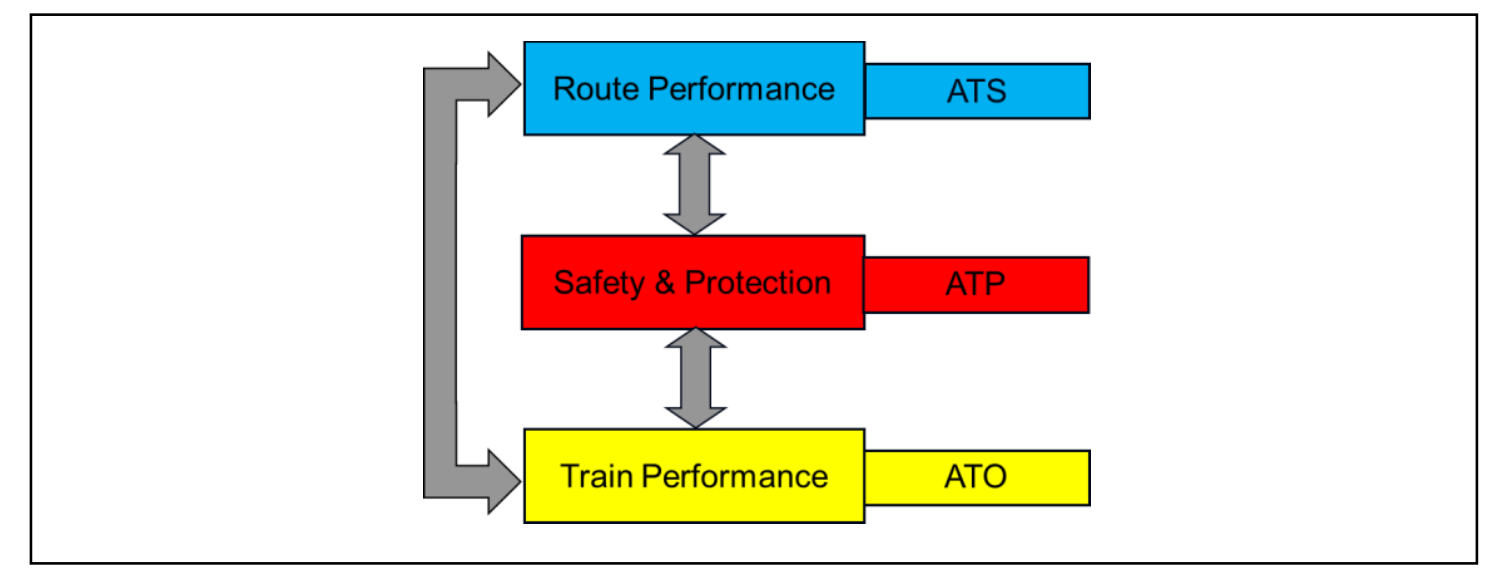

Fig. 5-4 CBTC Functional Sub-systems 
If we then repeat this exercise for the physical model, we can see where these products are (usually) implemented on the railway, as shown in Fig. 5-5.

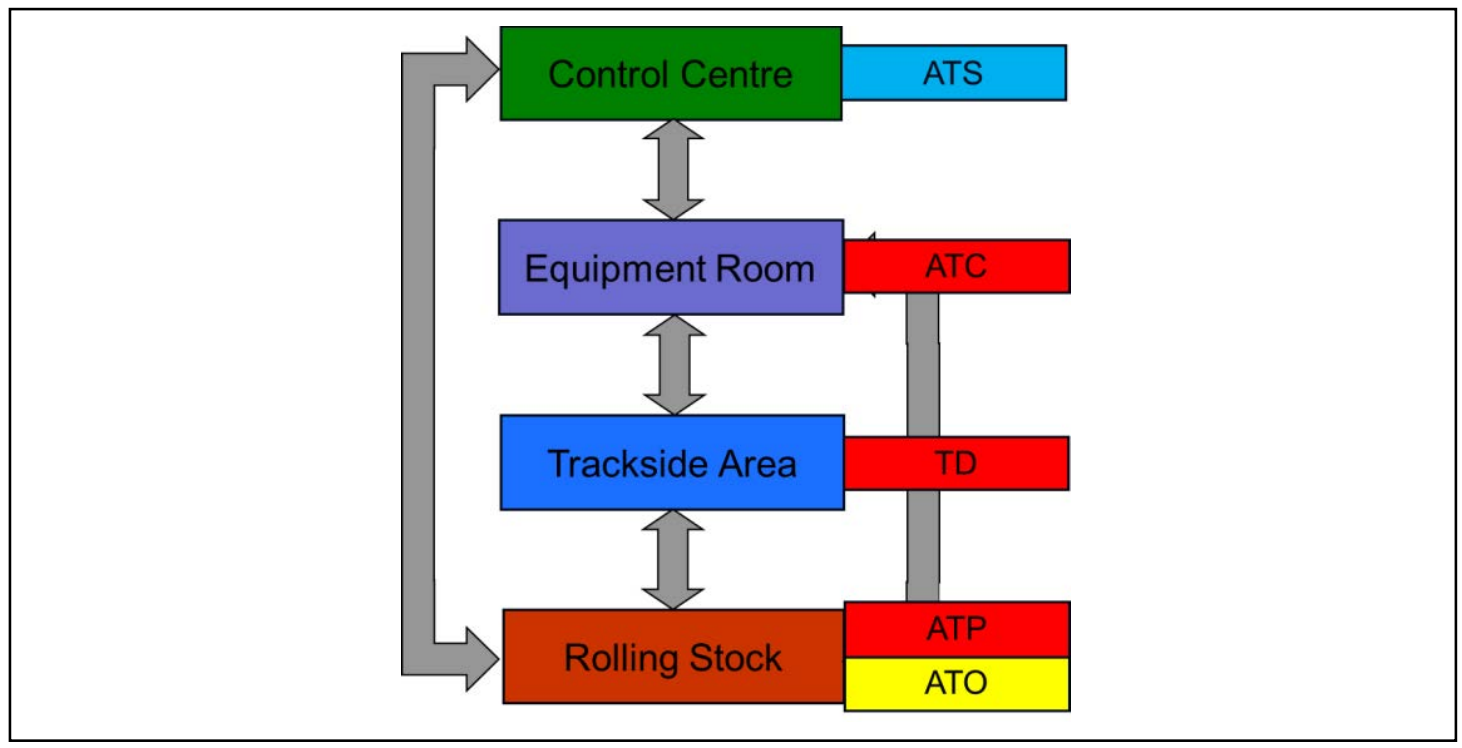

Fig. 5-5 CBTC Sub-System Physical Locations

From these two models, we can extrapolate the system flow and the products that make up each individual sub-system for a generic CBTC system in relation to locations as shown in Fig. 5-6.

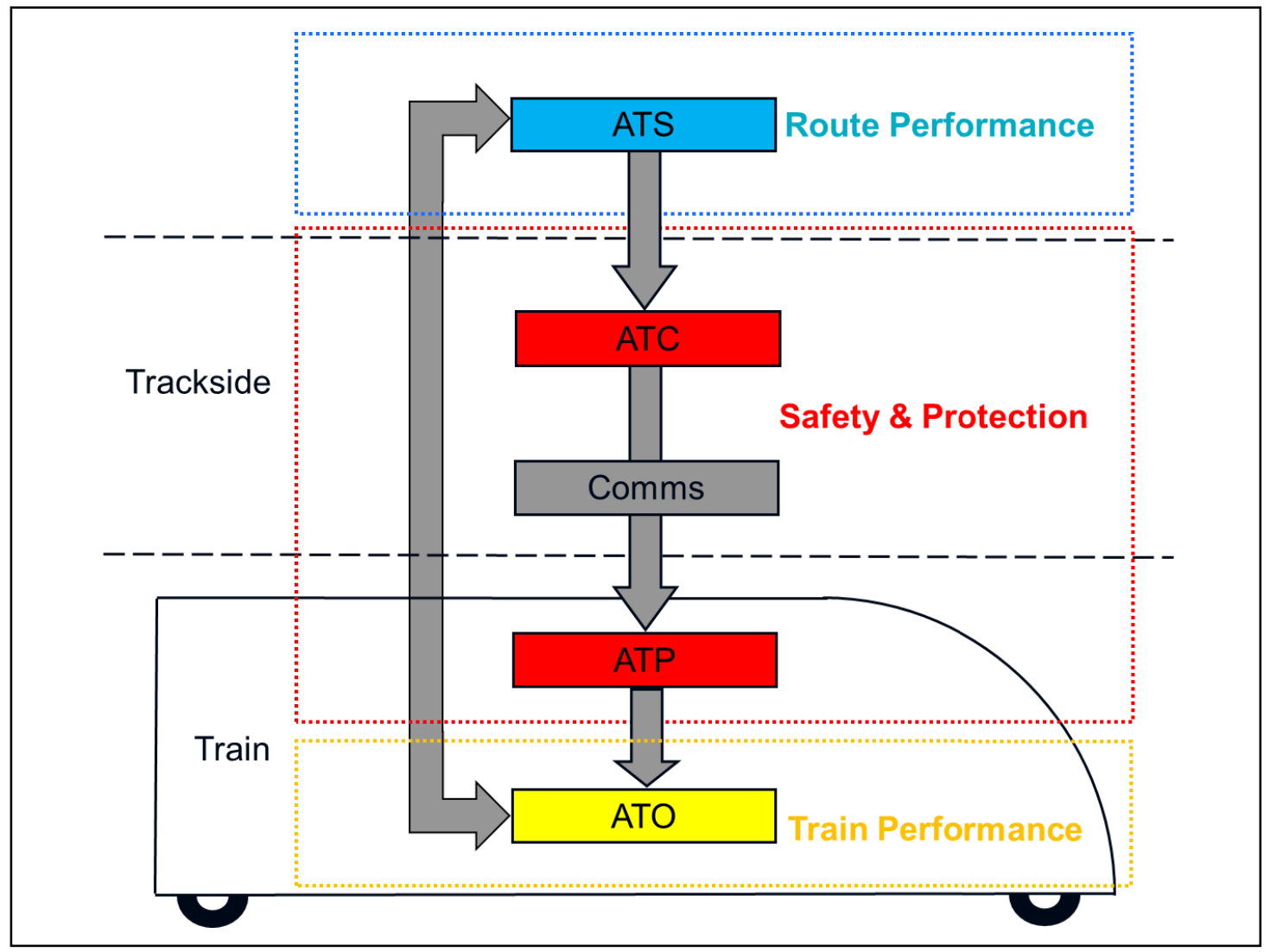

Fig. 5-6 CBTC System Flow

This then leads to the location map shown in Table 5-2 for CBTC. 


\begin{tabular}{|l|l|l|l|l|}
\hline & A & B & C & D \\
\hline $\mathbf{R}$ & ATS & & & \\
\hline $\mathbf{S}$ & & ATC & TD & ATP \\
\hline $\mathbf{T}$ & & & & ATO \\
\hline
\end{tabular}

Table 5-2 CBTC Location Map

Therefore, we can define these subsystems with the following suffixes to simultaneously identify their location and functionality:

- $\quad$ ATS-RA

- ATC-SB

- TD-SC

- $\quad$ ATP-SD

- ATO-TD

\subsection{ERTMS}

The main sub-systems of ERTMS (as defined in Section 1.7.3) are the following:

- European Traffic Management Layer (ETML)

- European Train Control System (ETCS)

- Global System for Mobiles - Railways (GSM-R)

The ETML is very much associated with the operating rules and traffic management of the railway and therefore clearly forms part of Route Performance.

GSM-R defines the wireless Communications for the system and thus forms part of the communications path.

We can therefore map the main functional elements for ERTMS onto the generic model as shown in Fig. 5-7.

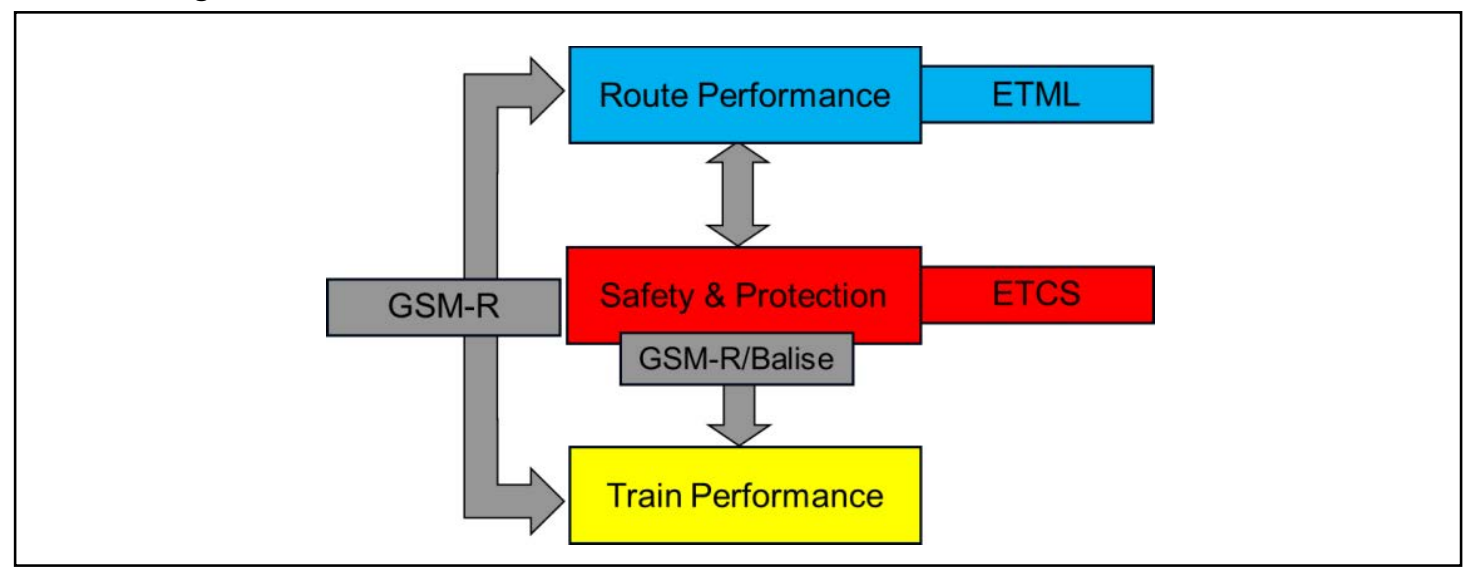

Fig. 5-7 ERTMS Functional Sub-systems

However, this does not easily translate onto the physical architecture due to the number of sub-systems that make up the ETCS system, as well as a number of additional elements that are required for ETCS Levels 1 \& 2. 
Therefore, we must consider the following main elements that make up the ETCS system in order to develop the physical model:

- Balises (fixed and switchable)

- Lineside Encoder Unit (LEU) (for Level 1 only)

- Radio Block Centre (RBC) (for Levels 2 \& 3)

- Driver Machine Interface (DMI)

- European Vital Computer (EVC) (NOTE: for the purposes of this study, this will include all associated systems that make up the ETCS on-board sub-system including GSM-R modems, Balise Readers, Odometer, train interface and Juridical Recorder Units)

We must also consider the following key sub-systems that are required for ETCS Levels 1 \& 2, but are not within the scope of ETCS itself:

- Interlocking (Inx)

- Train (and points) Detection (TD)

The Inx and TD perform the same safety-critical functionality in ETCS Levels 1 \& 2 as they perform for conventional signalling and are thus part of Safety \& Protection.

Balises are effectively another communication channel (though in their case unidirectional) from the infrastructure to the train.

Both the LEU and RBC take the safety-critical data and transform it into a form that can be transmitted to the train and they are therefore also part of Safety \& Protection.

As the EVC carries out the safety-critical on-board functions (including speed supervision and intervention), it too is part of Safety \& Protection.

As the DMI informs the Train Operator about their permitted movement (and hence the Train Operator's primary interface to the RCS system), it is part of Train Performance.

This results in three specific functional models of ERTMS for ETCS levels 1, 2 and 3 as shown in Fig. 5-8, Fig. 5-9 \& Fig. 5-10.

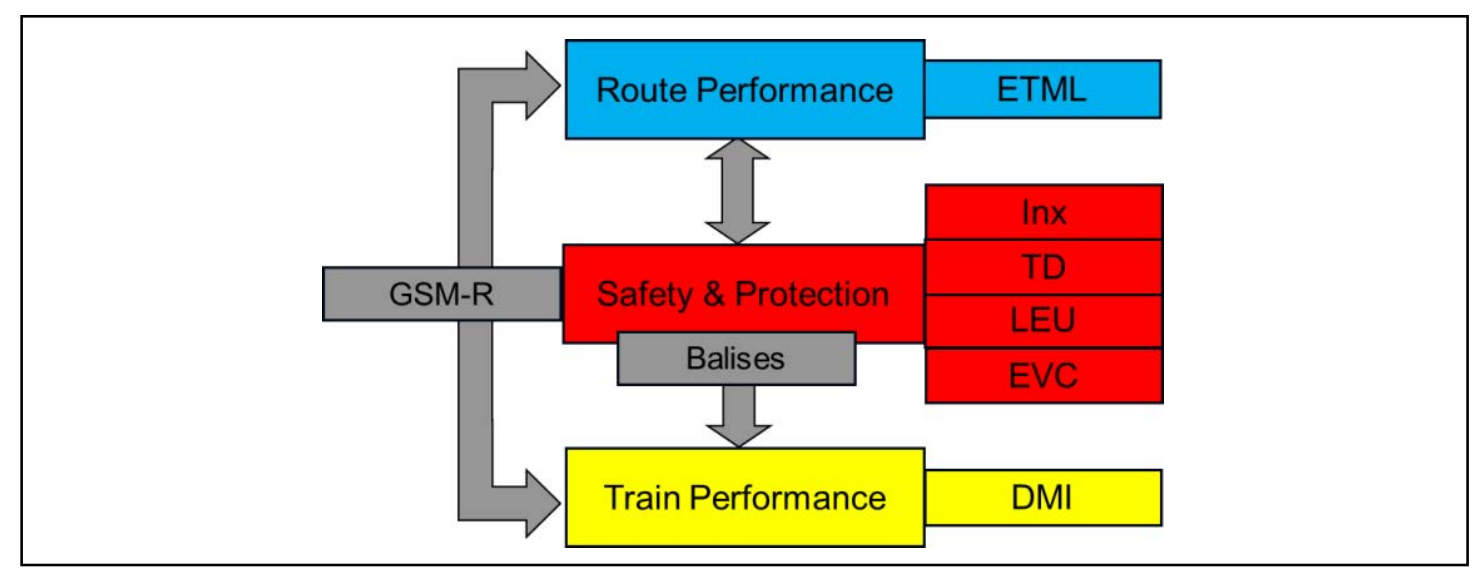

Fig. 5-8 ERTMS Functional Sub-systems (ETCS Level 1) 


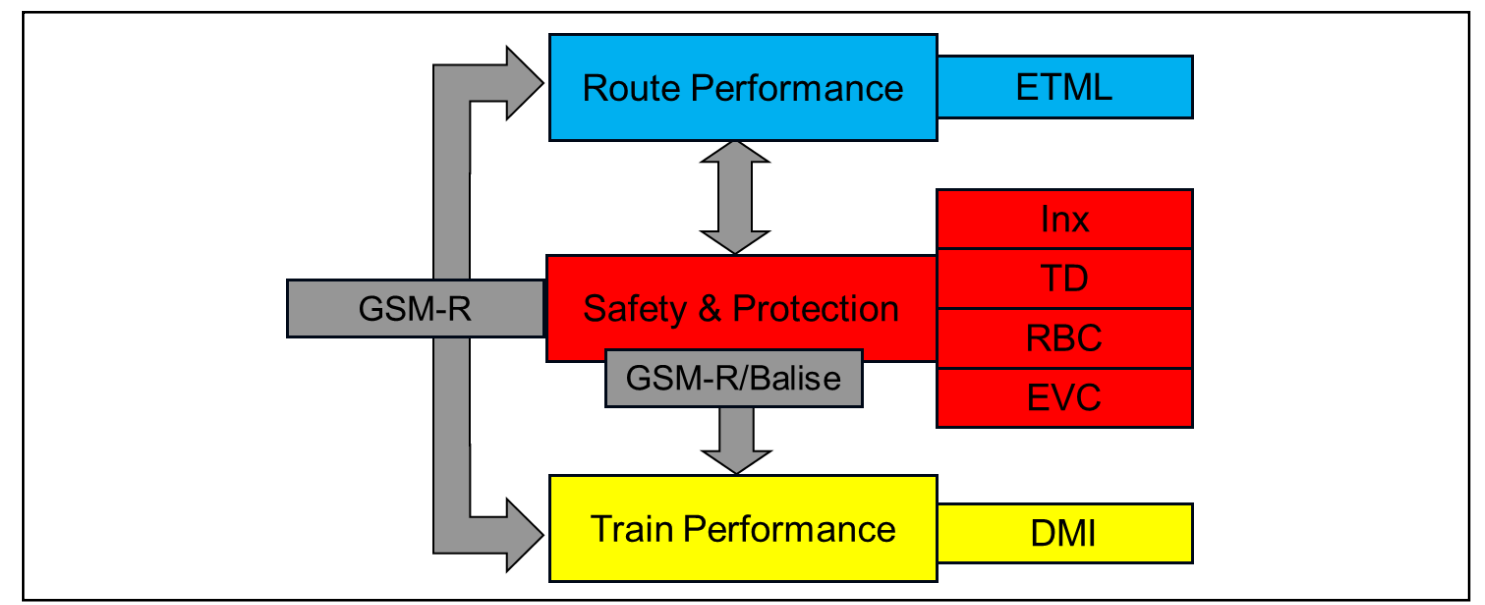

Fig. 5-9 ERTMS Functional Sub-systems (ETCS Level 2)

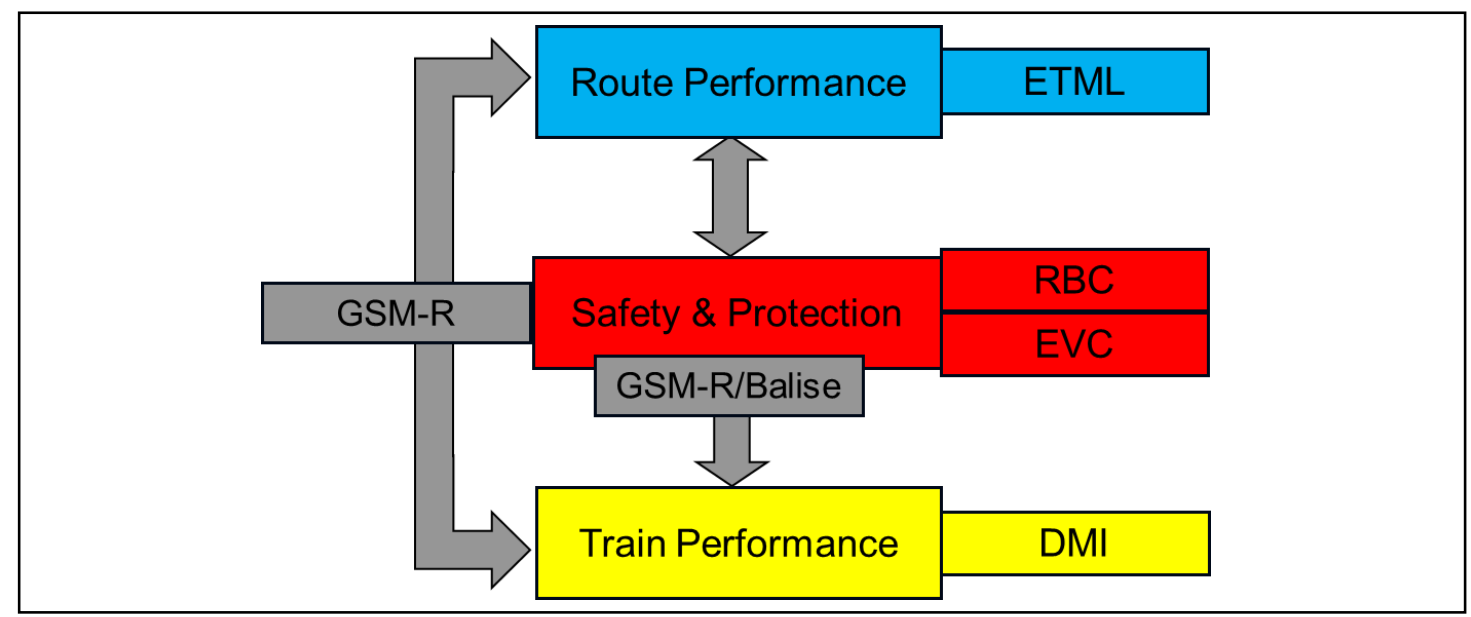

Fig. 5-10 ERTMS Sub-System Physical Locations (ETCS Level 3)

We can now develop three separate physical models of where these products are (usually) implemented on the railway for the three ETCS Levels of ERTMS as shown in Fig. 5-11, Fig. 5-12 and Fig. 5-13.

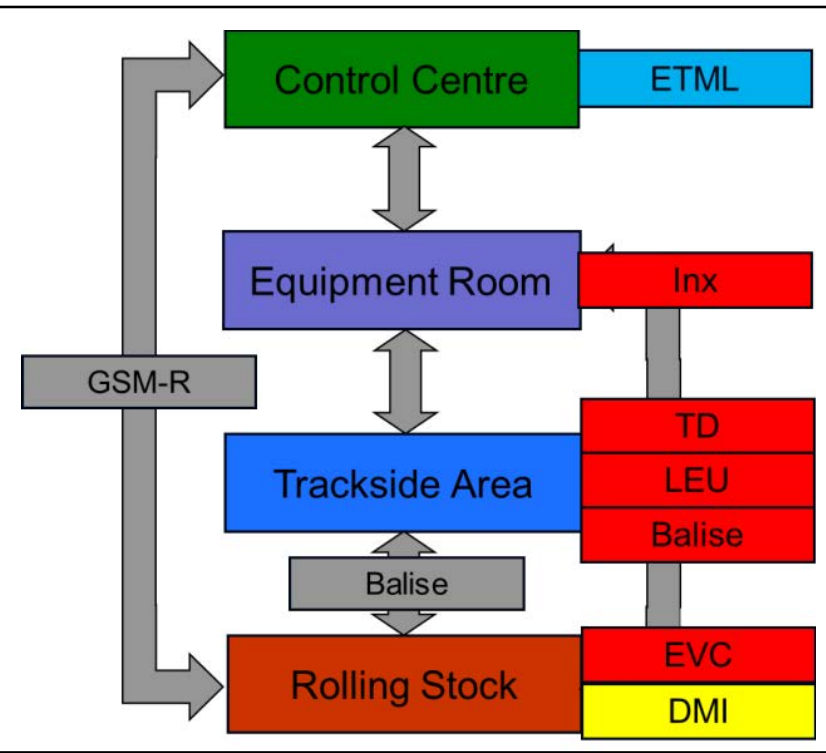

Fig. 5-11 ERTMS Sub-System Physical Locations (ETCS Level 1) 


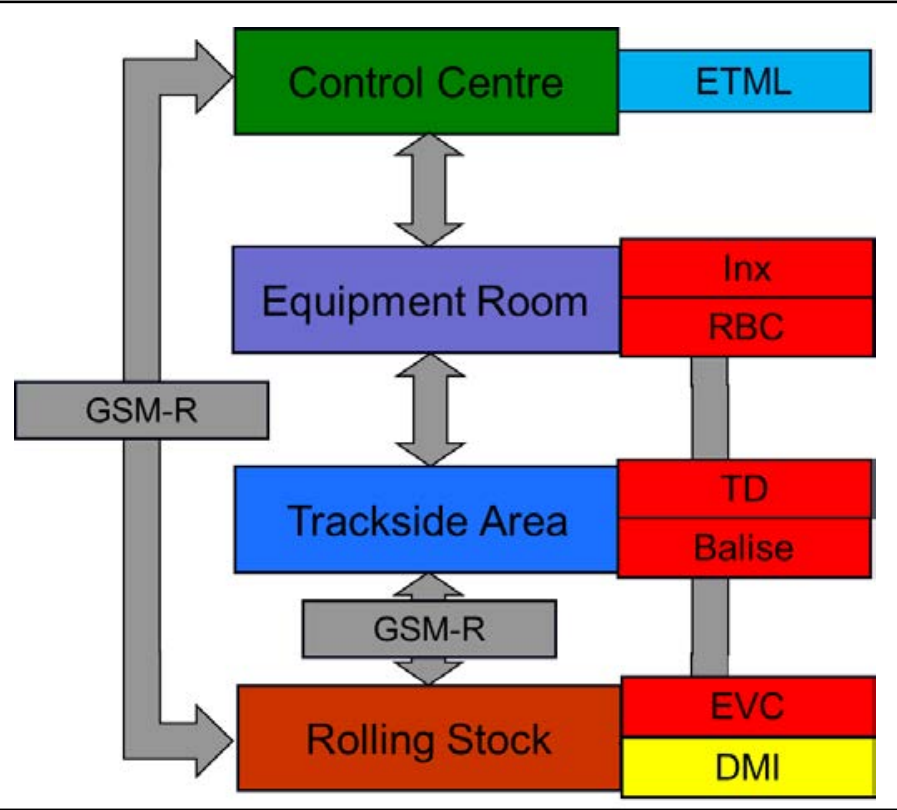

Fig. 5-12 ERTMS Sub-System Physical Locations (ETCS Level 2)

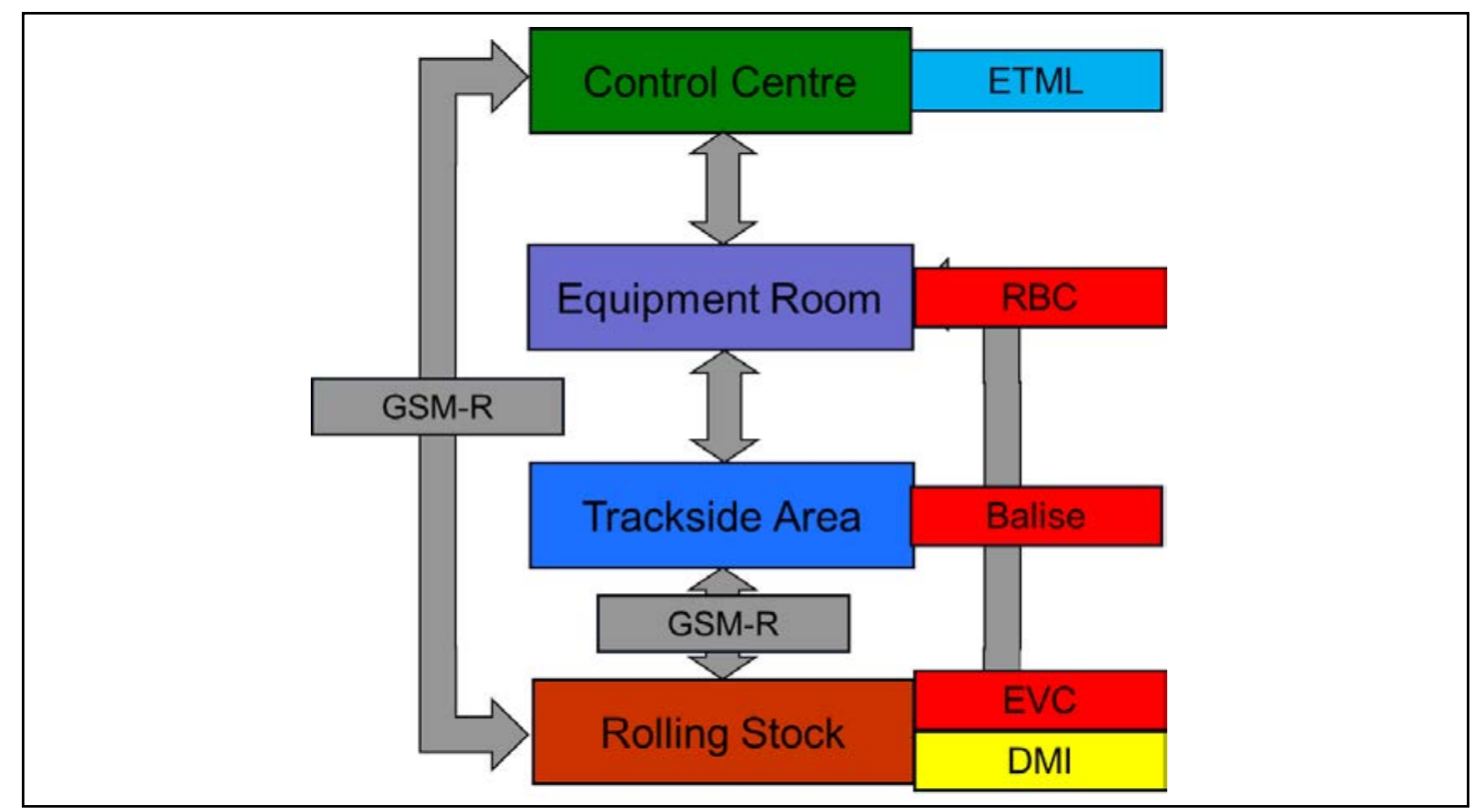

Fig. 5-13 ERTMS Sub-System Physical Locations (ETCS Level 3)

Notice how balises are divided into two types:

- Switchable Balises (used in Level 1 only) are purely a communication channel

- Fixed balises are a critical absolute position reference point and are therefore an intrinsic part of the Safety \& Protection layer

From these four models, we can extrapolate the system flow and the products that make up each individual sub-system for ERTMS/ETCS Levels 1, $2 \& 3$ in relation to locations as shown in Fig. 5-14, Fig. 5-15 \& Fig. 5-16. 


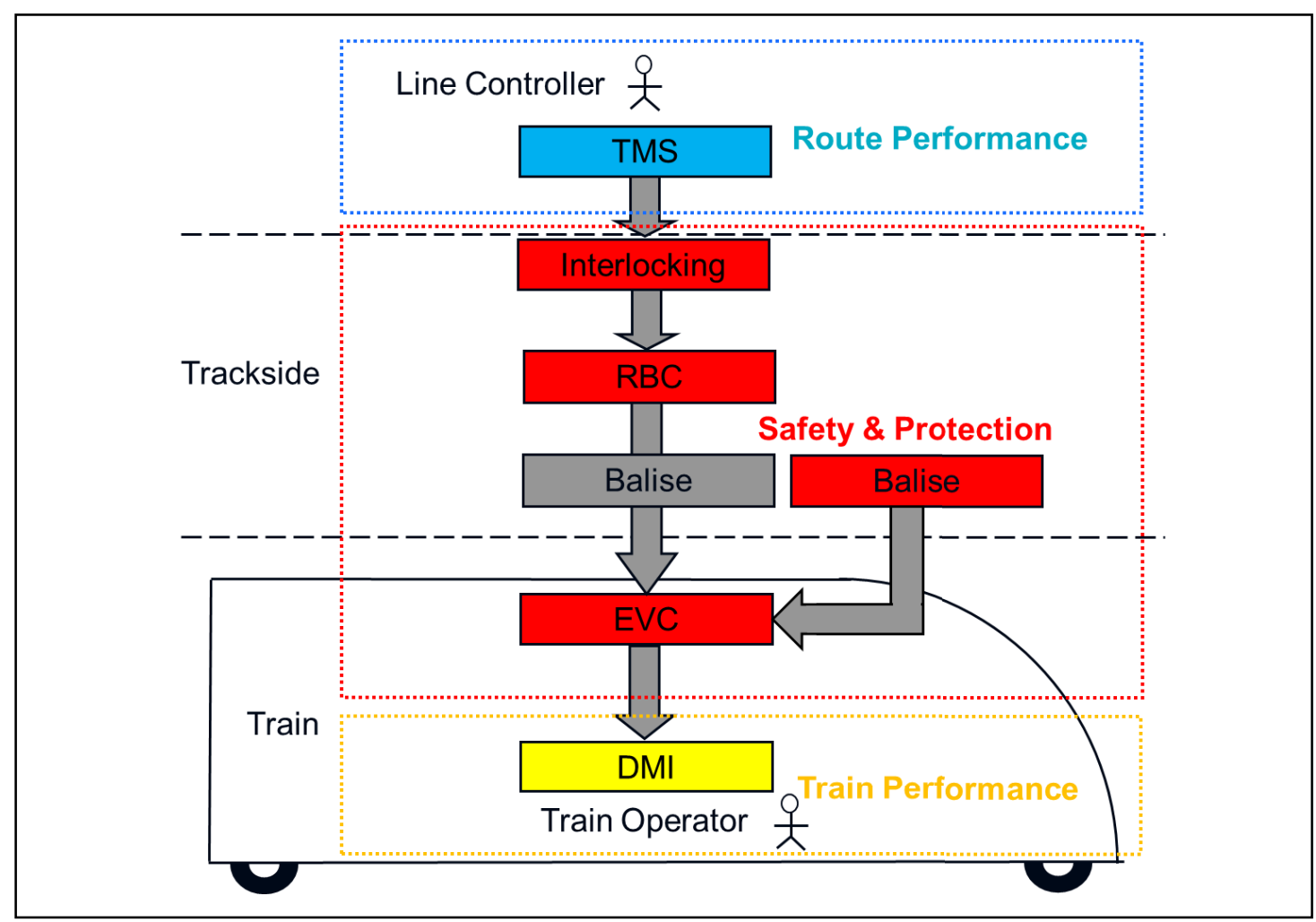

Fig. 5-14 ERTMS System Flow (ETCS Level 1)

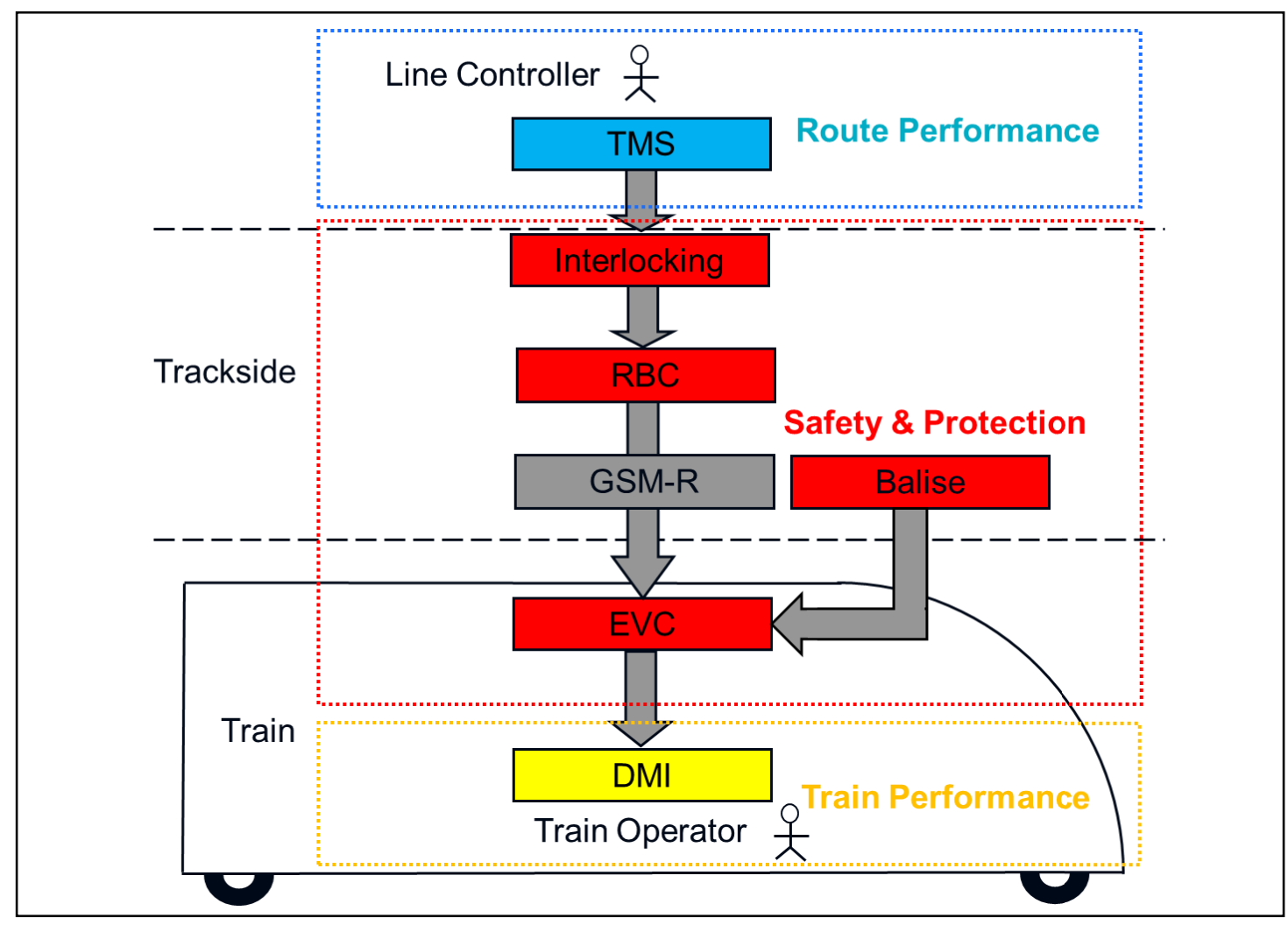

Fig. 5-15 ERTMS System Flow (ETCS Level 2) 


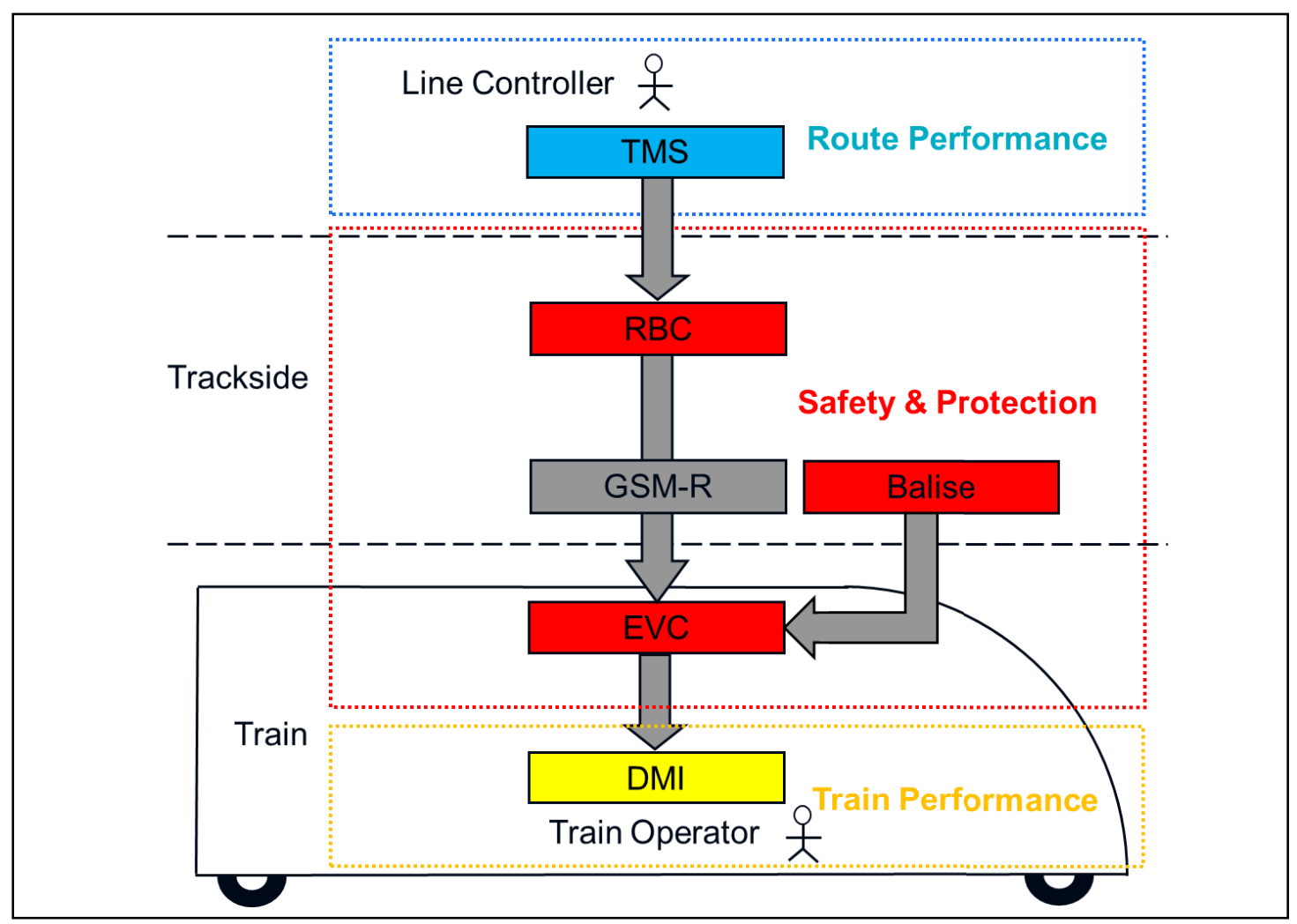

Fig. 5-16 ERTMS System Flow (ETCS Level 3)

This then leads to the location map shown in Table 5-3 for ERTMS.

\begin{tabular}{|l|l|l|l|l|}
\hline & A & B & C & D \\
\hline $\mathbf{R}$ & ETML & & & \\
\hline $\mathbf{S}$ & & Inx & TD & EVC \\
& & RBC & Balise & \\
\hline $\mathbf{T}$ & & & & DEU \\
\hline
\end{tabular}

Table 5-3 ERTMS Location Map

We can therefore define these subsystems with the following suffixes to simultaneously identify their location and functionality:

- ETML-RA

- $\ln x-S B$

- $\mathrm{RBC}-\mathrm{SB}$

- $\quad$ LEU-SB

- TD-SC

- Balise-SC

- EVC-SD

- DMI-TD

\subsubsection{ETCS Implemented With TMS \& C-DAS}

As the ETML layer of ERTMS is currently undefined, it is quite common for operators to utilise commercial 'off-the-shelf' TMS systems (as defined in Section 1.7.5.1) in conjunction with ETCS in order to provide better traffic optimisation. Operators are also starting to 
implement C-DAS systems (as defined in Section 1.7.5.2) to improve the performance reliability of services.

As the TMS is effectively the control system for the railway (responsible for routing, timetabling, etc.) it is clearly part of Route Performance.

C-DAS is all about improving the performance of individual trains, so is therefore part of Train Performance.

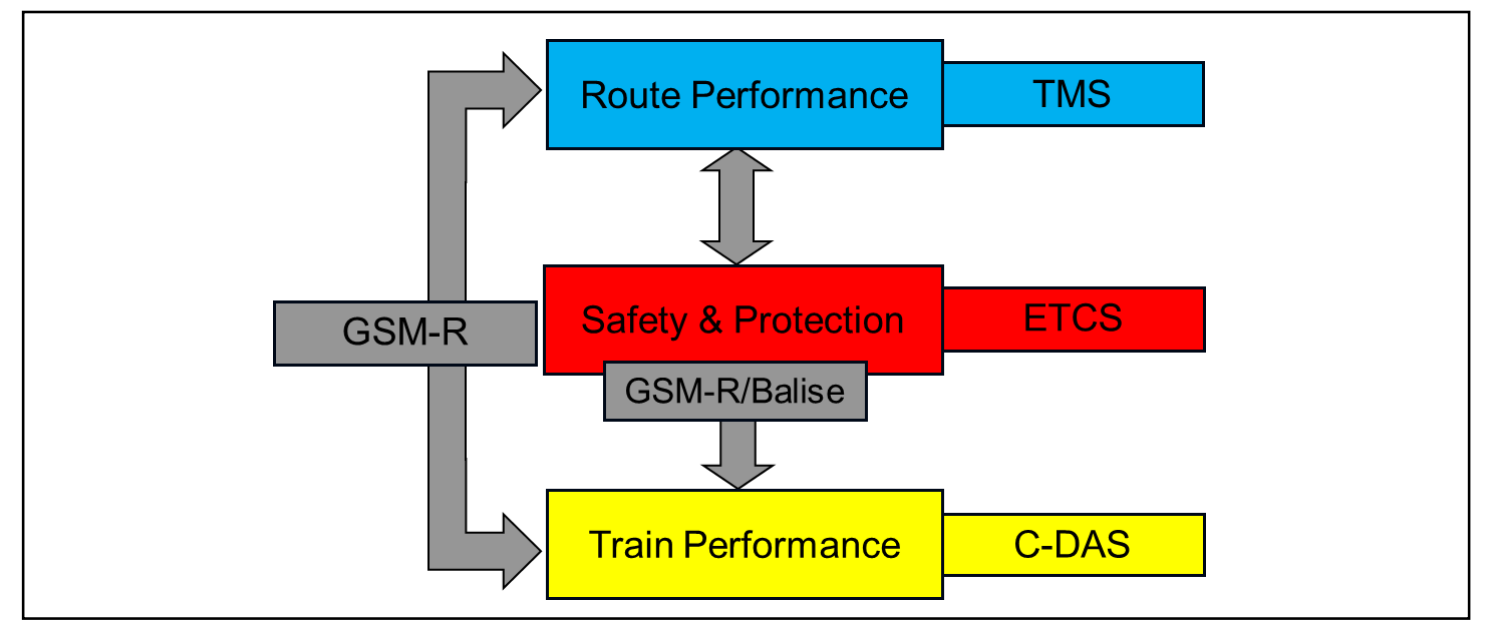

Fig. 5-17 ETCS With TMS \& C-DAS Functional Model

Though these two additional systems can theoretically be implemented with any ETCS Level, we shall utilise ETCS Level 2 as the baseline for the purpose of this example to generate the physical model shown in Fig. 5-19.

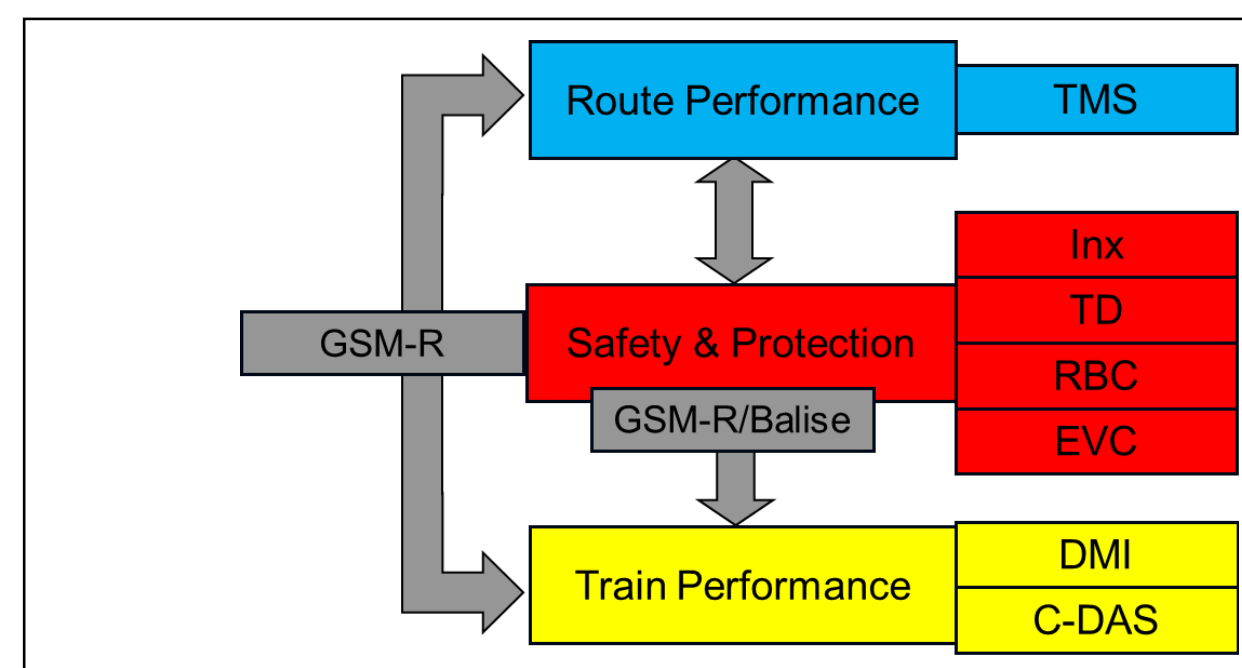

Fig. 5-18 ETCS Level 2 With TMS \& C-DAS Functional Model 


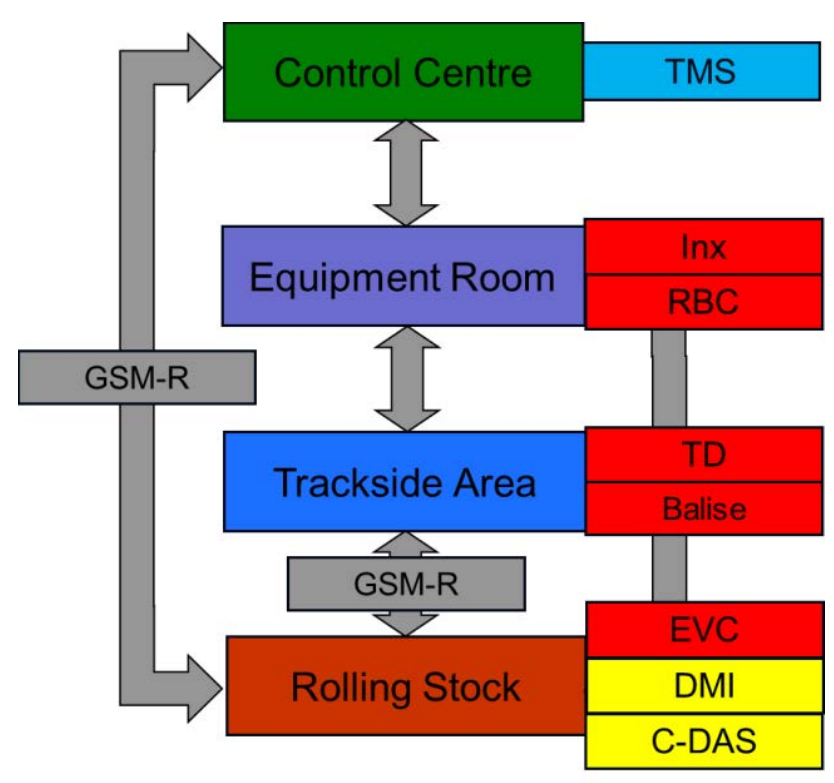

Fig. 5-19 ETCS Level 2 With TMS \& C-DAS Physical Model

We can extrapolate the system flow and the products that make up each individual subsystem for a combined TMS / C-DAS / ETCS Level 2 system in relation to locations as shown in Fig. 5-20.

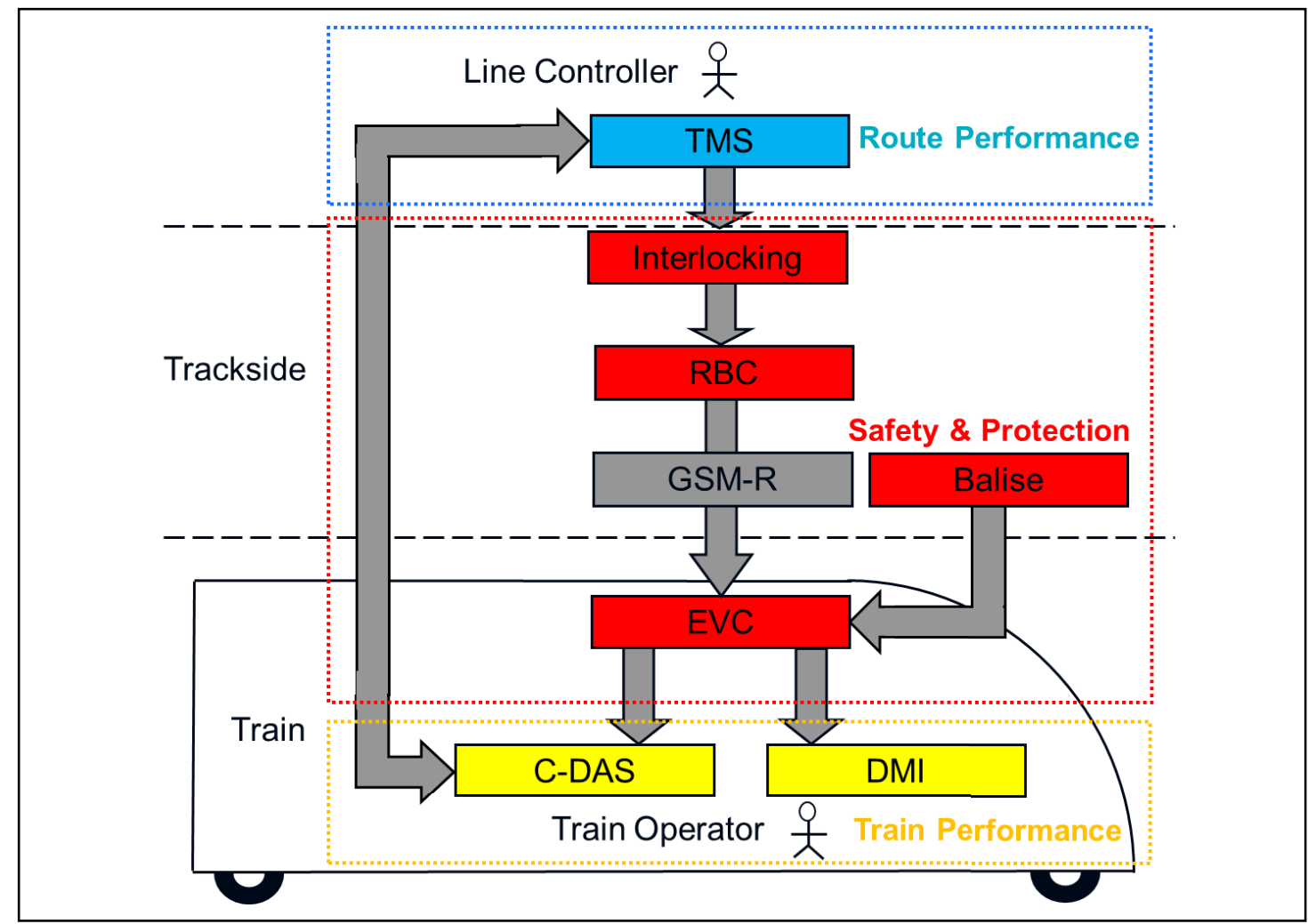

Fig. 5-20 ETCS Level 2 With TMS \& C-DAS System Flow

This then leads to the location map shown in Table 5-4 for a combined TMS / C-DAS / ETCS Level 2 system. 


\begin{tabular}{|c|c|c|c|c|}
\hline & A & B & C & D \\
\hline $\mathbf{R}$ & TMS & & & \\
\hline$S$ & & $\begin{array}{l}\text { Inx } \\
\text { RBC } \\
\text { LEU }\end{array}$ & $\begin{array}{l}\text { TD } \\
\text { Balise }\end{array}$ & EVC \\
\hline$T$ & & & & $\begin{array}{l}\text { DMI } \\
\text { C-DAS }\end{array}$ \\
\hline
\end{tabular}

Table 5-4 ETCS Level 2 With TMS \& C-DAS Location Map

Therefore, we can define these subsystems with the following suffixes to simultaneously identify their location and functionality:

- TMS-RA

- $\operatorname{Inx}-\mathrm{SB}$

- $\mathrm{RBC}-\mathrm{SB}$

- LEU-SB

- TD-SC

- Balise-SC

- EVC-SD

- DMI-TD

- C-DAS-TD

\subsubsection{ETCS Implemented With ATO}

It is possible to implement ATO as an "add-on" to an ETCS system in order to provide consistency of driving style and hence achieve the improved performance that ATO delivers as part of a CBTC system. It is generally assumed that a TMS system will be in-place as part of the system for the ATO to communicate with for its stopping points.

As we know from Section 5.2, the ATO is part of Train Performance; therefore an implementation of ATO with an ETCS Level 2 system is almost identical to the implementation with C-DAS shown in Section 5.3.1, as shown in Fig. 5-21, Fig. 5-22, Fig. 5-23 \& Fig. 5-24.

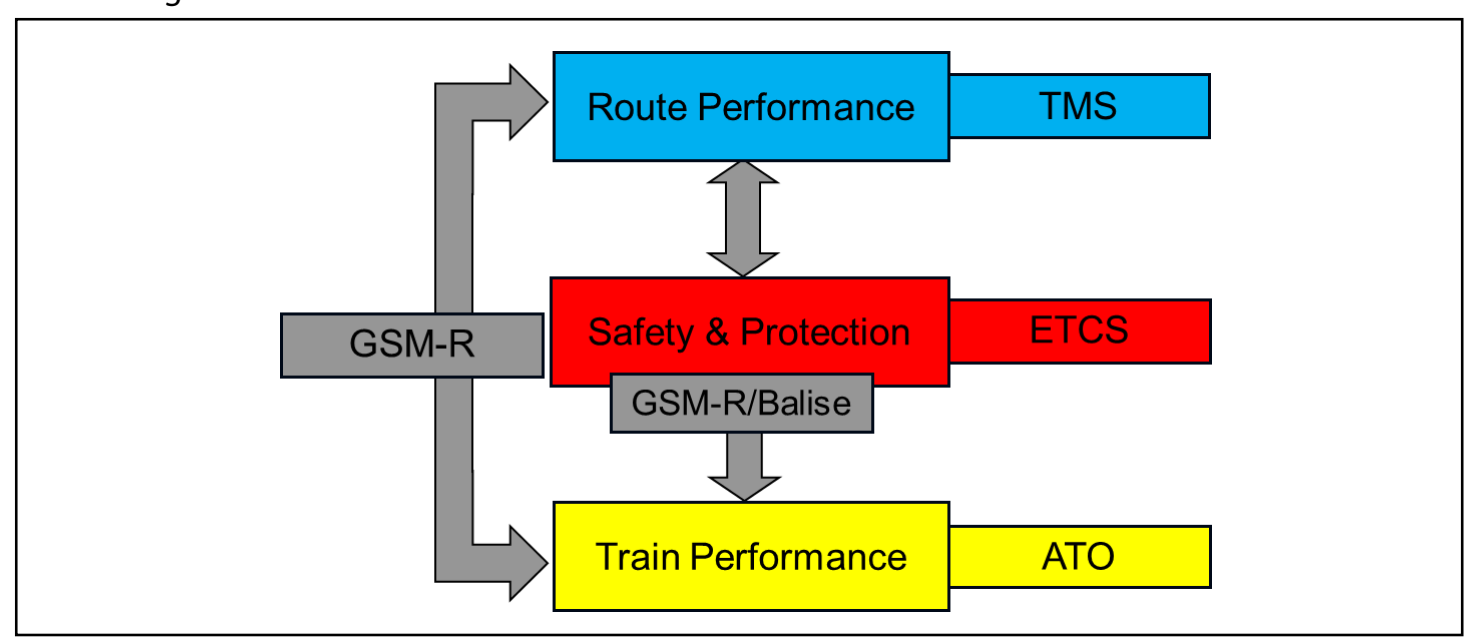

Fig. 5-21 ETCS With ATO Functional Model 


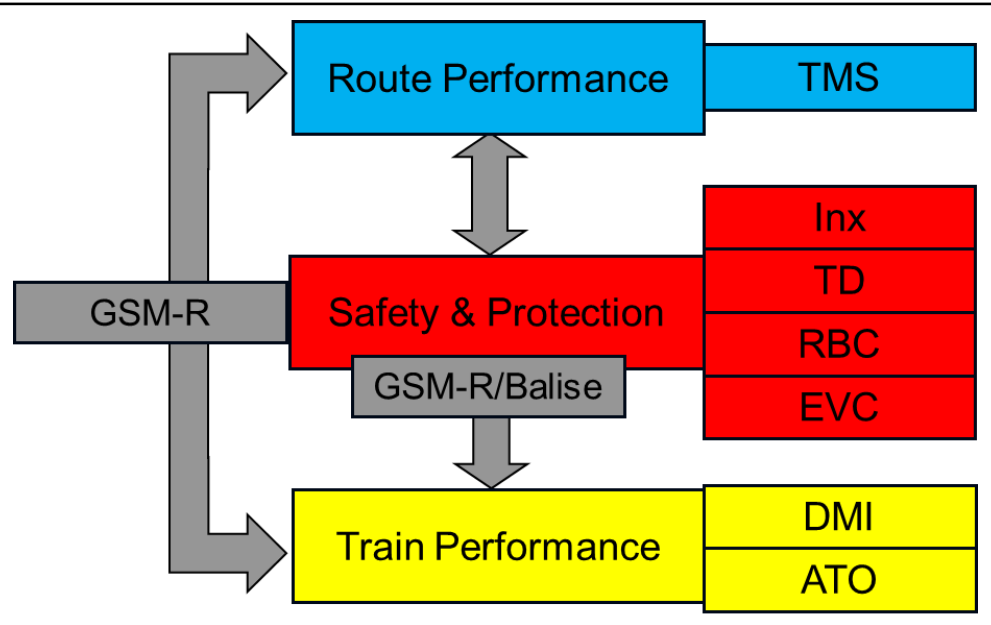

Fig. 5-22 ETCS Level 2 With ATO Functional Model

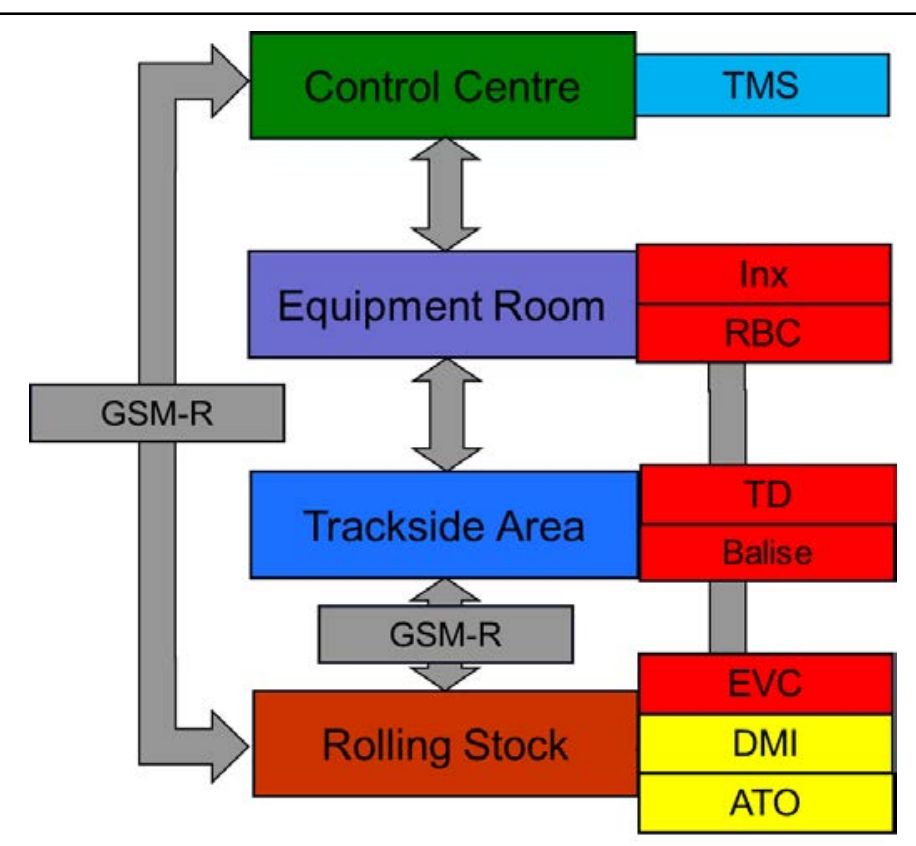

Fig. 5-23 ETCS Level 2 With ATO Physical Model 


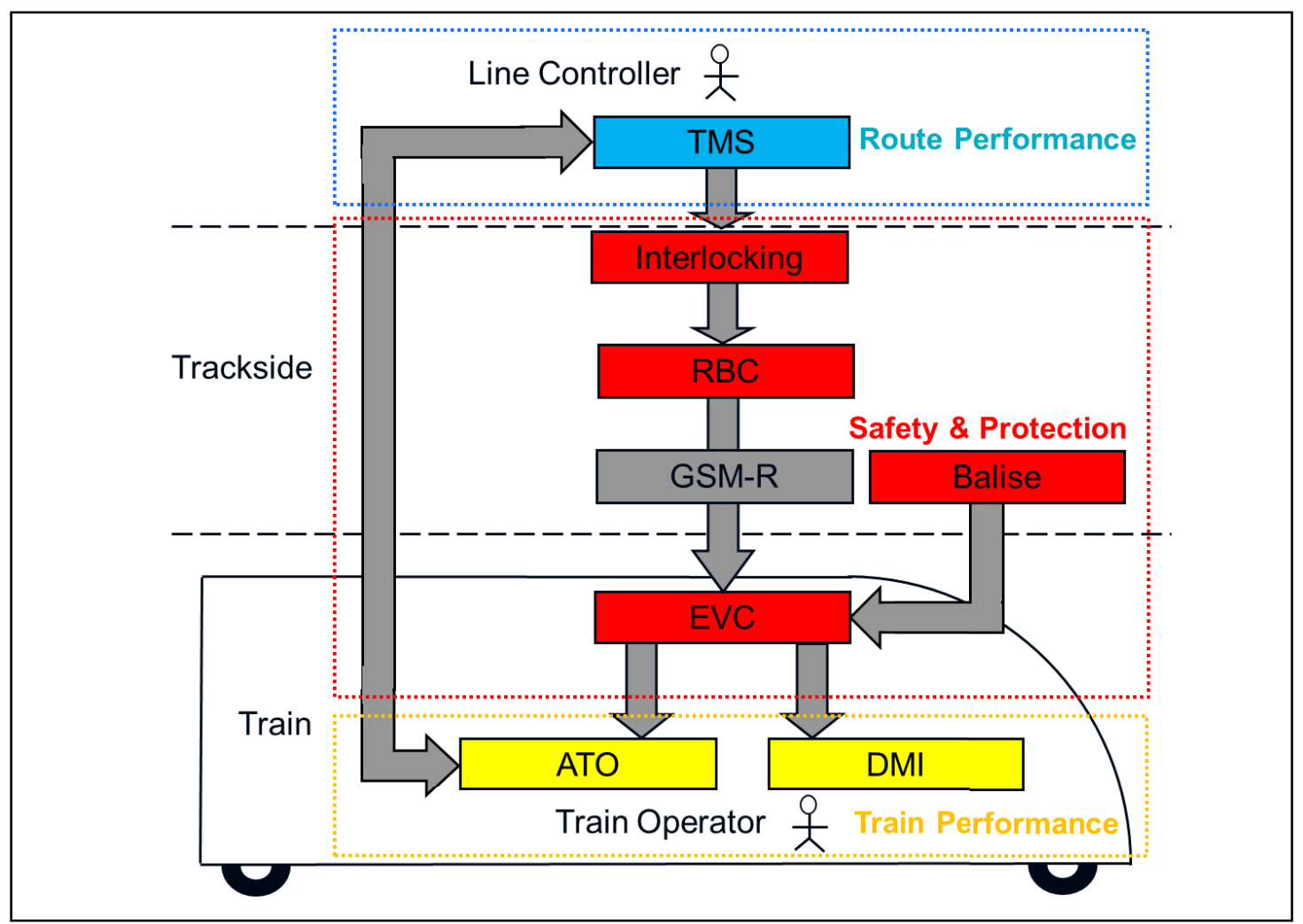

Fig. 5-24 ETCS Level 2 With ATO System Flow

This then leads to the location map shown in Table 5-5 for a combined ATO / ETCS Level 2 system.

\begin{tabular}{|l|l|l|l|l|}
\hline & A & B & C & D \\
\hline $\mathbf{R}$ & TMS & & & \\
\hline $\mathbf{S}$ & & Inx & TD & EVC \\
& & RBC & Balise & \\
\hline $\mathbf{T}$ & & LEU & & DMI \\
& & & & ATO \\
\hline
\end{tabular}

Table 5-5 ETCS Level 2 With ATO Location Map

We can therefore define these subsystems with the following suffixes to simultaneously identify their location and functionality:

- TMS-RA

- $\quad \operatorname{Inx}-\mathrm{SB}$

- $\mathrm{RBC}-\mathrm{SB}$

- $\quad$ LEU-SB

- TD-SC

- Balise-SC

- EVC-SD

- DMI-TD

- ATO-TD 


\subsection{PTC}

The main sub-systems of the example PTC system (as defined in Fig. 1-16 in Section 1.7.4) are the following:

- The Operational Control System (OCS)

- The Positive Train Control (PTC) system which consists of:

- The on-board system that determines the train's position and provides intervention if required

- The central interlocking system that monitors each train's position against its virtual block database to determine the train's movement authority

- The Driver's Display in the cab

Since the OCS is the Line Controller's main interface and is used to route the trains around the network, it is clearly part of Route Performance.

The PTC system is primary part of Safety \& Protection, as it ensures the safe separation of all trains as well as movement of points, etc.

As the Display informs the Train Operator about their permitted movement (and hence the Train Operator's primary interface to the RCS system), it is part of Train Performance.

We can therefore map our main functional elements for this example PTC system onto the generic model as shown in Fig. 5-25.

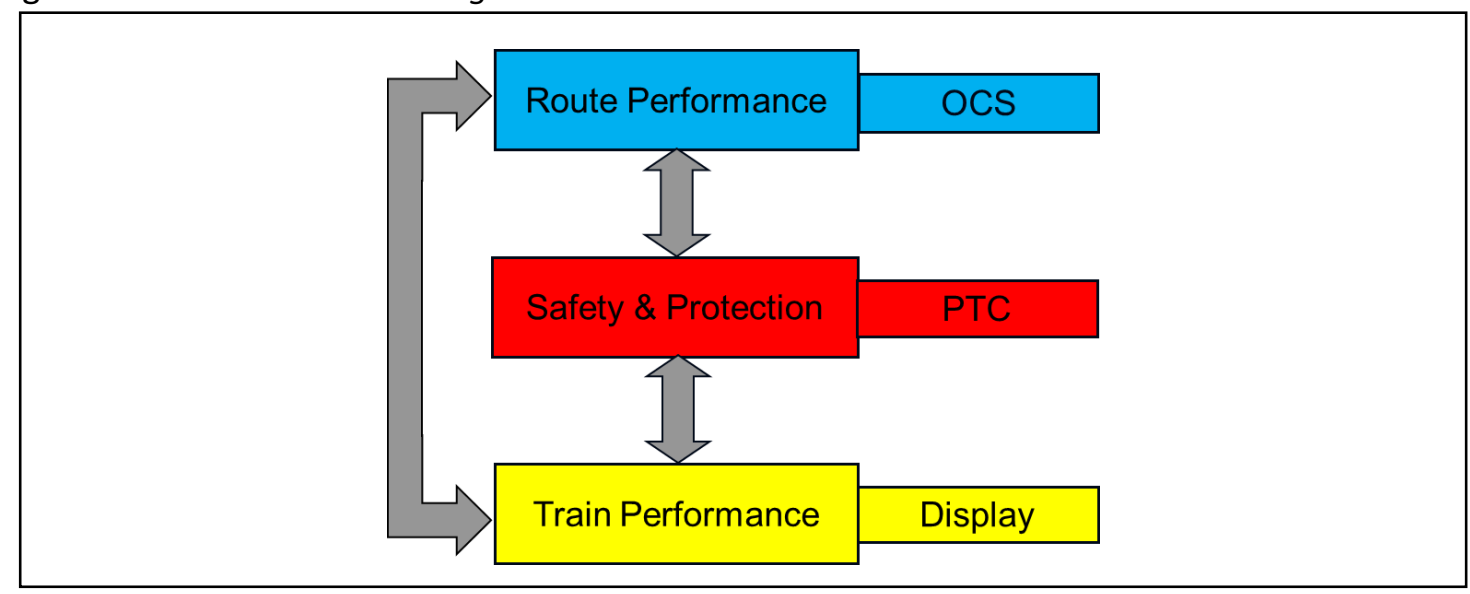

Fig. 5-25 PTC Functional Sub-systems

If we then repeat this exercise for the physical model, we can see where these products are (usually) implemented on the railway, as shown in Fig. 5-26. 


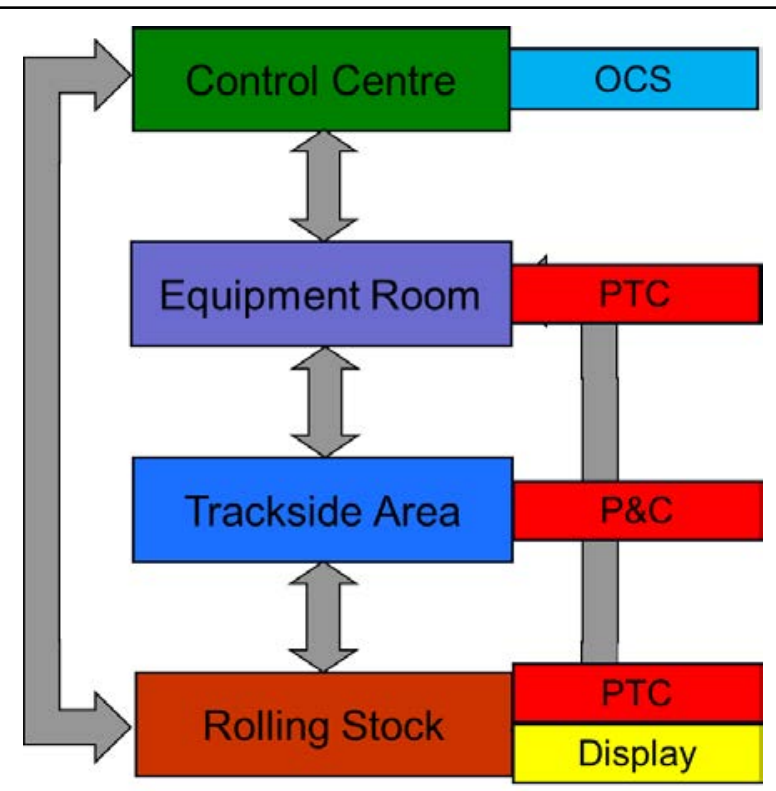

Fig. 5-26 PTC Sub-System Physical Locations

The PTC in the Equipment Room will be the central interlocking and control system, whilst the onboard PTC will be the system that manages speed control and intervention of the vehicle. Only Points \& Crossings ( $P \& C$ ) control and detection will be required in the trackside area.

From these two models, we can extrapolate the system flow and the products that make up each individual sub-system for the example PTC system in relation to locations as shown in Fig. 5-27:

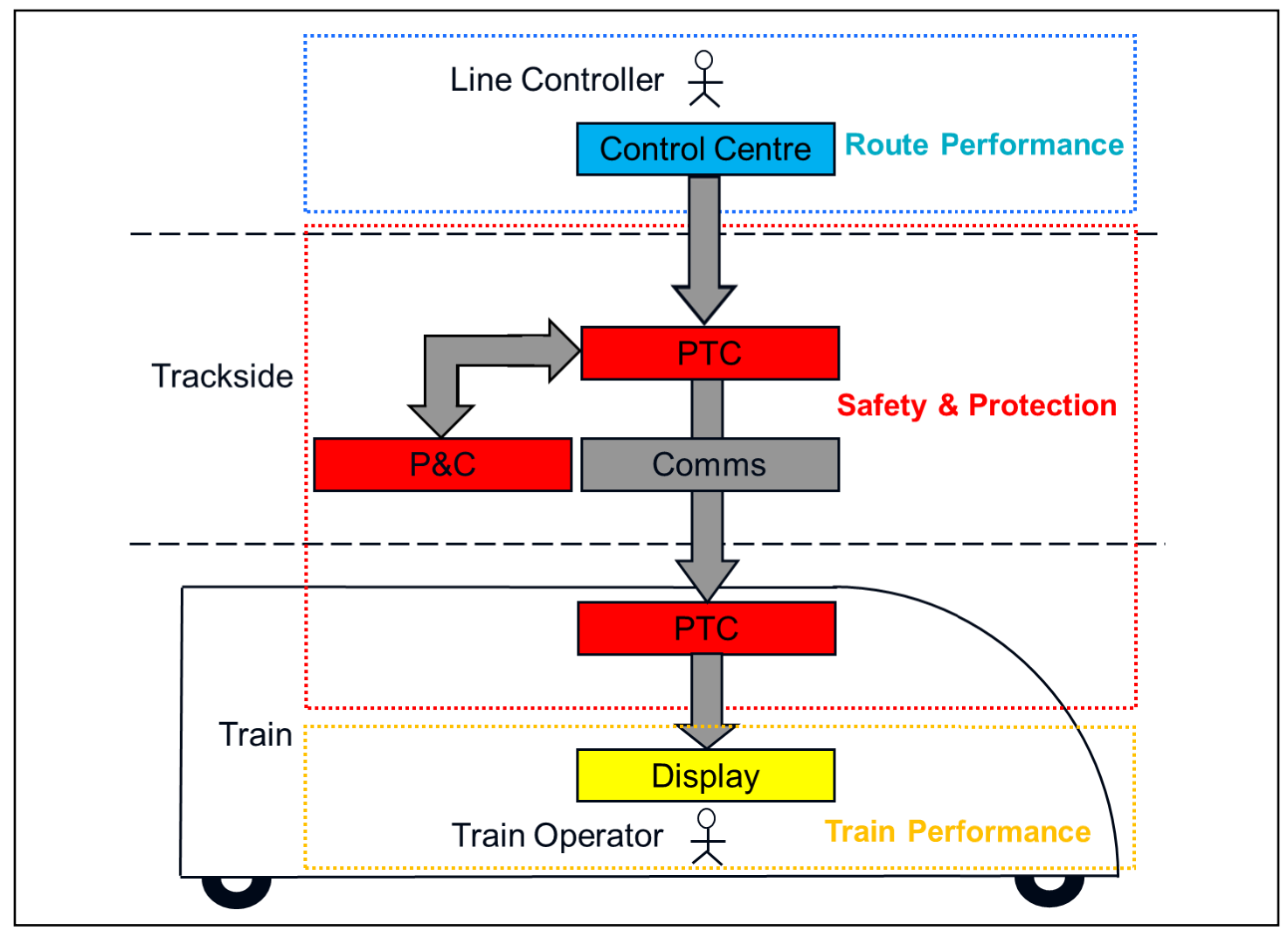

Fig. 5-27 PTC System Flow 
This then leads to the location map shown in Table 5-6 for PTC.

\begin{tabular}{|l|l|l|l|l|}
\hline & A & B & C & D \\
\hline $\mathbf{R}$ & OCS & & & \\
\hline S & & PTC(lineside) & & PTC(on-board) \\
\hline $\mathbf{T}$ & & & & Display \\
\hline
\end{tabular}

Table 5-6 PTC Location Map

Therefore, we can define these sub-systems with the following suffixes to simultaneously identify their location and functionality:

- OCS-RA

- Interlocking-SB

- $\quad$ PTC(lineside)-SB

- PTC(on-board)-SD

- Display-TD 


\section{Proposed Method for Modelling RCS Capability}

I have so far proposed generic models for RCS systems that can map any system onto them in order to more clearly define the relationship between their functionality and physical architecture.

I would now like to propose a method for potentially utilising the functional model to determine the capability of an RCS system based on the requirements to achieve a particular number of Trains Per Hour (TPH).

However, in order to explain this method, I must first introduce the concept of negativefeedback control systems.

\subsection{Negative Feedlback Control Systems}

Many systems are subject to outside influence that can affect their output (Bequette, 2003), as shown in Fig. 6-1.

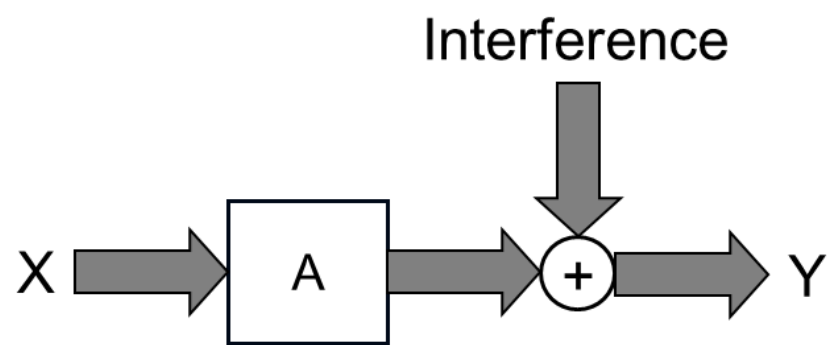

Fig. 6-1 Open-Loop System with Interference

In the example of Fig. 6-1, System A has input $\mathrm{X}$ with the aim of achieving output $\mathrm{Y}$. However, due to the interference being introduced to the system, it is more likely that the output will either fail to reach the target output or drop below it over time.

It has long been established that by utilising an appropriate sub-system ' $\mathrm{B}$ ' that feeds back the output of system ' $A$ ' to its input, this can enable the output of system ' $A$ ' to be stabilised (Bequette, 2003), as shown in Fig. 6-2.

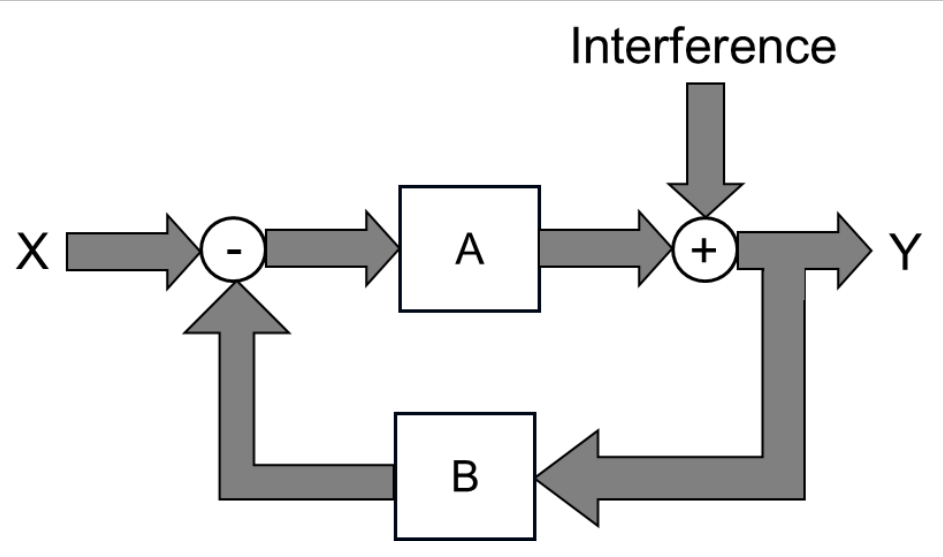

Fig. 6-2 Closed-Loop Negative Feedback System 


\subsection{RCS as a Negative Feedback Control System}

An initial view of the RCS functional model developed in section 4.1 does not lend itself to being modelled as a negative feedback control system. However, it should be considered how RCS operates within the overall railway system. Specifically, it should be observed how the RCS system controls and interacts with the rolling stock. It is fundamentally the functions of the Safety \& Protection (S\&P) layer such as train detection, interlocking and ATP that permit trains to move and limit the capacity of the system. Therefore, it can be shown that the operation of the railway works through the S\&P layer as shown in Fig. 6-3.

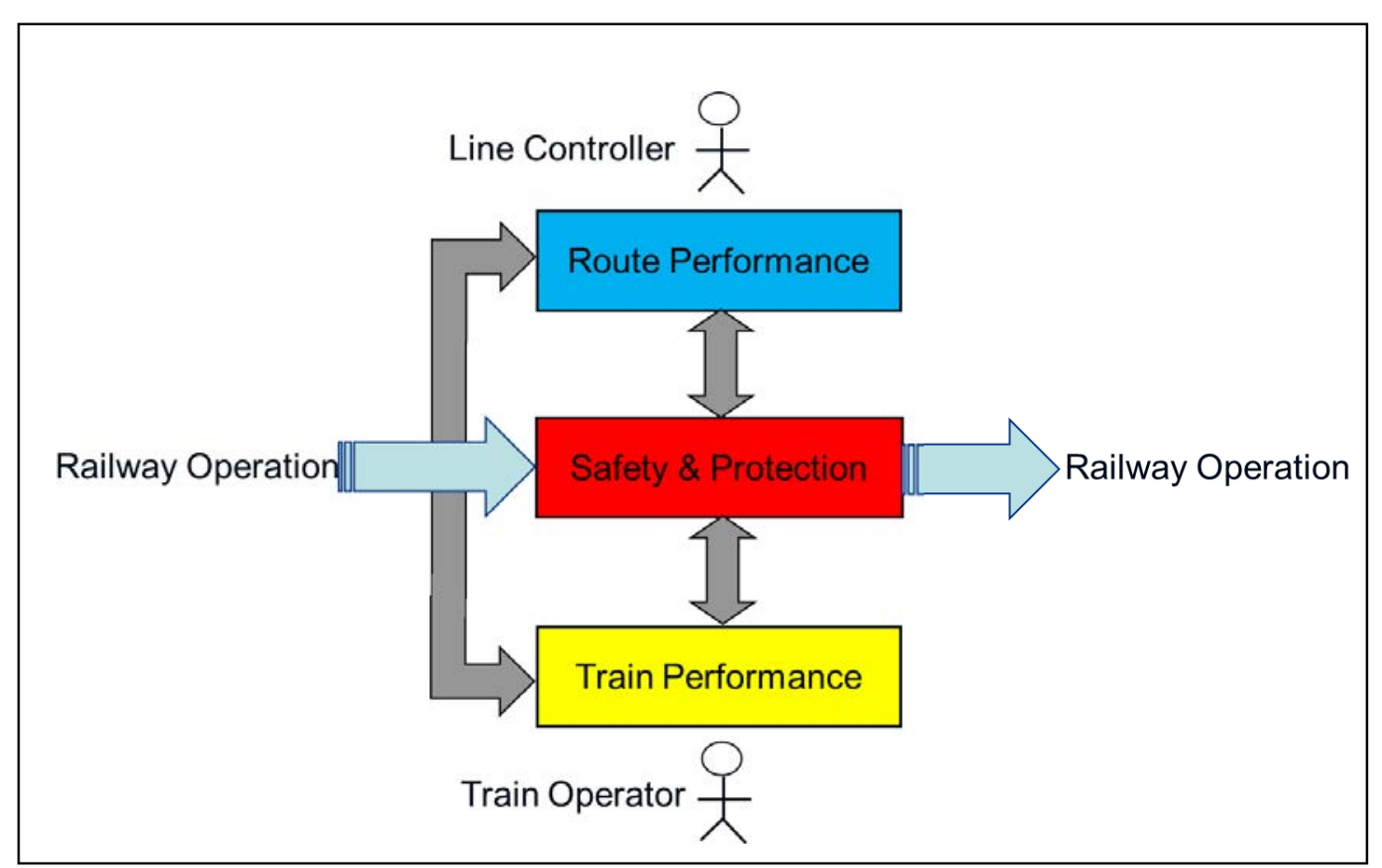

Fig. 6-3 Railway Operation of RCS System

It is now possible to re-draw the RCS Functional Model as a negative-feedback control system, where the S\&P layer is the main system and the Route Performance (RP) \& Train Performance (TP) layers are the feedback systems as shown in Fig. 6-4.

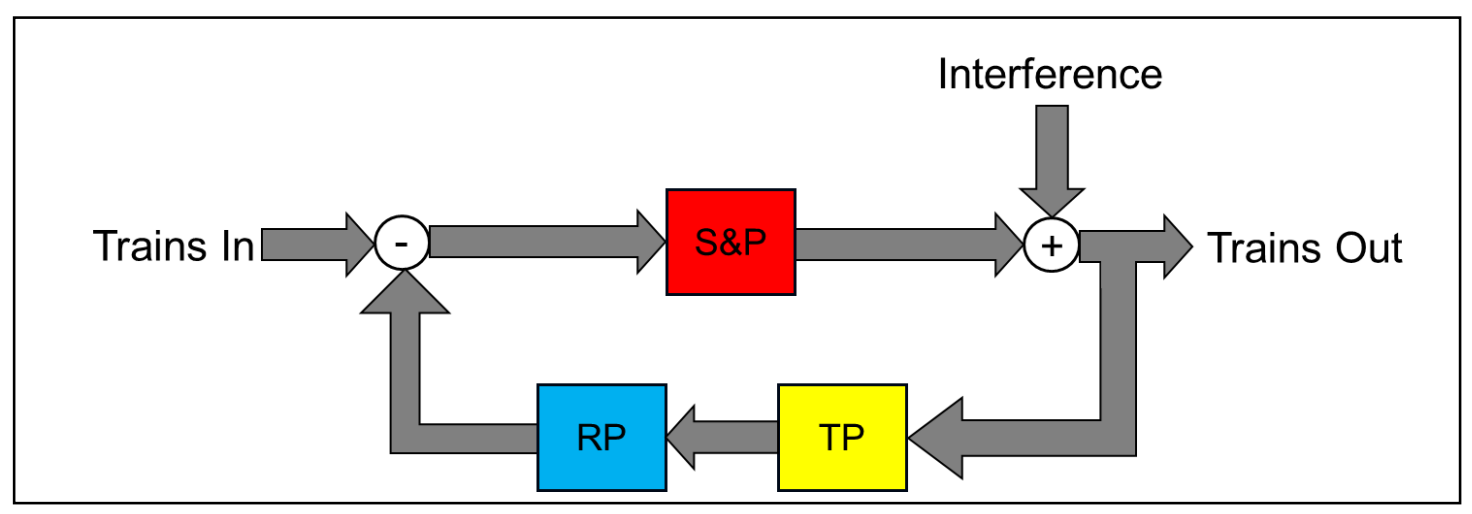

Fig. 6-4 RCS System as a Negative-Feedback Control System

This now means that in terms of operation of the railway's performance, the RCS system works in the following way: 
1. The S\&P layer determines the maximum TPH that the system can deliver

2. The TP \& RP layers ensure that that maximum TPH is maintained

3. The interference in this case is anything that causes trains to not run to timetable (passengers holding doors open, obstructions in the track, breakdowns, etc.)

\subsection{Specific RCS Systems in a Negative-Feedback Model}

It is possible for the main types of RCS mapped onto the generic model in Chapter 5 to be converted into this negative-feedback model as shown in the following sections.

\subsubsection{Conventional Signalling}

The conventional signalling system shown in Fig. 5-3 can be redrawn as a negative feedback system as shown in Fig. 6-5.

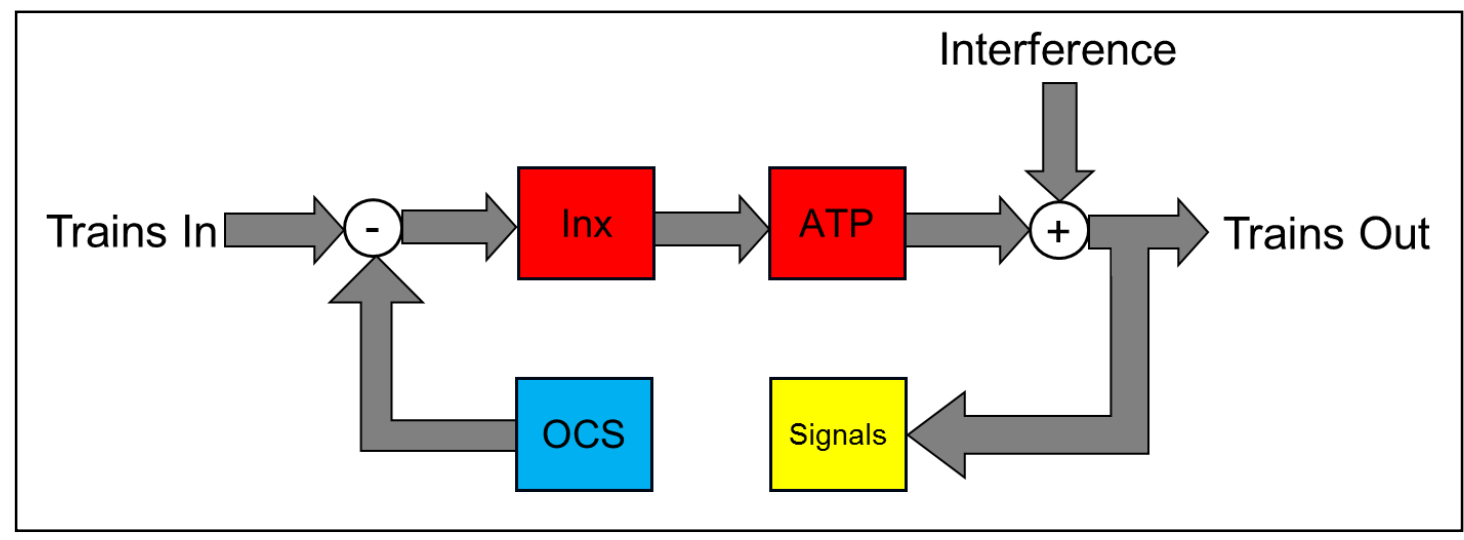

Fig. 6-5 Conventional Signalling System as a Negative-Feedback System (Broken Loop)

As can be seen, a fundamental flaw with conventional signalling is the lack of direct feedback between the Train and Route Performance layers (effectively a broken loop), hence often making it difficult to recover quickly and efficiently from incidents.

\subsubsection{CBTC}

The CBTC system shown in Fig. 5-6 maps clearly onto the negative feedback model, providing a fully closed-loop system as shown in Fig. 6-6.

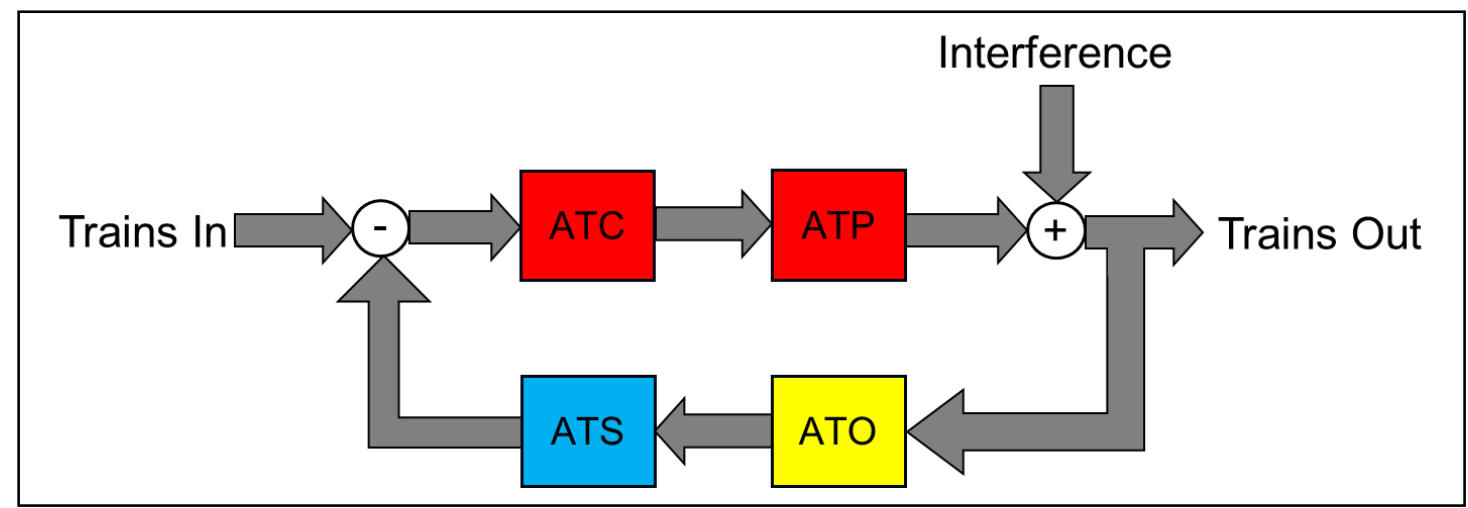

Fig. 6-6 CBTC System as a Closed-Loop Negative-Feedback System

This is mainly due to CBTC systems often being designed as a complete single system, with the primary requirement being to continuously deliver as many trains as possible within an hour, with little concern for timetabling different trains and service patterns. 


\subsubsection{ERTMS}

For the purposes of this analysis, we shall concentrate on two versions, ERTMS Level 2 and ETCS Level 2 with TMS \& C-DAS, to provide a comparison of what the additional systems provide in terms of negative feedback.

The ERTMS Level 2 system as shown in Fig. 5-15 can be redrawn as a negative feedback system as shown in Fig. 6-7.

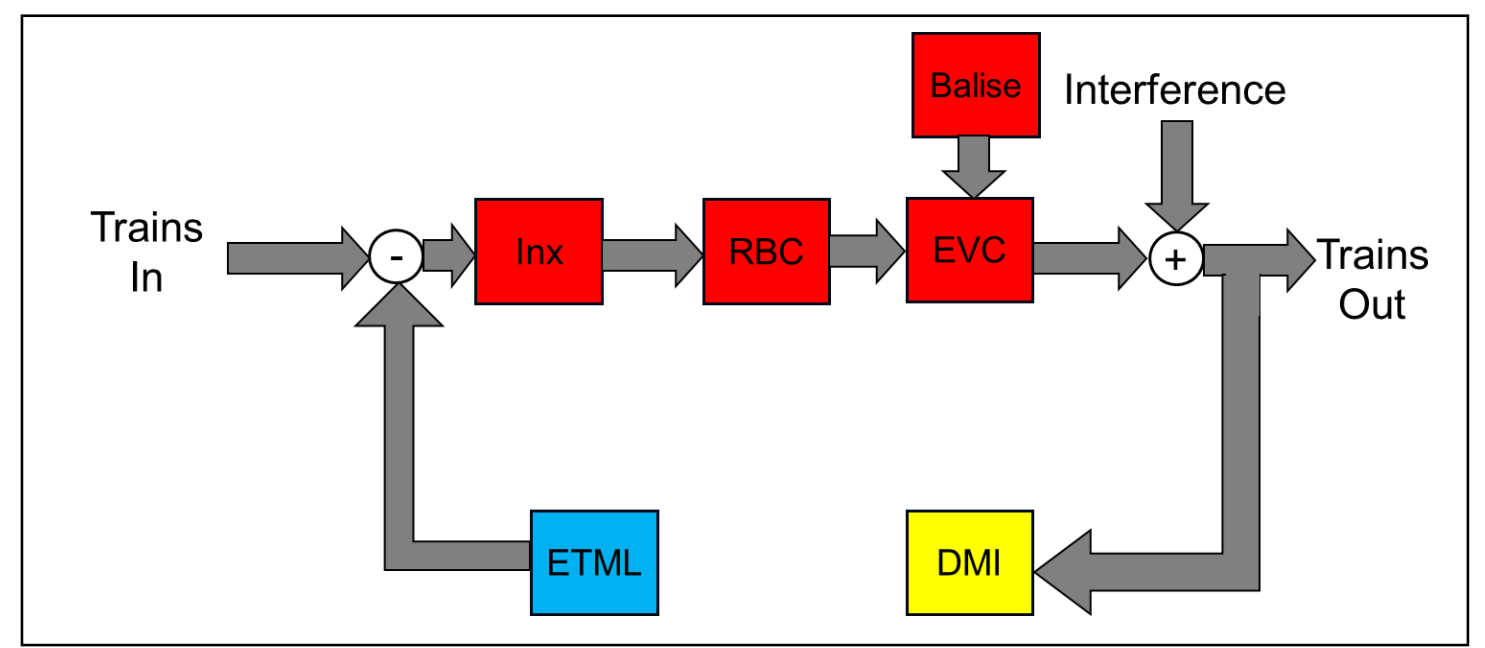

Fig. 6-7 ERTMS Level 2 as a Negative-Feedback System (Broken Loop)

As with conventional signalling, ETCS on its own does not provide direct feedback between the train and Route Performance layers (effectively a broken loop), hence often making it difficult to recover quickly and efficiently from incidents.

The combined ETCS Level 2 with TMS \& C-DAS systems as defined in Fig. 5-20 can be redrawn as a closed loop system as shown in Fig. 6-8.

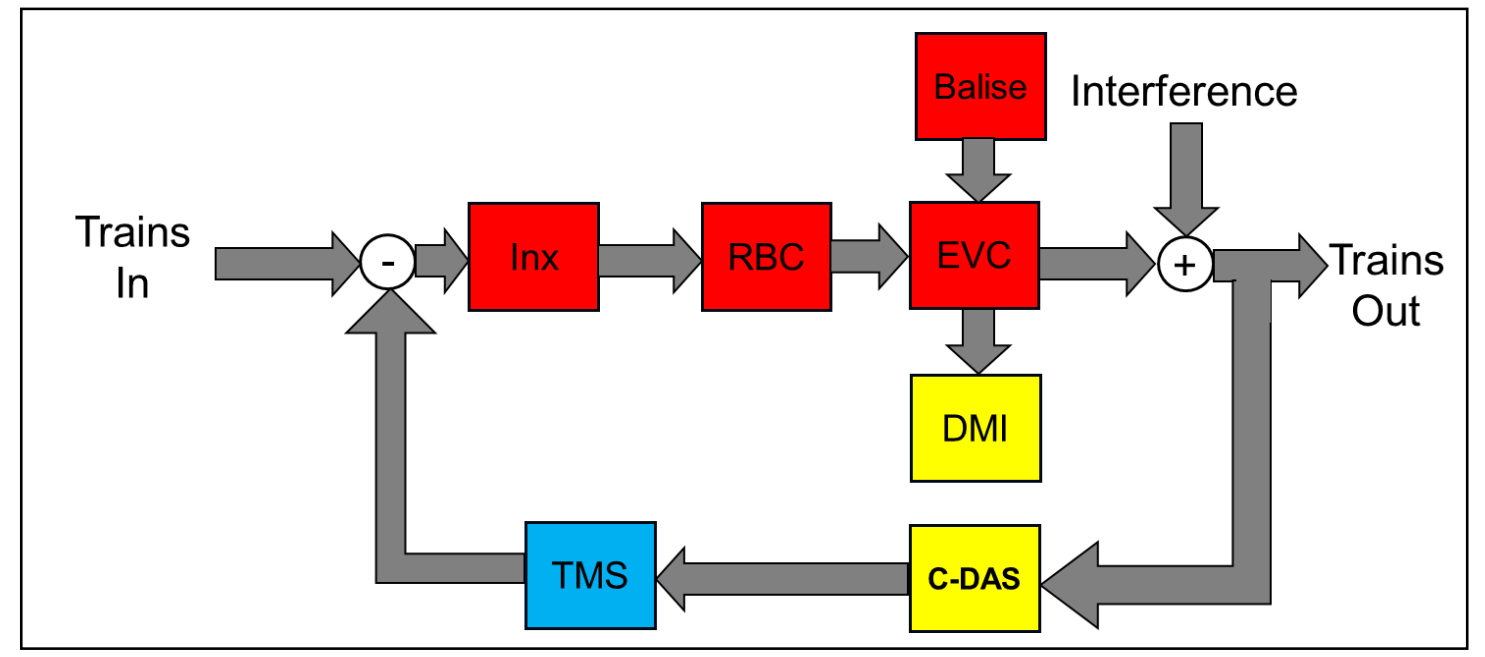

Fig. 6-8 ETCS Level 2 With TMS \& C-DAS as a Closed-Loop Negative-Feedback System

Although the main sub-systems (Interlocking, ETCS, TMS \& C-DAS) have been developed separately as distinct sub-systems, Fig. 9-4 shows how they can be integrated together to form a complete system to deliver and maintain a particular train capacity based on timetable requirements. There are, of course, several challenges, to this such as the issue of 
the driver not having a single source of truth to drive to (having separate displays for both ETCS \& C-DAS).

\subsubsection{PTC}

The PTC system shown in Fig. 5-27 can be shown as a negative feedback system as shown in Fig. 6-9.

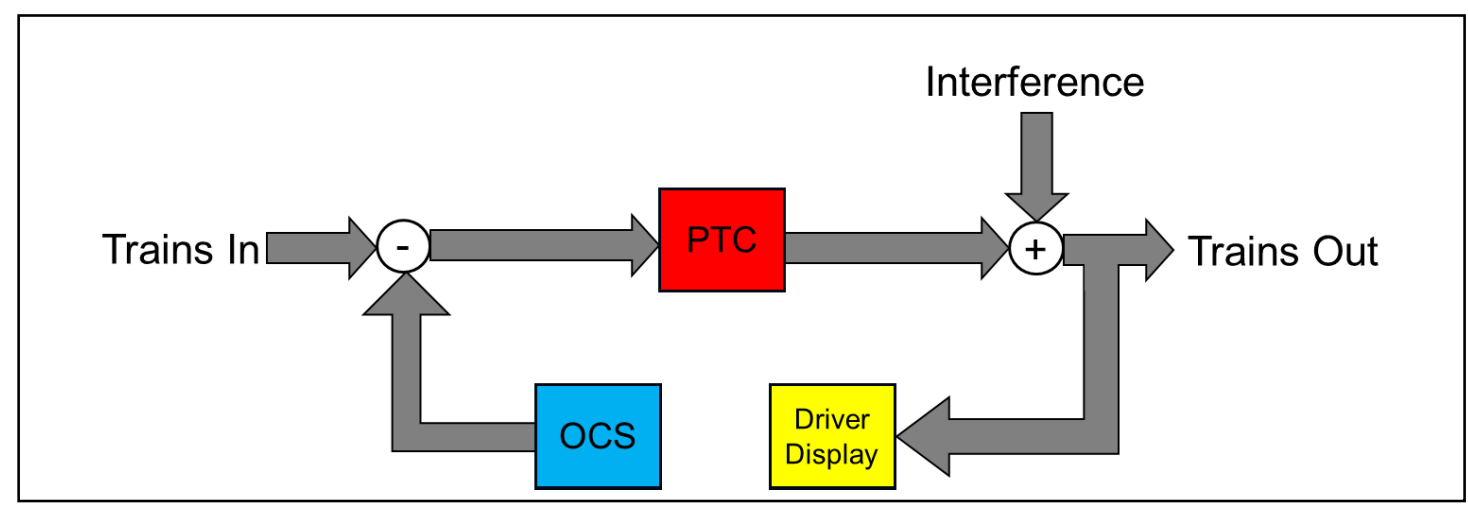

Fig. 6-9 PTC as a Negative-Feedback System (Broken Loop)

As with conventional signalling and ETCS without TMS \& C-DAS, PTC on its own does not provide direct feedback between the train and Route Performance layers (effectively a broken loop), hence often making it difficult to recover quickly and efficiently from incidents. 


\section{Organisational Interfaces}

For many mainline applications, there is frequetly a segregation of the operations between the infrastructure and the rolling stock. Often on European Railways, there is an Infrastructure Manager (IM) who manages, operates and maintains the infrastructure assets, and a Railway Undertaking (RU) who operates passenger or freight services and hence manages, operates and maintains the rolling stock and its associated assets.

This means that there will often be a minimum of two stakeholders with a vested interest in the development, implementation and operation of the RCS system who will have responsibilities for different sub-systems within the RCS system, both in terms of delivery and operational maintenance. It is therefore important to consider operational interfaces between sub-systems, as well as purely technical ones. This will be explored in the remainder of this Chapter.

As an example, let us look at the combined TMS, ETCS Level 2 \& C-DAS that was defined in Section 5.3.1. Since we have the functional elements in the physical model, we can extrapolate the high-level system architecture into a system flow diagram that shows which components and sub-systems must be implemented within each stakeholder's assets as shown in Fig. 7-1.

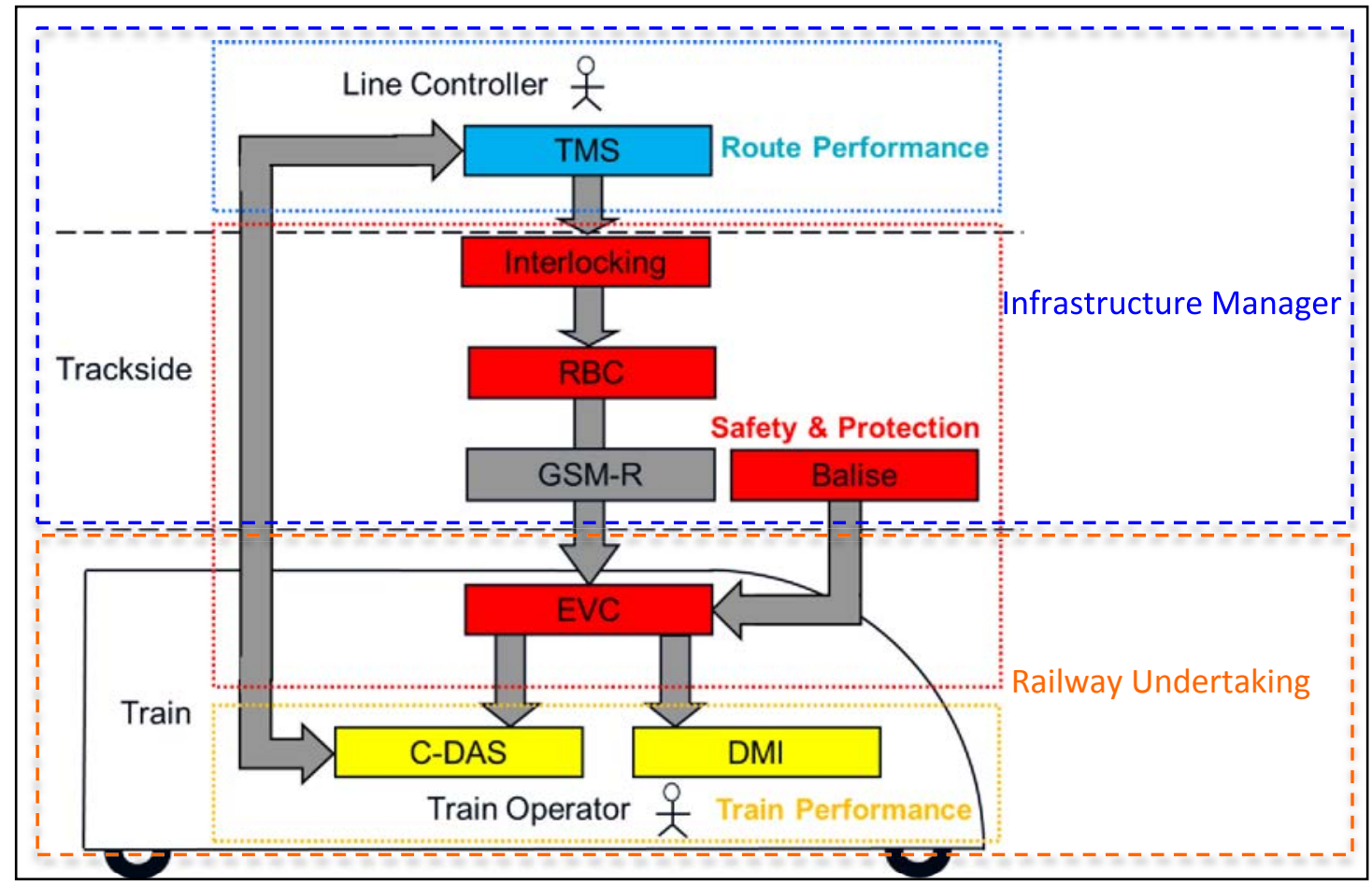

Fig. 7-1 ETCS Level 2 With TMS \& C-DAS System Flow Organisational Boundaries

From this, we can see that there are a number of key interfaces that must be managed both internally within the organisations as well as externally between the IM and RU. The interfaces can also either be internally within the three main functional layers: Route Performance (RP), Safety \& Protection (S\&P) and Train Performance (TP) or between them. A summary of the main sub-system interfaces are shown in Table 7-1. 


\begin{tabular}{|l|l|l|l|}
\hline System 1 & System 2 & Functional Interface & $\begin{array}{l}\text { Organisational } \\
\text { Interface }\end{array}$ \\
\hline TMS & Inx & RP - S\&P & Internal IM \\
\hline Inx & RBC & Internal S\&P & Internal IM \\
\hline RBC & EVC & Internal S\&P & IM - RU \\
\hline Balise & EVC & Internal S\&P & IM - RU \\
\hline EVC & & S\&P - & Internal RU \\
\hline EVC & & S\&P - & Internal RU \\
\hline & TMS & - RP & RU - IM \\
\hline
\end{tabular}

Table 7-1 ETCS Level 2 With TMS \& C-DAS Functional \& Organisational Interfaces

As can be seen, there are 3 main types of organisation interfaces:

- Those internal to the IM

- Those internal to the RU

- Those that crossover between the IM \& RU

The following Sections of this Chapter will look at these three types of interface in more detail, as well as what technical interfaces they cover and highlight some of the key challenges that need to be addressed to manage them.

\subsection{Internal IM Interfaces}

There are two main internal interfaces that the IM must manage, as shown in Table 7-2.

\begin{tabular}{|l|l|l|l|}
\hline System 1 & System 2 & Functional Interface & Organisational \\
\hline TMS & Inx & RP - S\&P & Interface \\
\hline Inx & RBC & Internal S\&P & Internal IM \\
\hline
\end{tabular}

Table 7-2 ETCS Level 2 With TMS \& C-DAS Internal IM Interfaces

The interface between the Interlocking system and the RBC is internal to the S\&P layer which means that both elements are safety critical. The interface will usually be a fixed connection between the interlocking and RBC, which are often co-located in the same equipment room.

The interface between the TMS and the Interlocking system is a bit more complicated, as it is also a functional interface between the RP and S\&P layers. This creates a number of issues and challenges:

- It is vital that the TMS cannot override the Interlocking in any way.

- The TMS and Interlocking are likely to be located in separate buildings, so a long distance communication network will likely be required

- The TMS and RBC may potentially be procured from separate suppliers, so it is vital that a common communications protocol is agreed between the two systems

As can be seen, the IM has no sole responsibility for any TP functions, as these are related to the performance of individual trains. 


\subsection{Internal RU Interfaces}

There are two main internal interfaces that the RU must manage, as shown in Table 7-3.

\begin{tabular}{|l|l|l|l|}
\hline System 1 & System 2 & Functional Interface & $\begin{array}{l}\text { Organisational } \\
\text { Interface }\end{array}$ \\
\hline EVC & & S\&P - & Internal RU \\
\hline EVC & & S\&P - & Internal RU \\
\hline
\end{tabular}

Table 7-3 ETCS Level 2 With TMS \& C-DAS Internal RU Interfaces

Both internal RU interfaces deal with the functional interface between the S\&P and TP layers. However, as the first one (EVC \& DMI) is part of the complete ETCS on-board system, the interface should be managed by the supplier as part of the ETCS specification.

The second interface (between the EVC \& C-DAS) is more complex, as not only is C-DAS a separate system from ETCS (and hence could be provided by a separate supplier), but its display could potentially have some similar outputs to the ETCS DMI, creating a conflict between the two. Thus there are the following issues and challenges with this interface:

- It is vital that C-DAS cannot override the EVC in any way

- C-DAS and ETCS may potentially be procured from separate suppliers, so it is vital that a common communications protocol is agreed between the two systems

- If the DMI and C-DAS display are fitted in parallel, then a detailed human factors assessment must be carried out to ensure that there is no contradictory information displayed on them

As can be seen, the RU has no sole responsibility for any RP functions, as these are related to the performance of the overall railway network, not individual trains.

\subsection{Interfaces Between IM \& RU}

The most complex interfaces to manage are possibly those that crossover between the IM and RU. The main three interfaces that fall into this category are shown in Table 7-4.

\begin{tabular}{|l|l|l|l|}
\hline System 1 & System 2 & Functional Interface & $\begin{array}{l}\text { Organisational } \\
\text { Interface }\end{array}$ \\
\hline RBC & EVC & Internal S\&P & IM - RU \\
\hline Balise & EVC & Internal S\&P & IM - RU \\
\hline & TMS & - RP & RU - IM \\
\hline
\end{tabular}

Table 7-4 ETCS Level 2 With TMS \& C-DAS Organisational Interfaces

Although the first two interfaces (RBC-EVC \& Balise-EVC) are both internal to the S\&P layer and parts of the complete ETCS system, they may still have challenging interface issues as the on-board and infrastructure elements of the ETCS can be procured separately from different suppliers. Although the European Technical Standards for Interoperability (TSI) (UNIFE, 2013) manage compatibility between the on-board and infrastructure sub-systems, there are 'gaps' in these standards that member states must 'plug' using National Technical Rules (NTR). Thus every Country could implement ETCS slightly differently. It is therefore critical that extensive laboratory and site testing is carried out of the interface between the ETCS on-board and infrastructure elements to ensure compatibility between the two. This results in the following issues and challenges: 
- The wireless communication between the RBC and the EVC must work off the same protocol and ensure that they are both sending and receiving the relevant data that they expect from each other.

- The on-board system must interpret the rolling stock's braking and motoring characteristics correctly and be in line with the principles by which the infrastructure layout within the RBC and the placement of balises have been designed to

The other interface between the RU and IM, C-DAS-TMS, is more complicated still, as it covers the interface between the TP and RP layers. This means that it may not only require the interface of two separate suppliers, but that it is also the key point where the overall management of the railway network (an IM responsibility) must work together with the performance of individual trains (a RU responsibility) to ensure the most efficient service. This could potentially lead to conflicting requirements between the RU and the IM. For example the IM may want to get as many trains as possible to pass through a particular section in an hour in order to sell more train paths, whilst an RU that uses Diesel trains may want their vehicles to drive as economically as possible in order to keep fuel costs low. This results in issues and challenges such as:

- C-DAS and TMS may potentially be procured from separate suppliers, so it is vital that a common communications protocol is agreed between the two systems

- An agreement must be reached between the IM and RU of agreed targets for key outputs such as journey times, line capacity, fuel efficiency, etc.

- The development of the specific application data for the TMS and C-DAS should be developed by a single integrated design team if at all possible 


\section{Project Organisations for Developing \& Delivering RCS}

Traditionally, when managing assets, the railway industry has adopted what has come to be known as the 'silo' approach, where assets are grouped together in common sub-systems such as Rolling Stock, Signalling and Control Centres, each with their own team of specialists who manage their assets separately from the other teams, with little co-ordination and cooperation.

This approach has a tendency to lead to conflicting requirements when delivering new systems, as each team gathers their own requirements individually and feeds them to the design team as shown in Fig. 8-1.

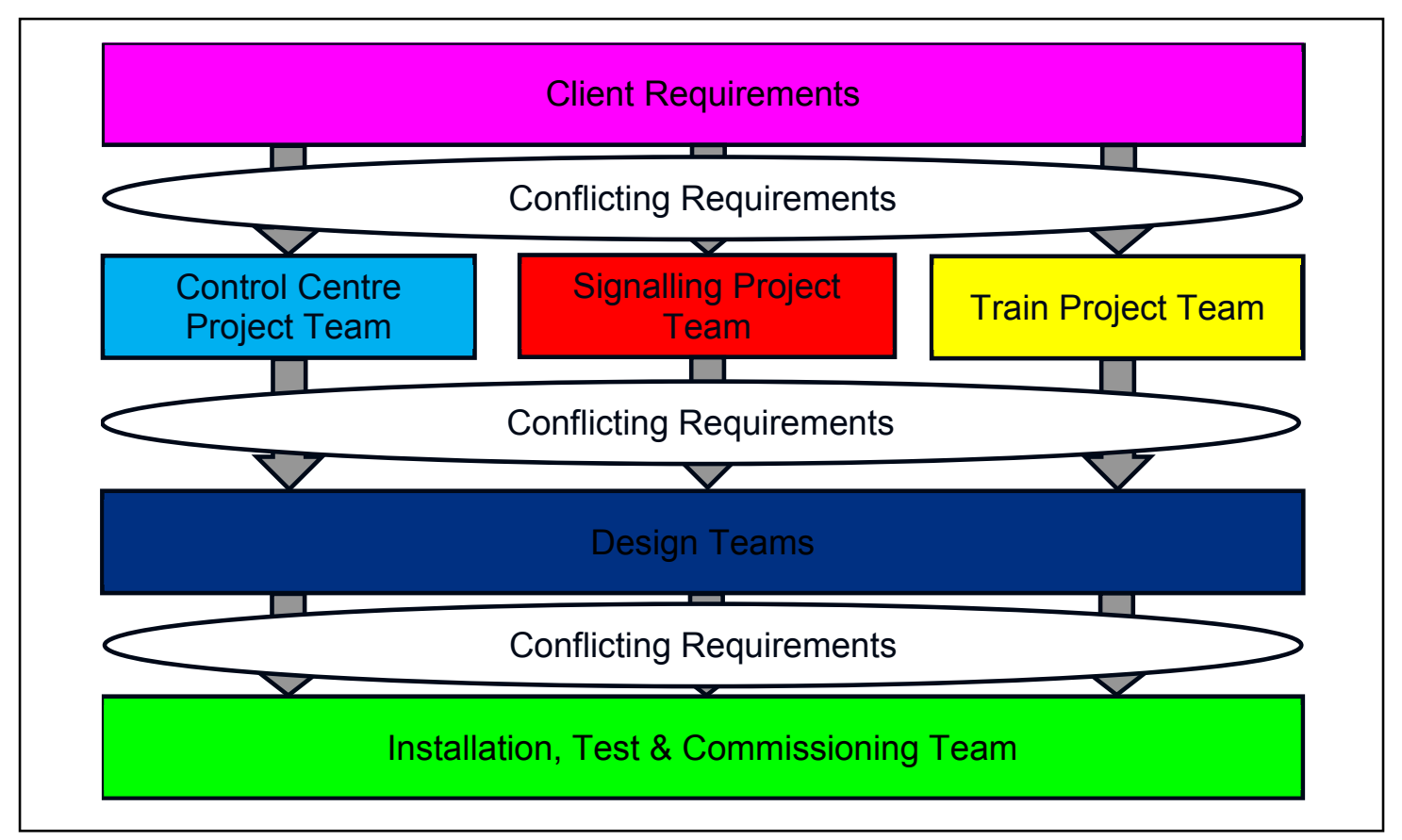

Fig. 8-1 Challenges of RCS Delivery Structures

This, in turn, can lead to large amounts of design re-work cycles as the different requirements are fed to the design team at different times as shown in Fig. 8-2.

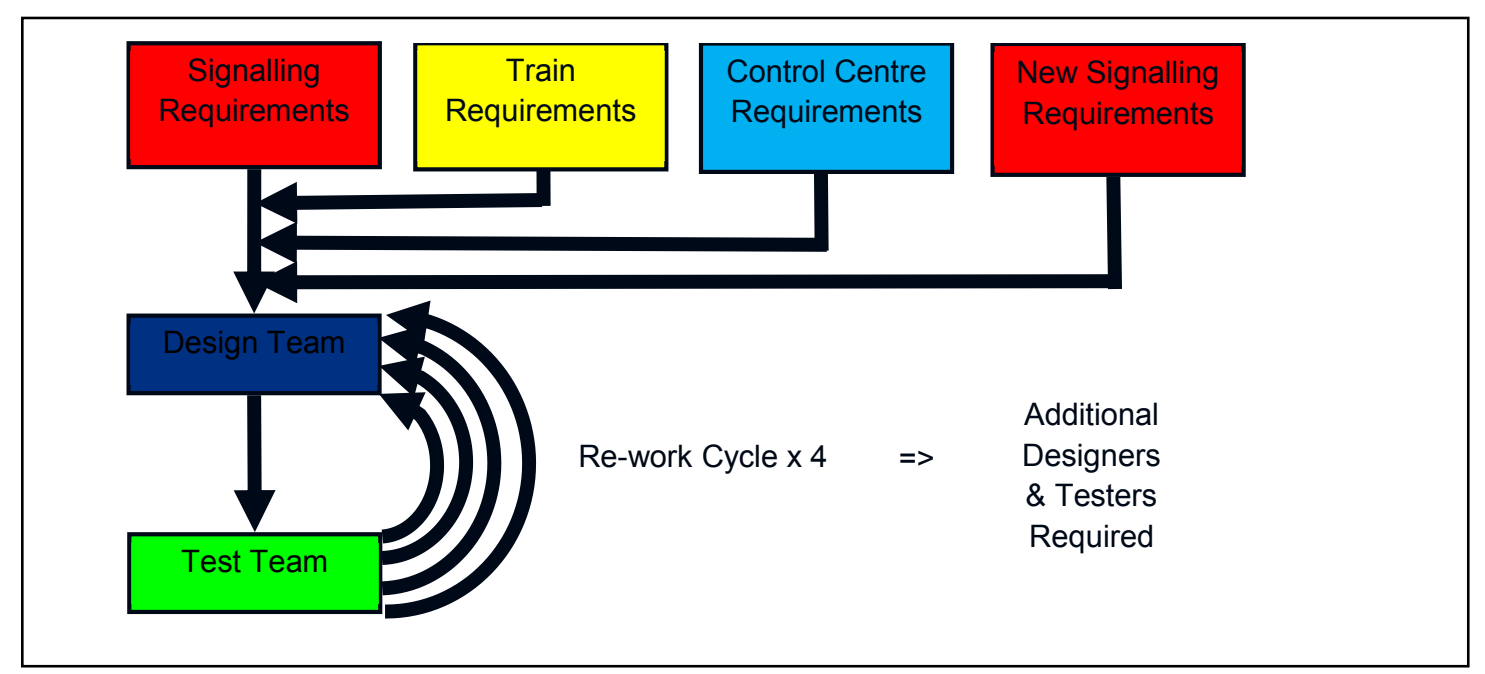

Fig. 8-2 Conflicting Requirements and Re-work Cycles 
This can be avoided by utilising a systems engineering approach as shown in Fig. 8-3.

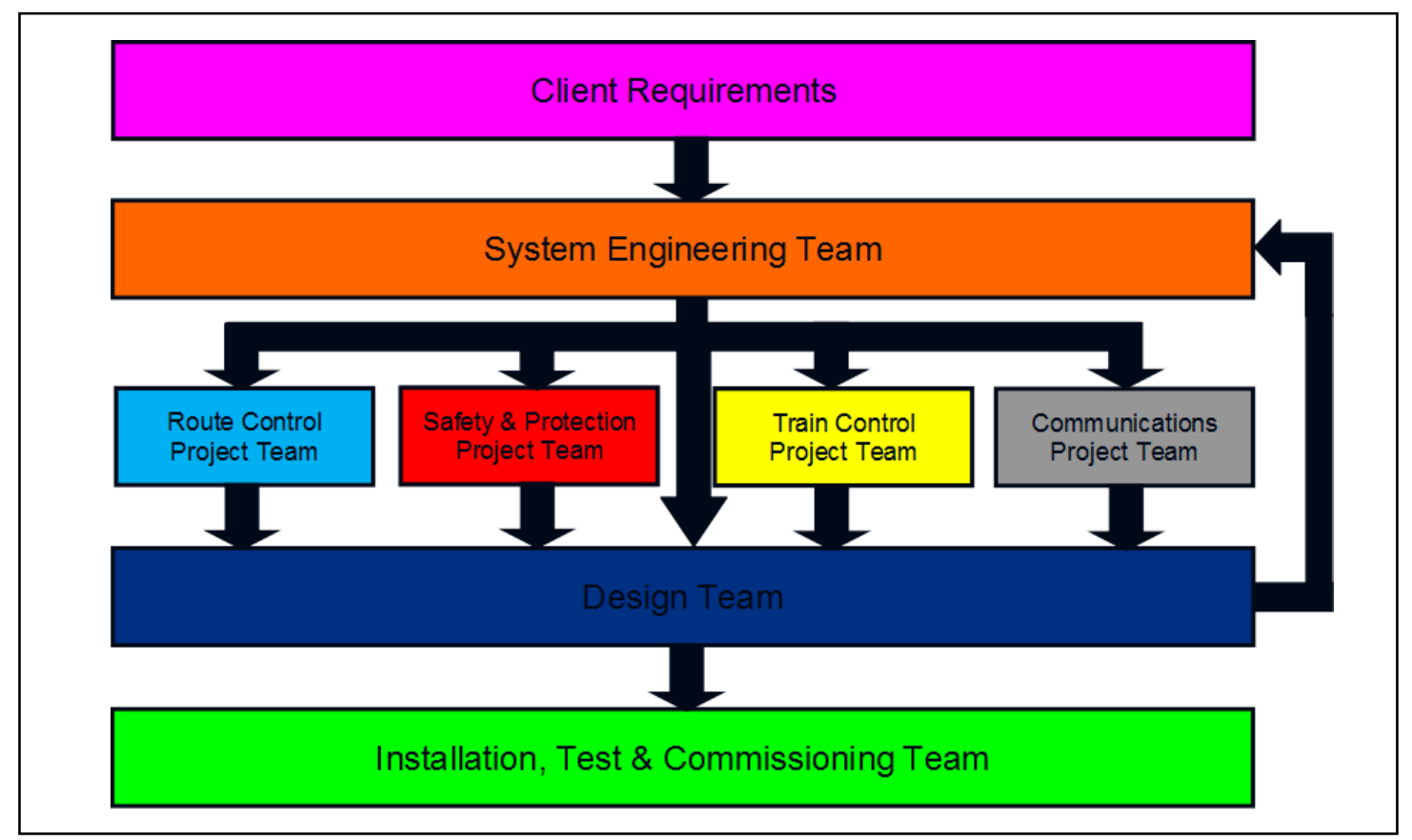

Fig. 8-3 Role of Systems Engineering Team

The Systems Engineering team:

- Acts as single point of contact with the client

- Is responsible for all requirements capture

- Disseminates sub-system requirements to relevant project teams

- Manages all interfaces between all sub-systems

- Manages all configuration control

- Approves changes to the system made by the Design Team

This now enables a more streamlined design process, where the Systems Engineering team 'filters' all the design requirements so that there are no conflicting interests and reduces the amount of required re-work cycles as shown in Fig. 8-4.

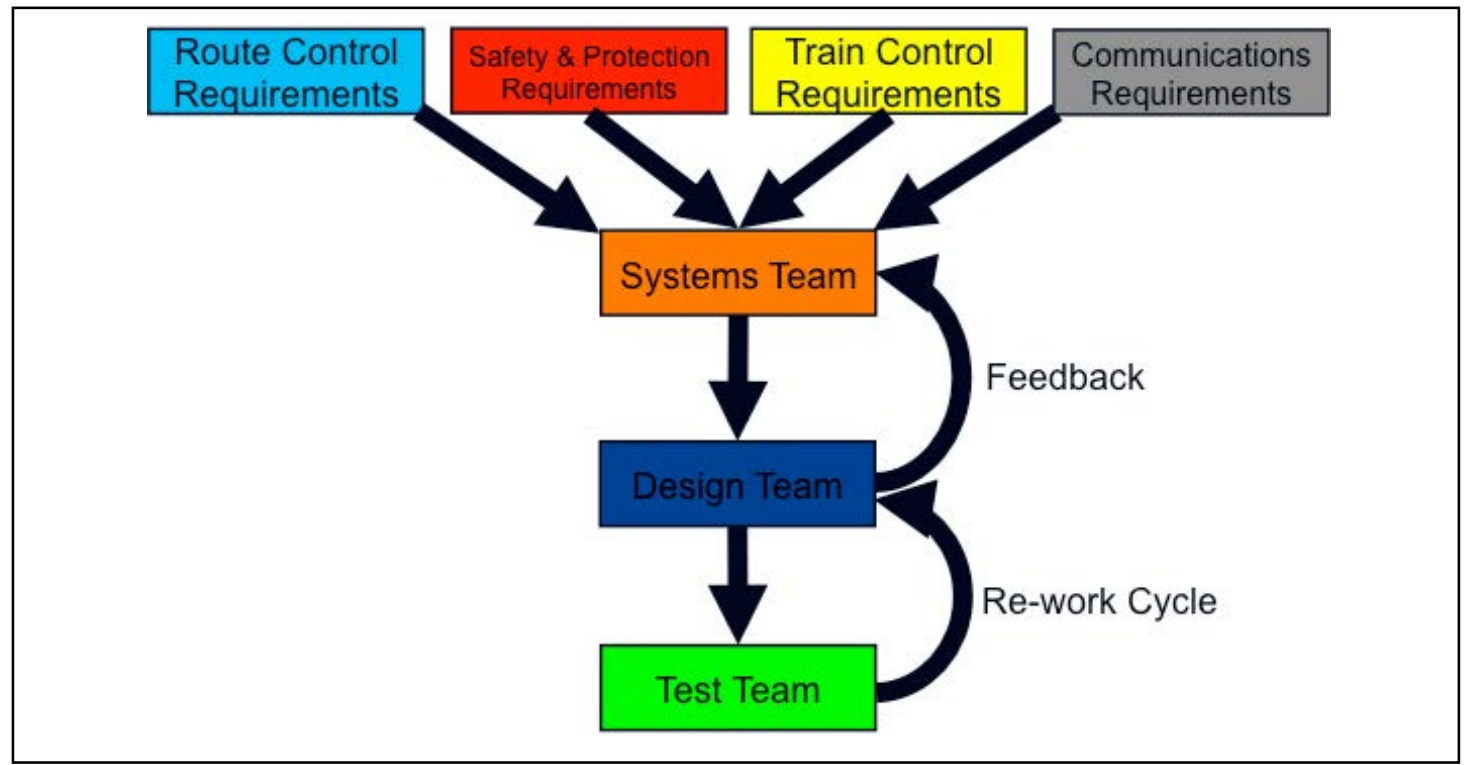

Fig. 8-4 Systematic Approach to RCS Design \& Development 


\subsection{Current Project Delivery structures}

As can be seen from Chapter 4, one of the complexities of RCS is that it is actually a system that is itself made up of other systems. This is often referred to as a System Of Systems (SOS) (Faulconbridge \& Ryan, 2014). An important aspect of the delivery of any complex SOS such as RCS is the structure of the delivery process.

Although there are many variations of delivery structure employed throughout the railway industry, they broadly fall into two main types, Project Management led and Engineering Management led.

(King, 2016)

\subsubsection{Project Management Led Delivery}

In a project management led structure there is usually a single Project Manager responsible for both the System Engineering (sometime called Project Engineering) and Design Engineering functions as shown in Fig. 8-5. The Systems Engineers are responsible for technical compliance against standards, whilst Design Engineers develop the scheme layouts and specific application data.

(King, 2016)

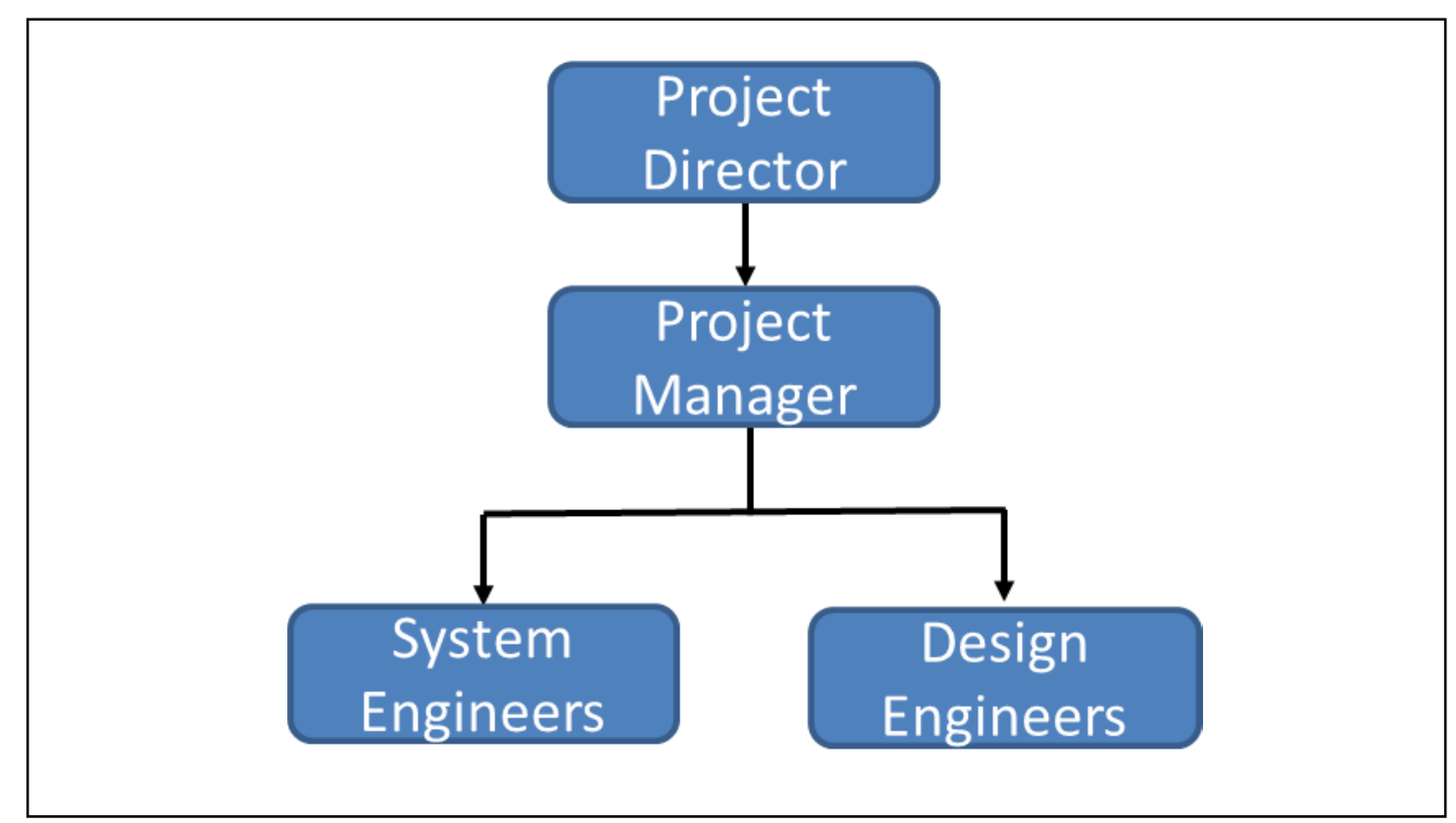

Fig. 8-5 General Project Management Led Structure (King, 2016)

The advantage of this approach is that it has a simple structure and is very focussed on the delivery of the project, ensuring that delivery targets are met and that the project is kept within budget.

However, it has several disadvantages. Firstly there can be a lack of technical direction that can lead to the system being unreliable or not meeting requirements. Also as there is such a strong focus on delivery, technical quality can be sacrificed, resulting in poor performance. The capture and control of requirements is also very difficult using this model, as the System Engineers have no authority over the Design 
Engineers and hence control of the flow of requirements from their fundamental needs to design requirements.

(King, 2016)

\subsubsection{Engineering Management Led Delivery}

In an engineering management led structure, there are two management roles that report to the Project Director, a Project Manager and an Engineering Manager, as shown in Fig. 8-6. Such an arrangement and has been adopted by many organisations (Hollywell, 2014).

(King, 2016)

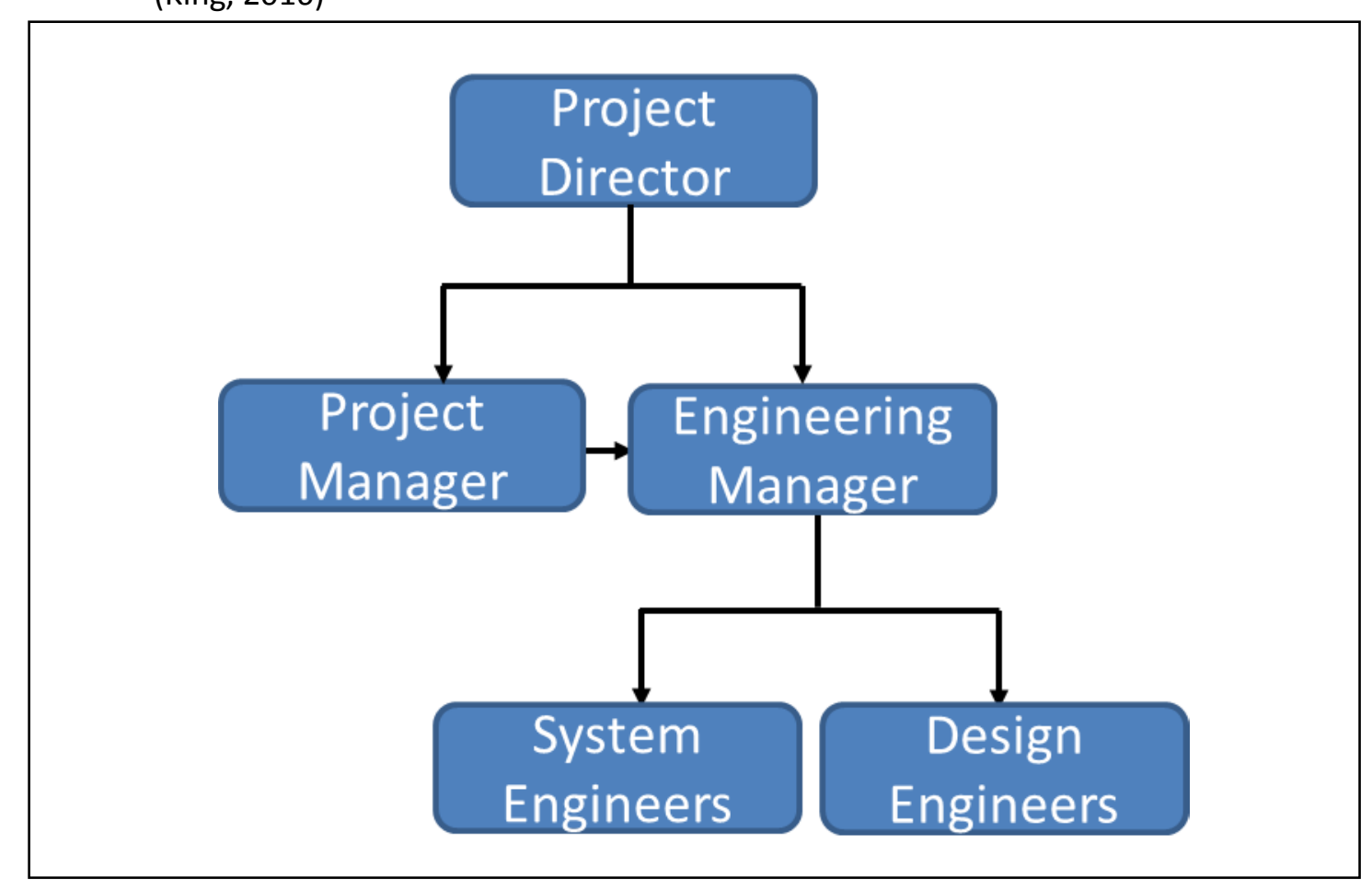

Fig. 8-6 General Engineering Management Led Structure (King, 2016)

The Project Manager still retains responsibility for the delivery and budget of the project, but the Engineering Manager takes responsibility for the technical quality of the project and the delivery of the system architecture.

This approach has the advantage of being more focussed on technical quality and enables better requirements capture, as there is more of a balance between the delivery of the project and ensuring the system's technical quality and compliance.

However, it has other disadvantages. Keeping control of the requirements can still be difficult, as the System Engineers still do not have direct authority over the Design Engineers. This model can also suffer quite badly from scope creep if the Design Engineers are not kept in check and engage directly with the end users to add more and more features. There is also a risk of cost and programme overrun as the solution could become over-engineered.

(King, 2016) 


\subsection{Proposed System-Centric Structure}

We should approach creating the project team structure that we require to deliver an RCS system in the same way that we develop an RCS system, by first defining the fundamental requirements of the structure. In terms of a system like this, there are three fundamental requirements that must be maintained by the team:

\section{Programme}

a. Ensure overall project delivery including Contract Performance Requirements

b. Ensure project is delivered on-time and to budget

2. System Development

a. $\quad$ Ensure system meets operational, maintenance \& performance requirements

b. Ensure integration of all sub-systems into complete systems and manage associated interfaces

\section{Design}

a. Design the layout of the new system

b. Ensure the safety \& integrity of the new system

From these requirements we can extrapolate three key roles:

1. Project management

2. Systems Engineering

3. Design Engineering

The key is how these roles will interact with each other. I would propose that there should be three managers who report to the Project Director:

1. Project Manager

2. Systems Engineering Manager

3. Design Authority Manager

The Project Manager and their team would be responsible for keeping the project to time and budget.

The Systems Engineering Manager and their team would be responsible for gathering all end-user requirements and developing the system requirements and architecture.

The Design Authority Manager and their team would be responsible for the design of the layout and the specific application data ensuring that the system designed is not only fit for purpose but also fundamentally safe.

There should be a two-way interaction between the Project Manager and Systems Engineering Manager, with the latter acting as a 'technical translator' to the Project Manager on the issues of the system. The System Engineering team should also be the only team that engages with the end-user(s) to identify their requirements. It is also the responsibility of the Systems Engineering team to maintain a database of all requirements and disseminate them as appropriate to the Design team. 
The Design Authority Manager and their team must design the system to ensure that it is safe as well as meeting all technical requirements, which should in turn be checked by the Systems Engineering team to ensure that all requirements are met.

(King, 2016)

This proposed structure is shown in Fig. 8-7. 


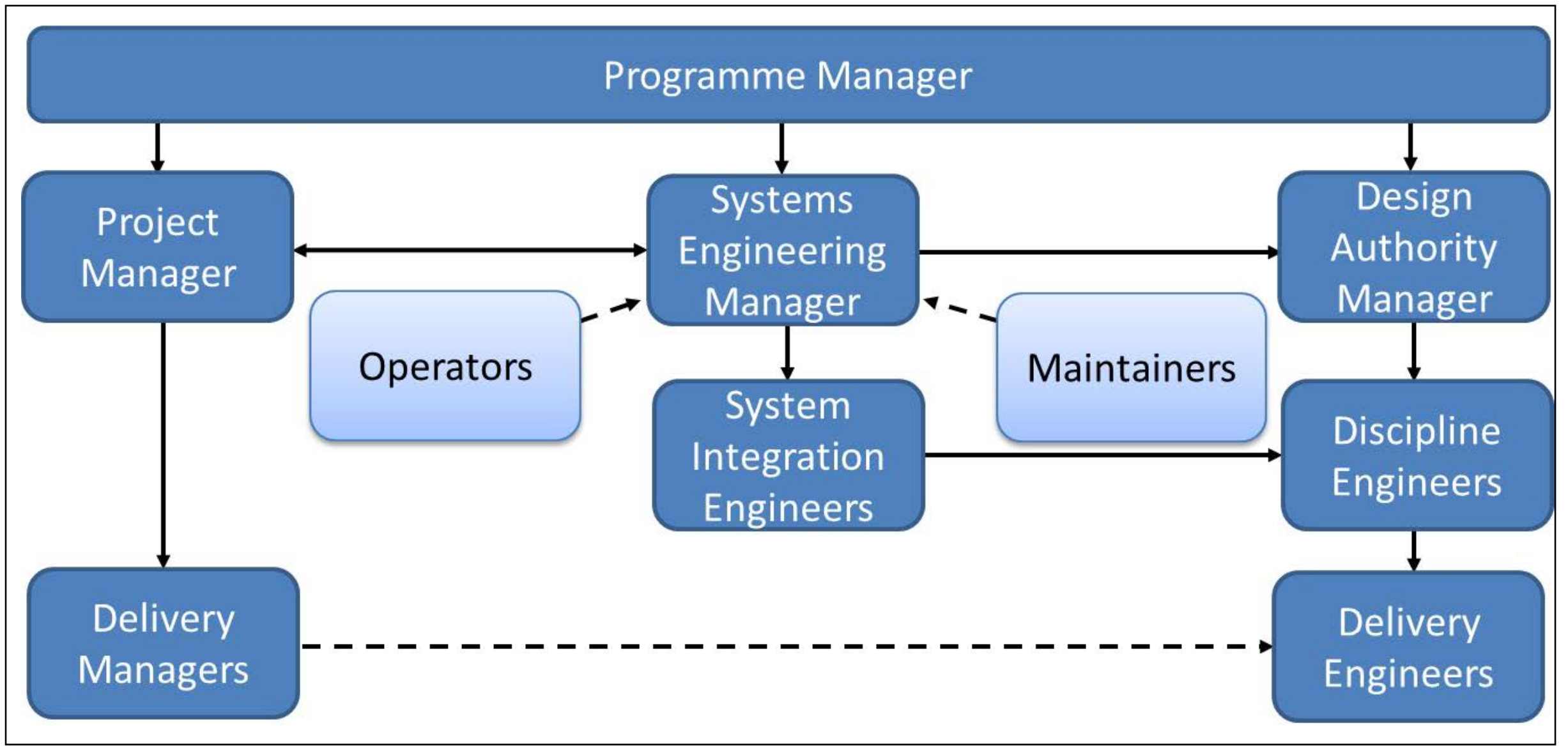

Fig. 8-7 Proposed System-Centric Structure (King, 2016) 


\section{Findings and Recommendations}

RCS systems are critical to both the safety and performance of the railway and are complex Systems Of Systems. They have clearly defined functional sub-systems that make up these two key criteria.

A systematic approach to the deployment, as well as the development, of RCS is vital in order to ensure successful development, delivery and integration of modern RCS systems such as ERTMS, CBTC, PTC, etc.

This report has covered predominantly four main areas of research in relation to the challenges facing the development and delivery of RCS systems:

1. A study of the development and delivery of RCS Systems

2. The benefits of a generic RCS system model

3. Modelling RCS as a negative-feedback control system

4. The issues of current project delivery structures

This Chapter has therefore been divided into five Sections, where the conclusion of each of these four topics will be examined in detail before concluding with recommendations for further work in this area of research.

\subsection{Development and Delivery of RCS Systems}

It must be acknowledged that RCS systems go through at least two V-lifecycle models as shown in Chapter 3; the first being the research and development carried out by the supplier to develop a generic system that can be taken to market, and the second being the specific application of the system required by a particular operator on their railway.

Whilst Metro RCS systems are often procured as complete single systems, mainline RCS systems are often made up of multiple separately procured sub-systems that must then be integrated into a complete RCS system. This results in mainline applications of RCS having to follow a complex Wlifecycle, where multiple suppliers' development V-lifecycles must then be integrated by the operator in a separate $\mathrm{V}$-lifecycle for the specific application.

\subsection{Generic System Model}

Though there are many types of RCS systems available throughout the world today, they can all be 'mapped' onto a generic functional model that covers the key functional requirements of routing trains efficiently, ensuring the railway's safety and optimising the performance of individual trains. However, these functional layers do not map directly onto physical locations, as components of key sub-systems are divided amongst rolling stock and infrastructure locations. Therefore, it is also necessary to have a physical model that individual sub-system components can be 'mapped' onto in order to manage implementation of the system.

I believe that the proposed simple functional and physical models defined in Chapter 4, along with their defined suffix shorthand, are extremely useful in identifying how technology relates to the fundamental requirements of any RCS system.

This report also shows in Chapter 5 how specific systems map onto the model and how different sub-systems are used to achieve the same requirements in different physical locations. 
I hope that these models will make it easier for different members of the railway industry to understand how these different systems work and how they relate to each other.

For further research, I would recommend investigating how models such as the ones defined in this research could be utilised to simplify the operational and technical design of transitions between different systems that are fitted on the same railway line.

\subsection{RCS As A Negative-Feedback Control System}

I propose that RCS systems can be modelled as a negative-feedback control system, where the S\&P layer is the main system of the operational railway that determines the maximum TPH the system can deliver, whilst the RP \& TP layers are the feedback systems that regulate the system to maintain that maximum TPH.

I would propose for further research that this potential model is investigated further to determine if it can be modelled mathematically to ultimately determine what type of sub-systems are required in order to achieve the required TPH of a particular application.

\subsection{Proposed Delivery Organisation}

One of the main challenges facing the railway industry in terms of implementing RCS is not technical but managerial, particularly in the structure of project teams as shown in Chapter 8.

I propose that the first major challenge is the relationship between Project Management, Systems Engineering and Design Engineering. The structure proposed in Section 8.2 offers a somewhat radical new approach to this challenge, which provides a good way forward in this area.

However, I also feel that this is another area of study where significantly more research is required, particularly in relation to how assurance and approvals interface to delivery teams as well as the relationship between client and delivery organisations and the differences (if any) that are required between their structures.

\subsection{Future Work}

I would like to develop the proposed RCS negative feedback model further. Particularly, I would like to investigate if it is feasible to mathematically represent the RCS system both in the time domain using algebra and in the complex frequency domain utilising Laplace Transforms. From this, it should be feasible to use the model to determine if a particular system will be stable based on the functionality of the three functional layers. 


\section{References \& Bibliography}

Amtrak, 2007. Incremental Train Control System on Amtrak's Michigan Line. [Online]

Available at:

https://www.arema.org/eseries/scriptcontent/custom/e arema/library/2007 Conference Proceedi ngs/Incremental Train Control System 2007.pdf

[Accessed 2015].

AREMA, 2009. Meeting the Communication Challenges for Positive Train Control. [Online]

Available at:

https://www.arema.org/files/library/2009 Conference Proceedings/Meeting the Communication

Challenges for Positive Train Control.pdf

[Accessed 2015].

Beckford, J. \& Dora, J., 2013. Reimagining the Railway. Copyright John Beckford and John Dora.

Bequette, B. W., 2003. Process Control: Modeling, Design, and Simulation. :Prentice Hall

Professional.

Blanchard, B. S. \& Fabrycky, W. J., 2011. Systems Engineering and Analysis. :Pearson.

BNSF, n.d. BNSF Railway. [Online]

Available at: www.bnsf.com

[Accessed 2015].

Booth, P. D., 2010. Intermittent and Continuous Train Detection.

Bouch, C. J. \& Roberts, C., 2013. Developing system models to help Great Britain's railways embrace innovative technologies with confidence. Volume 227 of the Journal of Railway Engineering.

Bourne, A. \& Clark, G., 2007. Jubilee and Northern Upgrade Project The Challenges of Applying Proven Product to an Existing Railway. ,

Boxer, P., Morris, E., Anderson, W. \& Cohen, B., 2008. Systems-of-Systems Engineering and the Pragmatics of Demand.

Bruegge, B. \& Dutoiyt, A. H., 2010. Object-Oriented Software Engineering. :Prentice Hall.

BSI, 2013. BS EN 62290-1:2006. Railway applications - Urban guided transport management and command/control systems - Part 1: System principles and fundamental concepts, : British Standard Institution.

Cimatti, A., Roveri, M., Susi, A. \& Tonetta, S., 2012. Validation of Requirements for Hybrid Systems: a Formal Approach. ACM Transactions on Software Engineering and Methodology, Vol. 21, No. 4, p.

Article 22.

Clark, J. O., 2008. System of Systems Engineering and Family of Systems Engineering From a Standards Perspective.

Colburn, R. A., 2013. History of Railroad Signals,. The Institute of Electrical and Electronics Engineers. Tech Focus. 
Collis, S., Schmid, F. \& Tobias, A., 2013. Managing incidents in a complex system: a railway case study; London: Springer-Verlag.

Cooksey, A., 2001. Implications for Signalling of the Ladbroke Grove Inquiry. ,

DeRosal, J. K., Grisogono, A., Ryan, A. J. \& Norman, D. O., 2008. A Research Agenda for the Engineering of Complex Systems.

Doherty, A. \& Harmon, I., 2007. Using Systems Engineering to Develop the Future Railway and to Deliver an Effective and Affordable Railway. ,

Farrell, J., 2015. The Modelling of External Systems That Interface to the Communications Based Train Control System and Simulation of the Integrated System Will Reduce Risk at the Implementation Phase and Provide Programme Benefits.

Faulconbridge, I. \& Ryan, M., 2014. Systems Engineering Practice. :ArgosPress.

Ferrari, A., Spagnolo, G., Martelli, G. \& Menabeni, S., 2014. From commercial documents to system requirements: an approach for the engineering of novel CBTC solutions. Berlin Heidelberg, SpringerVerlag.

Firesmith, D., 2013. Using V Models for Testing; :Software Engineering Institute, Carnegie Mellon University.

FRA, 2008. Positive Train Control. [Online]

Available at: www.fra.dot.gov/Page/P0621

[Accessed 2015].

Free, A. \& Marshall, P., 2014. Resignalling the Great Western Main Line. IRSE News Issue 204 , July/August.

Ghazel, M., 2014. Formalizing a subset of ERTMS/ETCS specifications for verification purposes. Transportation Research Part C 42, p. 60-75.

Hitachi, 2013. Features of Railway Traffic Management Systems. [Online] Available at: http://www.hitachi-rail.com/products/traffic management/feature01.html [Accessed 2015].

Hollywell, P., 2014. Synergistic Integration of Systems Engineering and Project Management: Investigating Engineering Consultancy Project Management Processes, London: University College.

Hossein, M., Hemmat, A., Mohamed, O. A. \& Boukadoum, M., 2015. Formal Modelling, Verification and Implementation of a Train Control System.

IEC, 2010. 61508:2010 Functional safety of electrical/electronic/programmable electronic safetyrelated systems, : International Electrotechnical Commission.

IEEE, 2011. 1474.1. IEEE Standard for Communications-Based Train Control (CBTC) Performance and Functional Requirements, : IEEE. 
Keseljevic, C., 2005. Fulfilling The Real Needs of Customers - An Urgent Challenge to Railway Technology. ,

King, K. M., 2016. Systems Engineering Framework for Railway Control \& Safety Systems. IEEE International Conference on Intelligent Rail Transportation (ICIRT).

Leonhardt, J., Macchi, L., Hollnagel, E. \& Kirwan, B., 2009. A White Paper on Resilience Engineering for ATM; Cooperative Network Design, : Eurocontrol.

Lewis, G. et al., 2008. Engineering Systems of Systems.

Lewis, M. J. T., 2001. Railways in the Greek and Roman world; Early Railways. ,

Li, C. \& Zhang, L., 2015. Train Control System Modelling and Design Based in AADL.

Liu, R., Whiteing, A. \& Koh, A., 2013. Challenging established rules for train control through a fault tolerance approach: applications at a classic railway junction. Volume 227 of the Journal of Railway Engineering.

May, T., 2000. The Victorian Railway Worker. :Shire.

Moens, G. \& Stokes, R., 2003. CTRL Signalling and Communications.

Mohan, S., 2014. Next Generation Train Positioning Systems. IRSE News Issue 202, July/August .

Ning, B., Tang, T., Qiu, C. \& Wang, Q., 2004. CTCS-Chinese Train Control System.

Noffsinger, J., 2014. The Challenge of Positive Train Control Implementation. IRSE News Issue 205, July/August.

Oh, S., Yoon, Y., Kim, K. \& Kim, Y., 2013. Design of ATP functions and Communication Interface Specifications for Korean Radio-based Train Control System. ,

Peng, H., 2011. Research on Urban Railway Knowledge-based CBTC System.

Poré, J., 2003. Migration to ERTMS on Existing Lines. ,

Qiu, S., Sallak, M., Schön, W. \& Cherfi-Boulanger, Z., 2014. Availability assessment of railway signalling systems with uncertainty analysis using Statecharts. Simulation Modelling Practice and Theory 47, p. 1-18.

Rebovich, G. J., 2008. The Evolution of Systems Engineering.

RNE, 2013. GLOSSARY OF TERMS RELATED TO RAILWAY NETWORK STATEMENTS. [Online] Available at:

www.rne.eu/tl files/RNE Upload/Network\%20Statements/RNE Network Statement Glossary V5. $\underline{\text { pdf }}$

[Accessed 2015].

RRAUK, 2013. The Academic Response to the Rail Technical Strategy 2012, : Rail Research Association UK. 
RSSB, 2012. The Future Railway The Industry's Rail Technical Strategy 2012 Supporting Railway Business, : RSSB.

Scheerer, W. J. \& Baker, J. K., 2003. Communications Based Train Control. ,

Schmelzer, C., 2010. Standardization of CBTC Systems - Mixed Operation on Shared Lines in accordance with ERTMS/ETCS Standards. Brunswick, Germany,

Schmid, F., 2002. Train Control Research in Europe. Institution of Railway Signal Engineers Proceedings.

Sharpe, J., Ramdas, V., Fawkner, L. \& Roberts, C., 2015. Vision Case for Capacity Improvements Woking to Waterloo, A Whole System Approach to the Identification of Key Technologies;.

Smith, P., Majumdar, A. \& Ochieng, W., 2012. An overview of lessons learnt from ERTMS implementation in European railways. Journal of Rail Transport Planning \& Management 2, p. 79-87.

Tazaki, T. et al., 2012. Development of CBTC for Global Markets. Hitachi Review Vol. 61 No. 7.

TETRA and Oxford Information Labs., 2016. TETRA and Critical Communications Association. [Online] Available at: http://www.tandcca.com

[Accessed 2016].

TfL, 2015. Transport for London. [Online]

Available at: https://tfl.gov.uk/

[Accessed 2015].

Thompson, E., Kazi, T. \& Scott, A., 2012. Bridging the Gap Between Technology and Adoption: A Case Study; Mott MacDonald commissioned by RSSB to deliver research project T906 ERTMS/ETCS Driver Machine Interface (DMI) options for future train cab design, : RSSB.

UNIFE, 2013. The European Rail Traffic Management System. [Online] Available at: $\underline{w w w . e r t m s . n e t}$

[Accessed 2015].

Wang, J., Li, Y. \& Zhang, Y., 2016. Research on Parallel Control Mechanism and Its Implementation in ATP.

Wang, P. \& Goverde, R. M. P., 2016. Multiple-phase Train Trajectory Optimization With Signalling and Operational Constraints. Transportation Research Part C 69, p. 255-275.

Williamson, P., 2015. Personal discussion regarding requirements of successful organisational structure and project implementation [Interview] 2015.

Woodland, D., 2004. Optimisation of Automatic Train Protection Systems, Sheffield, UK: University of Sheffield.

Yelloz, G., 2011. Siemens CBTC Solution in Barcelona-The First Driverless Metro in Spain. , 
Yoon, J. H., Lee, J., Kim, T. \& Hong, S., 2008. An Integrated Process Model for the Systems

Development Requiring Simultaneous Consideration of the SE Process and Safety Requirements;

Zhu, H. et al., 2016. Analysis and design of Driver Advisory System (DAS) for energy-efficient train operation with real-time information. Birmingham, UK, IEEE. 


\section{Papers Arising From This Research Work}

Formal Contributions to Professional Institutions / Societies, Conferences and Journals:

'Systems Engineering Framework for Railway Control and Safety Systems' IRSE News Issue 218, 2016

'Systems Engineering Framework for Railway Control and Safety Systems' 2016 IEEE International Conference on Intelligent Rail Transportation (ICIRT), 2016

'Event Report on Systems Engineering for Train Control and Communications' IRSE News Issue 224, 2016.

'A Systems Engineering Framework for Railway Control \& Safety System: The Mainline Challenge' Stephenson Conference, 2017.

Informal Contributions to Employers Forums, Professional Institutions and Societies:

'Systematic Approach to Command Control Signalling CBTC Projects,' Systems Engineering Community Newsletter, Mott MacDonald, November 2012

'Delivering ERTMS Systems,' Systems Engineering Community Newsletter, Mott MacDonald, March 2013

Papers Submitted \& Awaiting Publication:

'Railway Control \& Safety Systems as a Closed Loop Negative Feedback Control System,' IET International Conference International Conference on Railway Engineering (ICRE), May 2018 


\section{Appendix A: Author's Curriculum Vitae PROFILE:}

Chartered Electronic Systems Engineering Manager with extensive experience of safety critical control technology, particularly in the Railway industry on both mass transit and mainline systems, including Automatic Train Control systems.

Reliable, trustworthy, numerate and meticulous with good communication skills.

Pre and post graduate experience demonstrating an ability to work on own initiative or as part of a team and deal with administrative duties.

Experience of managing staff and co-ordinating the integration of large multi-discipline projects.

Close ties with Academia and strong international experience including Netherlands, Poland, Belgium, Canada, USA, Brazil, India, Kuala Lumpur, South Africa, Mozambique, Guinea and Australia.

\section{PERSONAL DETAILS:}

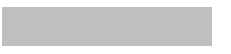

Nationality: British

Driving License: Full, clean

Professional Membership: $\quad$ CEng, MIET

EDUCATION:

$1999-2003 \quad$ University of Leeds

Electronic \& Electrical Engineering MEng. (Hons)

Four year Masters degree covering range of Electronic and Electrical Engineering.

Third year individual project: Design and Development of a Compact and Low-Power GPS Data Logger.

Fourth year group project: Design and Development of an Asset Tracking Device System using Bluetooth Technology.

\section{PROFESSIONAL:}

Chartered Member of the Institute of Engineering and Technology (IET)

Member of the Institute of Electrical and Electronic Engineers (IEEE)

Member of the International Council Of System Engineers (INCOSE)

Member of the Institute of Railway Signalling Engineers (IRSE) 
Mentor for IET Graduate Trainees seeking professional chartership.

Hold certificate in Engineering Safety Management, Engineer's Overview (Yellow Book Course).

Completed Safe Working Of Trains correspondence course.

\section{EXPERIENCE:}

October 2017 - Present

October 2017-Present

\section{Frazer Nash}

Senior Consultant

Principal Systems Engineer responsible for the development, delivery and integration of complex multi-discipline projects within the railway industry.

Projects include:

- Melbourne Metro

- Cyber Security

- Franchise Review

- Franchise Bid

\section{August 2016 - October 2017 WSP}

August 2016-October 2017 Principal Systems Development Engineer

Principal Systems Engineer responsible for the development, delivery and integration of complex multi-discipline projects within the railway industry.

Projects include:

- Digital Railway Assurance

- Beaulieu Park Station

- Brisbane Rail ETCS

- Tel Aviv Red Line Metro

- HS2 Enabling Works

- Crossrail Safety Assurance

\section{February 2012 - July $2016 \quad$ Mott MacDonald Group}

February 2012 - July $2016 \quad$ Head of Train Control Systems Technology

Engineering Manager responsible for the delivery of all technical aspects of Train Control System projects and business strategy, including ERTMS, PTC and CBTC systems (including ATC). Key Projects included:

- London Tramlink System Upgrade

- Mumbai Monorail Signalling Assurance

- Etihad Rail ERTMS Programme

- Edmonton Light Rail Transit CBTC Assurance 
- Nacala Rail and Port Systems Engineering

- Crossrail Rolling Stock ERTMS and Depot System technical assessment

- Rail for London Crossrail Asset Management System development

- Kuala Lumpur KTMB KVDT Feasibility Study

- Kjifhoek ETCS Level 1 Notified Body Assesssment

- Kazakhstan Iron Ore Rail Spur Feasibility Study

- Thameslink Depot System Assessment

- Siemens Vectron Notified Body Assessment

- Simandou Rail, Mine \& Port Signalling and Systems Engineering Specification

- Northern Line Extension CBTC Support

- ETCS Limited Supervision Research Study

- Chiltern ERTMS Feasibility Study

- Panama Metro Line 2 CBTC System

- Belgian ETCS Strategy

- Rio Metro CBTC Due Diligence Study

- Toronto Regional Express Railway CBTC Business Case

- Bay Area Rapid Transit System CBTC Upgrade

- Docklands Light Railway Life Expired Asset Study

- Sydney Trains ATRICS System Study

- Simandou Mining Railway System

- Melbourne Metro CBTC Upgrade

- New Trains for Docklands

- Heathrow Express ETCS Level 2 ISA

\section{August 2010 - February 2012 Invensys Rail}

August 2010 - February2012 Lead Systems Engineer (Victoria Line Upgrade)

Senior Project Engineer overseeing all aspects of System Architecture and Integration for Victoria Line Upgrade on London Underground.

Responsible for development and integration of complete Distance To Go - Radio (DTG-R) Signalling and Train Control System (STCS) across all three main subsystems (Control Centre, Signalling and Automatic Train Control).

Main duties include managing scope of system (including development and management of Technical Scope Database), interface design and development of integrated system test rig.

Also responsible for liaison with Design, Installation, Testing and Commissioning staff on project as well as Research \& Development department.

Also assisted with development of Performance Monitoring and Improvement System.

Responsible for management of Systems Engineering staff on project. 


\section{June 2008 - August $2010 \quad$ Network Rail}

Dec 2009 - August 2010Systems Engineer (ERTMS / ATO)

Provide technical advice and support on ERTMS/ATO issues to Future Train and Operational Control Systems and other Network Rail groups and departments and other industry bodies, in particular for systems integration and approvals.

Assess ERTMS/ATO proposals and give engineering expert judgement in the approvals process on behalf of Future Train and Operational Control Systems.

Provide the ERTMS/ATO engineering input to the compilation, updating and review of drawings, standards, specifications, and manuals.

Provide the technical input on ERTMS/ATO to the assessment of the potential costs, risks and benefits to Network Rail and the railway industry.

Represent Future Train and Operational Control Systems on ERTMS/ATO issues with other UK and European railway industry organisations.

July 2009 - Dec2009 Senior Signal Equipment Engineer (Systems)

Responsible for the development and approval of Electronic Signalling Systems used on Network Rail Infrastructure, particularly Computer-based Interlockings and Signalling Control Systems.

Provide technical expertise into the development of signalling equipment and systems engineering policy. Produce product specifications, determine acceptance criteria and carry out acceptance of signalling equipment and systems. Act as the principal contact with manufacturers and servicing agents on technical issues. Provide a consultancy service on signalling equipment and systems to the rest of the organisation and to external bodies as required. Produce life cycle supporting products for signalling equipment and systems, including development and input into standards, manuals, drawings, technical training courses, competence requirements and reliability analysis. Assess applications for derogations and non-compliances against standards and recommend responses. Participate in, and lead as directed, Engineering verification activities in support of the national programme. Provide signalling equipment and systems technical mentoring and coaching to engineers throughout the organisation to support professional development and sustainability of expertise in the organisation. Monitor safety and reliability of signalling equipment and systems and make recommendations regarding any necessary improvements to or withdrawal of equipment or procedures.

June 2008 - June 2009 Rail Vehicle Projects Design Engineer (ERTMS)

Responsible for the design and delivery of fitment of train on-board European Train Control System (ETCS) equipment for both the Cambrian Early Deployment Scheme and the National European Rail Traffic Management System (ERTMS) programme with Future Trains Operational Control Systems (FTOCS) team.

Major projects included: Being Main UNISG Suppliers Contact, Writing ERTMS Readiness Specification for Train On-board Equipment, Carrying out Power Supply Upgrade Study on Cambrian 
Class 158 Vehicles, Power Supply Crossfeed Design for ETCS Power Supply, Reviewing of Technical Documentation including Equipment Maintenance Manuals, Sub-Contractor Liaison and Vehicle ETCS Testing \& Commissioning.

\section{Jan 2008 - May 2008 Barloworld Scientific}

\section{Electronics Design Engineer}

Electronic Equipment design and development of laboratory scientific equipment. Main project involved design of Power Supply Unit for new version of Thermal Cyclers. Key duties included Circuit Design, Printed Circuit Board Design and Prototype Testing. Also responsible for writing Technical Reports.

\section{Sept 2005 - Dec 2007 Metronet Rail Equipment Engineering Services}

\section{Electronic Equipment Engineer}

Electronic Equipment design and development. Designed a variety of electronic systems for Rolling Stock, Signalling and Test Equipment. Key duties included Circuit Design, Printed Circuit Board Design, Mechanical Enclosure Design, Prototype Testing, Commissioning, On-site testing, Repair and Calibration. Also responsible for writing Technical Manuals, Test Procedures and producing Project Estimates and Time plans. Would occasionally assume team leader responsibilities or act as Site Person In Charge during overtime or night shift work.

Major projects included, Designing Portable Victoria Line Automatic Train Protection for Battery Locos, Reverse Engineering Signalling Train Speed Inductor Relay Amplifiers, Development of New Power Supply Boards for Central Line Automatic Train Control System, Carried out Software Updates to Digital Voice Announcement Systems, Assisting with Electromagnet Compatibility Survey at Stratford station, Designed and Developed Public Address Tester, Designed and Developed Door Cycle Tester. Also assisted with testing of Dual Frequency Dual Element Vane Relay as part of Safety Critical Rely Project and carried out repair and calibration of Victoria Line Auto Driver Boxes.

\section{Aug 2003 - Sept 2005 Graduate Trainee with Metronet Rail SSL}

Graduate training placements within the company's various engineering departments.

June 2005 - Sept 2005 Signalling Design

Design of Railway Signalling Layouts. Carried out project to investigate the feasibility of installing route-proving on sub-surface lines. Carried out pre-design and post-design wire counts. Updated track diversity report.

Mar 2005 - June 2005 Equipment Engineering Services

Electronic Equipment design and development. Carried out project to produce replacement components for obsolete digital logic blocks. Assisted with monitoring of EMC and train speed confirmation site surveys. Assisted with testing of ATO Simulator for Victoria Line. Assisted with Spot Data collection on Victoria. 
Jan 2005 - Mar 2005 Power and Signal Planning

Assist with planning upgrade to signalling and power distribution systems. Main project was to develop prioritisation programme for DC Traction Feeder Cables replacement. Also developed an Excel spreadsheet programme to monitor all Power Signalling projects being carried out during 2005 $-2006$.

Sept 2004 - Dec 2004 Rolling Stock Design

Working with design team on-site at train depot. Worked on various projects to assist with maintaining and modifying trains and depot equipment. Designed and developed a test box for passenger emergency alarm units. Assisted with train light tests. Audited train radio testing process and equipment. Re-designed under car de-icer safety bracket. Created Change to Rolling Stock form for new motor brush tests. Carried out on-train battery tests. Also carried out feasibility study to create test rig for fluorescent tube lighting inverters.

July 2004 - Aug 2004 Railway Signalling Principles Course

An 8 week course covering the basic principles of a modern underground railway signalling system. Including automatic and controlled signalling, relay circuits, design calculations, technical drawing, interlocking systems and computer control.

Jan 2004 - July 2004 Systems Modelling Department

Working with team to simulate underground train lines using in-house built computer simulation models. Carried out two main projects, the first to write a PERL script to convert the data of an old FORTRAN simulator into the data required for the current $\mathrm{C}++$ based Railway Engineering Simulator. The second project was to create a new set of front-end screens in $\mathrm{C}++$ using wxWindows graphics library tools for the Railway Engineering Simulator. Both of the above projects were carried out on the UNIX operating system. Also assisted with fault-finding on the UNIX server.

Sept 2003 - Jan 2004 King's Cross Underground Station Redevelopment Project

Working in the Mechanical and Electrical Department. Oversaw various electrical and communications installations as well as maintaining weekly report for ongoing work within the department. 